\title{
La diffusion quasi-élastique de neutrons : applications à des systèmes biologiques
}

\author{
M. Ferrand
}

\author{
Département de Biologie Moléculaire et Structurale, Service de Biophysique Moléculaire \\ et Cellulaire, Centre d'Études Nucléaires de Grenoble, 17 avenue des Martyrs, \\ 38054 Grenoble cedex 9, France
}

\begin{abstract}
Résumé. La diffusion quasi-élastique incohérente de neutrons est une technique permettant d'étudier les mouvements à caractère diffusif dans les phases condensées sur des échelles de temps de l'ordre de la picoseconde-nanoseconde. Cet article rapporte quelques applications récentes de cette technique à des systèmes biologiques, en mettant en évidence ses potentialités et ses limitations. Compte tenu de la complexité chimique et structurale des macromolécules biologiques, cet article insiste sur la nécessité d'utiliser des moyens complémentaires d'investigation des propriétés dynamiques de ces systèmes, notamment les simulations de dynamique moléculaire.
\end{abstract}

\section{INTRODUCTION}

La biologie est la science qui se consacre à l'étude des êtres vivants. Elle englobe des disciplines nombreuses et variées que l'on peut situer à différents niveaux d'organisation de la vie: biologie cellulaire, biologie moléculaire, biochimie, physiologie animale et végétale, écologie, etc ...

Lorsque l'on sonde au niveau atomique et moléculaire les processus sous-jacents à l'expression de la vie, c'est à dire les processus associés à une fonction biologique donnée, on obéit à une démarche dite réductionniste. Cette démarche consiste, en raison de la complexité des systèmes biologiques, à fragmenter ceux-ci en composantes plus simples, donc plus faciles à manipuler. C'est une stratégie efficace dans le champ de la biologie moderne: c'est en étudiant la structure moléculaire d'une substance extraite des cellules que Watson et Crick purent établir les bases chimiques de l'hérédité: l'ADN

Il existe une hiérarchie de l'organisation biologique, du microscopique vers le macroscopique, avec à chaque niveau hiérarchique une relation très étroite entre l'organisation structurale et la fonction biologique. L'objet de ce cours est de montrer comment s'établit la relation entre structure et fonction au niveau moléculaire, en la complétant par une composante "dynamique". On ne peut en effet contester à travers la notion de sélection naturelle des espèces (théorie de Darwin) l'idée d'évolution en biologie. Cette dynamique évolutive de la vie s'opère continuellement, de génération en génération, et s'exprime par l'adaptation de certaines espèces, en interaction avec leur environnement, au détriment d'autres qui disparaissent. L'évolution biologique se déroule à l'échelle de la centaine de millions d'années (âge de l'Univers: 10-20 milliards d'années, âge de la Terre: 4,6 milliards d'années), laquelle n'aurait lieu si, au niveau moléculaire, n'existait une dynamique des structures biologiques sur des échelles de temps beaucoup plus courtes, allant de la femtoseconde ( $f s$ ) jusqu'aux temps caractéristiques des cinétiques de réactions et processus biologiques ( $\sim$ seconde).

La diffusion de neutrons, et plus particulièrement la diffusion quasiélastique, est une technique permettant d'apprécier les processus dynamiques qui se déroulent sur des échelles de temps picoseconde-nanoseconde (ps-ns). Ce cours traite de l'application de cette technique à quelques exemples de systèmes biologiques, principalement issus de la classe des protéines.

\section{LES PROTEINES}

Depuis l'apparition des premières cellules jusqu'à celle des êtres vivants, le carbone a joué un rôle déterminant dans l'évolution de la vie sur Terre. La diversité biologique reflète la diversité 
moléculaire et la capacité du carbone à former des molécules volumineuses, complexes et variées, sans égale parmi les éléments chimiques.

Bien que 70 à $95 \%$ d'une cellule soient constitués d'eau, le reste renferme principalement des composés du carbone. Les protéines, les acides nucléiques, les glucides, les acides gras, les hormones, etc ... contiennent tous du carbone. Les atomes de carbone peuvent être liés les uns aux autres ou à d'autres éléments: principalement hydrogène, oxygène, azote, soufre et phosphore. Les chaînes carbonées forment le squelette des macromolécules biologiques. Elles varient en longueur et peuvent être droites, ramifiées ou cycliques, à caractère saturé (liaisons simples) ou insaturé (liaisons multiples: doubles ou triples).

Dans cette partie la diversité structurale des protéines est abordée, en essayant de dégager les propriétés physico-chimiques qui déterminent leur architecture moléculaire tridimensionnelle et leur degré de flexibilité dynamique, caractéristiques de leur fonction biologique.

\subsection{Organisation structurale des protéines}

D'où provient la diversité chimique en biologie? Les macromolécules biologiques ne s'élaborent pourtant qu'à partir de 40 à 50 monomères courants et quelques autres plus rares. Elaborer une variété illimitée de polymères à partir d'un nombre limité de monomères, c'est comme former des centaines de milliers de mots à partir des 26 lettres de l'alphabet: tout réside dans l'arrangement, c'est à dire dans la façon de combiner en séquence linéaire les unités structurales de base.

Les protéines sont fabriquées à partir de 20 acides aminés (encore appelés peptides ou résidus) différents en chaînes qui comportent habituellement plus de 100 acides aminés. Les protéines ont donc généralement des poids moléculaires supérieurs à $10 \mathrm{kDaltons}$. Les possibilités de combinaisons sont quasi-infinies: en toute rigueur $20^{100}$ pour une protéine (ou polypeptide) de 100 acides aminés. Pourtant le nombre de protéines existantes semble contraint par des facteurs biologiques puisque le nombre total de polypeptides a été estimé à «seulement» quelques centaines de milliers.

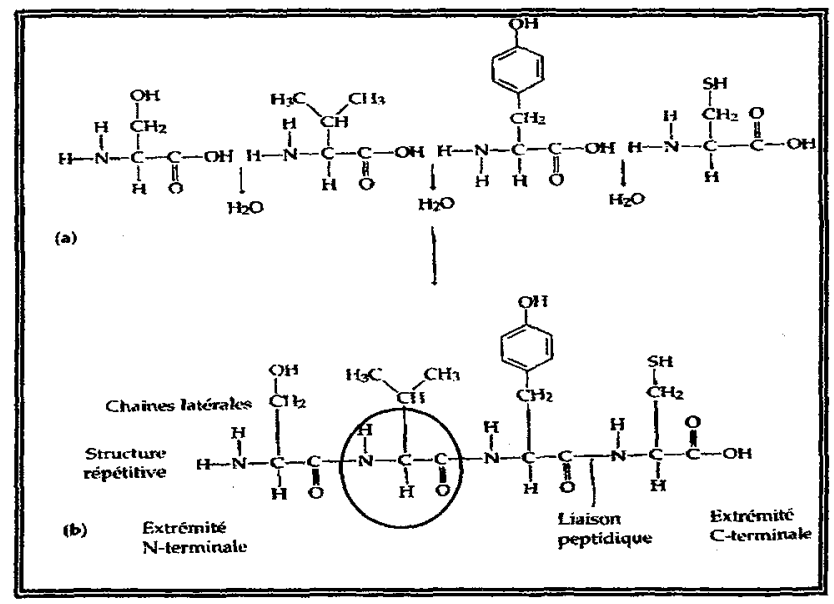

Figure 1 : (a) Réaction de condensation entre acides aminés, avec élimination d'eau et formation de liaisons peptidiques. (b) La chaîne polypeptidique possède une structure répétitive (cercle) complétée par les chaînes latérales des acides aminés. 
Les classes de macromolécules diffèrent par la nature de leurs monomères, mais les mécanismes chimiques que les cellules emploient pour synthétiser et dégrader les macromolécules sont toujours les mêmes. Les monomères, en l'occurrence les acides aminés pour les protéines, se lient au cours d'un réaction de condensation (fig. 1) unissant le groupement carboxyle d'un acide aminé au groupement amine d'un autre, pour former une liaison peptidique. L'effet global de cette réaction est l'ajout à la chaîne d'un monomère et l'élimination d'une molécule d'eau. La cellule doit fournir de l'énergie pour former les liaisons covalentes qui s'établissent, et le processus ne peut se produire qu'avec l'aide d'enzymes, des protéines spécialisées qui accroissent la vitesse des réactions chimiques dans les cellules. La réaction inverse de la condensation est l'hydrolyse, heureusement non spontanée dans les cellules en raison d'énergies d'activation élevées.

A une extrémité de la chaîne se trouve un groupement amine libre, alors qu'à l'autre extrémité figure un groupement carboxyle libre. La structure répétitive des atomes le long de la chaîne principale (ou brin polypeptidique -N-C-C-N-C-C-) porte les chaînes latérales des acides aminés. La longueur d'une chaîne polypeptidique varie de quelques monomères à plus d'un millier. Chaque polypeptide spécifique possède une séquence linéaire unique d'acides aminés.

\subsubsection{Conformation des protéines}

Une protéine se compose d'une ou plusieurs chaines polypeptidiques adoptant une forme tridimensionnelle définie, encore appelée conformation. La fonction d'une protéine repose sur sa conformation unique ainsi que sur sa capacité à reconnaître une autre molécule et de s'y lier. Par exemple une protéine hormonale se lie à un récepteur cellulaire; un anticorps se lie à une substance étrangère qui a envahi l'organisme; une enzyme spécifique reconnait son substrat. Le traitement de l'information dans le cerveau humain dépend également de la capacité des protéines à se lier sélectivement à d'autres molécules. Une cellule nerveuse envoie par exemple un signal à une autre en libérant des molécules spécifiques (neuro-médiateurs) qui possèdent une forme particulière. A la surface de la cellule cible se trouvent des récepteurs protéiques, dotés d'une conformation complémentaire à celle des molécules messagères.

Lorsqu'une cellule synthétise une protéine au niveau d'organites appelés ribosomes, la chaîne polypeptidique se replie spontanément, par des mécanismes complexes encore incompris, pour adopter la conformation fonctionnelle de cette protéine, sa conformation native (fig. 2).

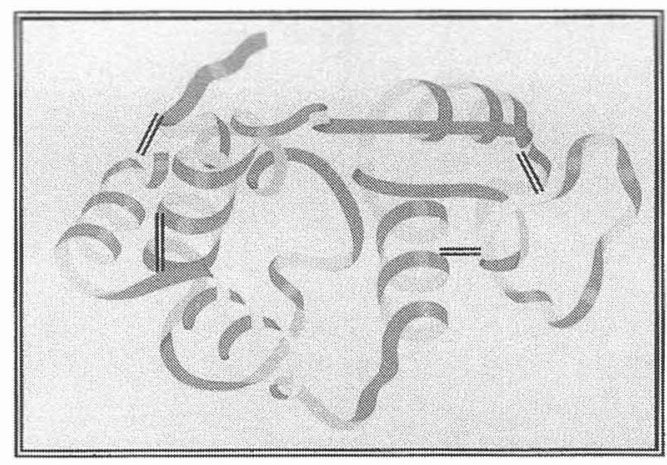

Figure 2 : Conformation native d'une protéine. La chaîne polypeptidique se replie en une forme spécifique. La protéine ici représentée est une enzyme spécifique appelée lysozyme. Sa structure a été simplifiée pour ne montrer que le brin polypeptidique en représentation type "ruban". Les doubles traits noirs représentent des liaisons chimiques intramoléculaires qui stabilisent la structure (ponts disulfures). 


\subsubsection{Niveaux d'organisation structurale des protéines}

\subsubsection{Structure primaire}

La structure primaire d'une protéine correspond à sa séquence unique d'acides aminés. A titre d'exemple, le lysozyme représenté sur la fig. 2 comporte 129 résidus, et l'arrangement de ces 129 résidus n'est pas laissé au hasard mais est commandé par l'information génétique. Le moindre changement dans la structure primaire peut modifier la conformation d'une protéine et entraver son fonctionnement. Un exemple: l'anémie à hématies falciformes est un trouble sanguin héréditaire causé par la substitution d'un seul acide aminé dans la structure primaire de l'hémoglobine, protéine responsable du transport de l'oxygène dans les globules rouges.

\subsubsection{Structure secondaire}

Dans la plupart des protéines, certains segments de la chaîne polypeptidique sont enroulés ou repliés de façon répétitive, formant ainsi des motifs qui contribuent à la conformation globale de la protéine. L'ensemble de ces motifs constitue la structure secondaire des protéines. La formation de ces motifs est liée à la création de liaisons hydrogène s'établissant à intervalles réguliers le long de la chaîne polypeptidique. L'atome d'hydrogène, faiblement positif, qui se trouve attaché à l'atome d'azote présente une affinité marquée pour l'atome d'oxygène, légèrement négatif, de la liaison peptidique voisine. Individuellement ces liaisons hydrogène sont faibles. Toutefois, comme elles se répètent souvent dans une région relativement longue de la chaîne polypeptidique, elles peuvent conférer une forme particulière à cette section de la protéine, par un effet coopératif.
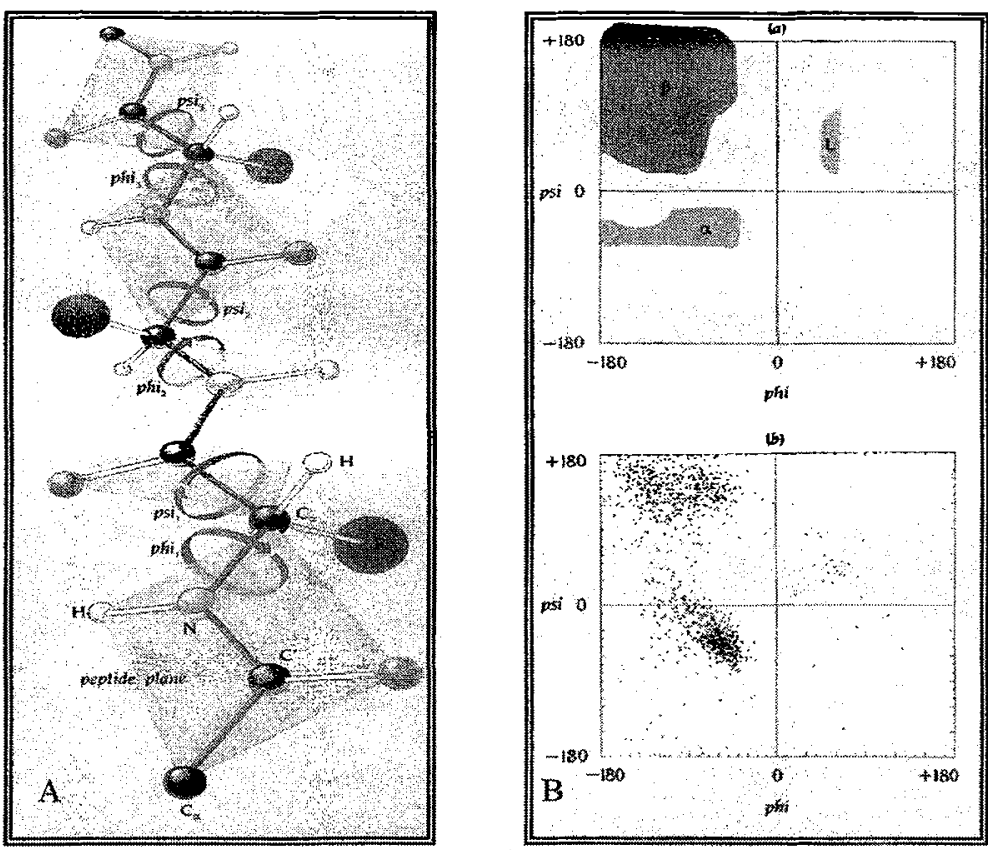

Figure 3 : (A) Définition conventionnelle des angles dièdres des groupements peptidiques. (B) Diagramme de Ramachandran, montrant les régions de l'espace conformationnel [phi, psi] les plus fréquemment observées dans les protéines (bas) et leur correspondance en termes de motifs de structure secondaire (haut). 
La mécanique moléculaire, qui définit la flexibilité d'un polypeptide, contraint le brin polypeptidique à adopter des conformations locales particulières. Sur la figure $3 \mathrm{~B}$ se trouve représenté un diagramme de Ramachandran, reproduisant les nombreuses conformations des angles dièdres phi et psi (tels que définis sur la fig. 3A) rencontrées dans les protéines. On constate que des régions sont privilégiées par rapport à d'autres, car la rotation autour de ces angles dièdres est souvent contrariée par des contacts stériques intra-brin ou entre le brin polypeptidique et les chaînes latérales. Les régions "autorisées" de l'espace conformationnel $(p h i, p s i$ ) favorisent la formation de motifs (ou éléments de structure secondaire) caractéristiques des protéines: hélices- $\alpha$, feuillets- $\beta$, etc ...

L'hélice- $\alpha$ (fig. 4) est un enroulement délicat maintenu en place par des liaisons hydrogène à toutes les quatre liaisons peptidiques. La période de répétition de l'hélice- $\alpha$ (pas de l'hélice) est de 3,6 résidus. Le feuillet plissé $\beta$ (fig. 4) représente une autre sorte de structure secondaire, dans laquelle le brin polypeptidique se plisse en accordéon. Les liaisons hydrogène entre les feuillets parallèles maintiennent la structure. Les feuillets- $\beta$ constituent la partie dense de nombreuses protéines globulaires.

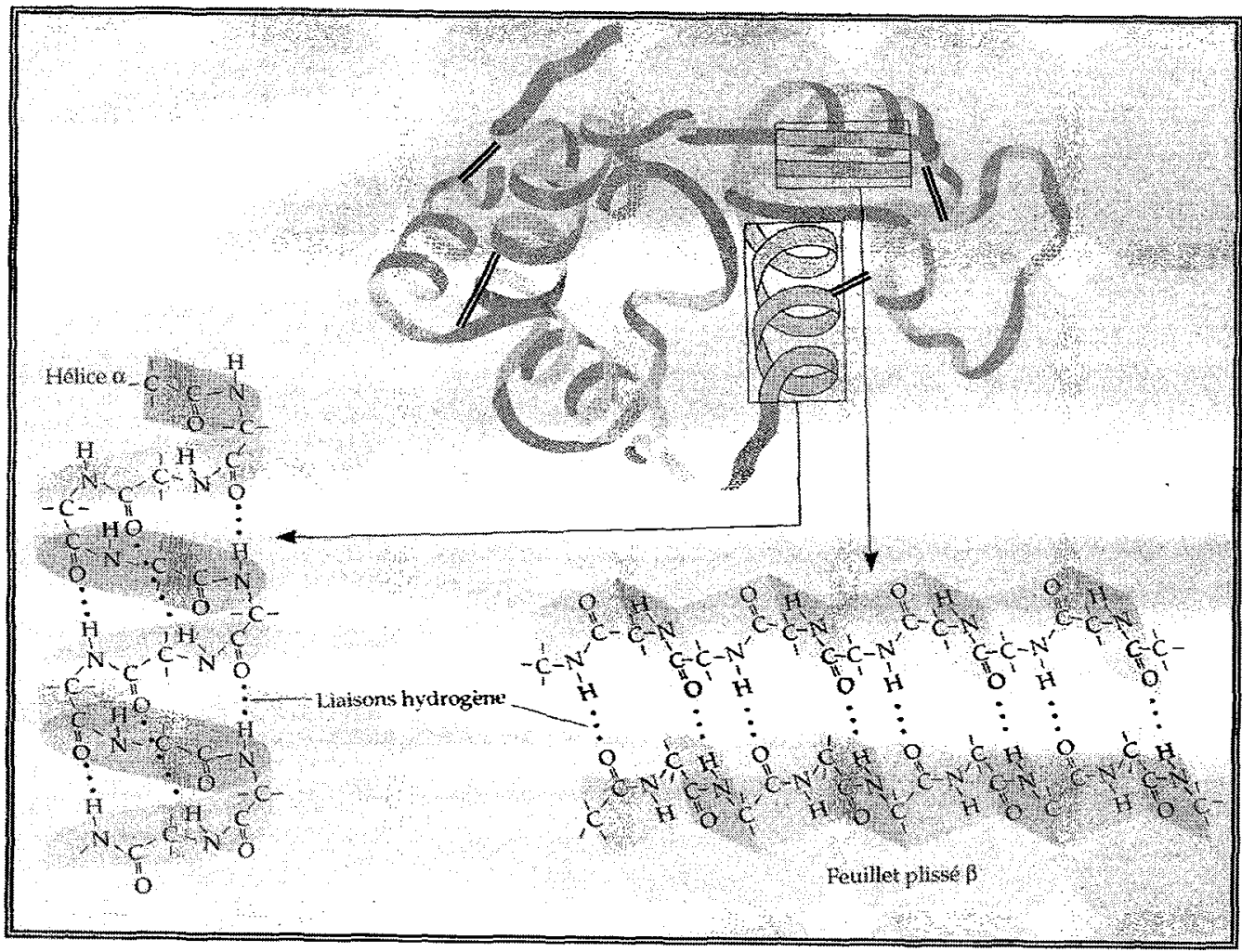

Figure 4 : Structure secondaire d'une protéine. Le lysozyme possède deux types d'eléments de structure secondaire: l'hélice- $\alpha$ et le feuillet- $\beta$. Les radicaux $R$, représentatifs des chaînes latérales, sont ici omis.

\subsubsection{Structure tertiaire}

La structure tertiaire correspond à l'ensemble des contorsions irrégulières dues aux interactions et liaisons entre les chaînes latérales. L'effet hydrophobe contribue à la mise en place de la structure 
tertiaire des protéines. Lorsqu'un polypeptide adopte sa conformation native, les acides aminés portant une chaîne latérale hydrophobe (non polaire) se rassemblent au cour de la protéine: c'est l'effondrement hydrophobe visant à éloigner ces résidus du solvant. Ce phénomène n'est vrai que pour les protéines cytosolubles. Pour les protéines membranaires il en est tout autrement: les résidus à caractère hydrophobe se positionnent en face des queues apolaires des lipides constituant la bicouche membranaire. Les liaisons hydrogène entre chaînes latérales sont également importantes, ainsi que les liaisons ioniques entre chaînes latérales chargées. Toutes ces interactions sont faibles mais leur effet cumulatif contribue à doter la protéine d'une structure stable. La conformation d'une protéine peut être encore renforcée par des liaisons covalentes, dites ponts disulfure, s'établissant entre deux résidus cystéine (généralement distants dans la séquence) pour donner une liaison thioéther. Tous ces types de liaisons peuvent coexister au sein d'une même protéine (fig. 5).

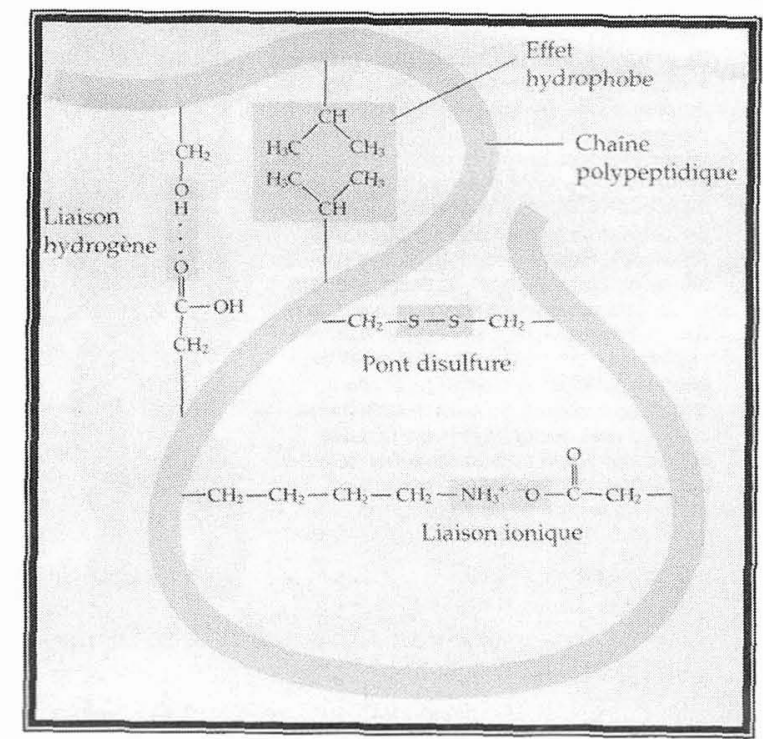

Figure 5 : Les différents types de liaisons entre chaines latérales, contribuant à la structure tertiaire des protéines.

\subsubsection{Structure quaternaire}

Certaines protéines peuvent être constituées de deux ou plusieurs chaînes polypeptidiques assemblées pour former une macromolécule fonctionnelle. Chaque chaîne polypeptidique est une sous-unité de la protéine. La structure quaternaire résulte de l'interaction entre ces sous-unités. Le collagène par exemple (fig. 6a) est une protéine fibreuse formée de l'assemblage de sous-unités en une triple "super-hélice", conférant ainsi une résistance exceptionnelle, ce qui en fait une protéine parfaitement adaptée pour soutenir les tissus conjonctifs comme les tendons et les ligaments. L'hémoglobine (fig. 6b) est également dotée de structure quaternaire, puisque constituée de 4 chaines polypeptidiques identiques deux à deux.

\subsubsection{Facteurs déterminant la conformation des protéines}

Etant donné que sa conformation unique confère à chaque protéine une fonction spécifique, quels sont les facteurs qui déterminent la conformation des protéines? En d'autres termes quels mécanismes gouvernent le repliement tridimensionnel des protéines? 
Une chaîne polypeptidique d'une séquence donnée d'acides aminés prend spontanément une forme tridimensionnelle; cette forme se maintient grâce aux interactions qui réalisent la structure secondaire et tertiaire. Cette conformation native apparaît normalement lors de la synthèse de la protéine dans la cellule. Si le $\mathrm{pH}$, les concentrations en sels, la température, ou d'autres aspects de son environnement ne sont pas respectés, la protéine peut se déplier, partiellement ou totalement. La protéine perd alors sa conformation native lors d'un processus dit de dénaturation, et sous cette nouvelle forme n'est plus fonctionnelle.

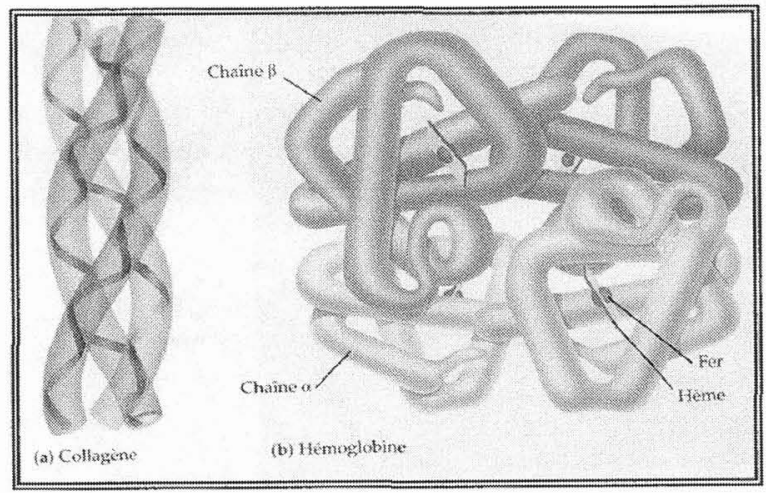

Figure 6 : Structure quaternaire du collagène (a) et de l'hémoglobine (b)

La plupart des protéines se dénaturent si on les transfère d'un milieu aqueux vers un solvant organique, comme l'éther ou le chloroforme: la protéine se retourne alors comme un gant, ses régions hydrophobes s'exposant au solvant de manière à écranter les parties hydrophiles. Parmi les autres agents dénaturants figurent les substances chimiques qui brisent les liaisons hydrogène (chlorure de guadinidium), les liaisons ioniques ou les ponts disulfure. La dénaturation peut également être causée par une chaleur excessive, qui agite les chaînes polypeptidiques suffisamment pour vaincre les interactions faibles qui stabilisent sa conformation.

Une protéine dénaturee peut reprendre sa forme originelle lorsqu'on la replace dans son environnement normal. Nous pouvons en conclure que l'information conduisant à l'adoption d'une forme spécifique est intrinsèque à la structure primaire de la protéine. C'est la séquence en acides aminés qui détermine la conformation native d'une protéine. Le mécanisme exact du repliement des protéines est pour l'heure inconnu, mais son étude constitue un des challenges importants de la biologie.

\subsection{Diversité fonctionnelle des protéines}

Nous avons déjà mentionné à plusieurs reprises le lien étroit existant en biologie entre structure et fonctionnalité: Au vu de la très grande variété de protéines existantes, on pourrait penser que leur diversité fonctionnelle est tout aussi considérable. En fait les organismes présentent des caractéristiques communes de leur métabolisme, ainsi que de leurs structures cellulaires et/ou tissulaires. Le métabolisme correspond à l'ensemble des réactions biochimiques d'un organisme. Les protéines interviennent dans les différents cycles et réactions chimiques associés au métabolisme, non pas dans leur globalité, mais généralement sous la forme de processus de reconnaissance n'engageant qu'une partie de leur structure: le site actif.

D'un organisme à un autre, le site actif d'une protéine effectuant la même fonction peut présenter une structure quasi-constante, ce qui, en vertu du principe de détermination de la conformation des 
protéines suivant leur séquence en acides aminés, implique que les séquences de ces sites actifs doivent être voisines. Le reste de la structure peut être plus ou moins variable entre deux protéines analogues (même fonction biologique accomplie dans deux organismes différents, fonctions voisines au sein d'un même organisme). Ainsi on rend compte d'une dégénérescence de lorganisation structurale des protéines, si leur fonction est uniquement prise en considération comme manifestation de la vie. En conséquence, les fonctions des protéines peuvent être résumées de façon "quasiexhaustive" en les classant par catégories (table 1).

D'un point de vue fonctionnel, les parties de la structure autres que le site actif sont souvent considérées comme inopérantes biologiquement. $\mathrm{n}$ n'en est rien puisque la reconnaissance d'une substance par le site actif, implique toujours des réarrangements conformationnels locaux du site actif, mais de façon concertée avec le reste du polypeptide. Il est donc nécessaire, afin de se faire une idée plus précise du mécanisme fonctionnel d'une protéine, de compléter la description structurale qui en est souvent faite (détermination de sa conformation native "moyenne" par diffraction de rayons-X ou RMN) par une analyse dynamique, trop rarement entreprise, permettant de dériver les fluctuations de sa structure interne. La partie qui suit met en évidence l'utilité de la diffusion quasi-élastique de neutrons pour la mesure des fluctuations de structure des protéines à l'échelle de temps de la picoseconde-nanoseconde.

Table 1 : Les différents types d'activité biologique présentés par les protéines.

\begin{tabular}{|c|c|}
\hline Fonction & Exemples \\
\hline Soutien & $\begin{array}{l}\text { Le collagène et l'élastine composent la structure fibreuse des lissus con- } \\
\text { jonctís animaux, tels que les tendons et les ligaments. La kératine est la } \\
\text { proteine des cheveux, des ongles, des comes, des plumes. des aiguilions } \\
\text { et des autres appendices culanés. }\end{array}$ \\
\hline Mise en réserve d'acides aminés & $\begin{array}{l}\text { L'ovalbumine est la proténe du blanc d'ceuf, utilisée comme source d'aci- } \\
\text { des aminés par l'embryon en voie de développement. La caséine, protéine } \\
\text { du lait, constitue la principale source d'acides aminés pour les patits Mam- } \\
\text { mifêres durant la période postnatale. Les Végétaux emmagasinent des } \\
\text { protéines dans les graines. }\end{array}$ \\
\hline Transport de substances & $\begin{array}{l}\text { L'hémoglobine. la proteine sanguine contenant du fer, transporte loxygene } \\
\text { des poumons vers les differentes parties du corps. D'autres protöines trans- } \\
\text { portent des ions ou des molécules à travers les membranes cellulaires. }\end{array}$ \\
\hline Régulation hormonale & $\begin{array}{l}\text { Une petite protéine, linsuline, une hormone sécrétée par le pancréas, con- } \\
\text { tríbue à la régulation de la concentration de glucose dans le sang. }\end{array}$ \\
\hline Reception de substances & $\begin{array}{l}\text { Les protëines réceptrices intégrées à la membzane d'une cellulo noveuse } \\
\text { détectent les signaux chimiques transmis par d'autres cellutes neveuses. }\end{array}$ \\
\hline Mouvement & $\begin{array}{l}\text { L'actine ef la myosine sont des protéines contractiles servant au mouve- } \\
\text { ment des muscles. D'autres protéines contractiles servent à faire onduler } \\
\text { les cils et les flagelles qui propuisent de nombreuses cellules. }\end{array}$ \\
\hline Immunité hurrorale & $\begin{array}{l}\text { Les anticorps, ces protöines spécifiques du plasma sanguin, combattent } \\
\text { les Bactéries et les Virus. }\end{array}$ \\
\hline Catatyse & $\begin{array}{l}\text { Les enzymes, ces protéines qui accétèrent la vitesse des reactions chimi- } \\
\text { ques, interviennent dans toute symthese ou dégradation de substances; ainzi, } \\
\text { les enzymes digestives hydrolysent les macromolécules presentes dans les } \\
\text { aliments. }\end{array}$ \\
\hline
\end{tabular}

\section{FLUCTUATIONS DYNAMIQUES DE LA STRUCTURE INTERNE DES PROTEINES. ETUDE PAR DIFFUSION QUASI-ELASTIQUE INCOHERENTE DE NEUTRONS}

\subsection{Dynamique des protéines: Historique}

Afin d'approfondir nos connaissances des principes gouvernant le repliement et le fonctionnement des protéines, la détermination de leur structure tridimensionnelle doit être complétée par la caractérisation de leurs mouvements internes. 
Bien que les processus dynamiques dans les protéines se produisent sur une gamme temporelle très étendue (de la femtoseconde $[f s]$ à la seconde), les propriétés physiques des protéines sont telles que les mouvements à l'échelle de la ps contribuent de façon significative aux fluctuations atomiques globales. Les fréquences associées à ces mouvements vont typiquement de 0 à $100 \mathrm{~cm}^{-1}$. Ce constat ne provient pas de résultats expérimentaux, mais de calculs théoriques (analyse en modes normaux) ou de simulations (dynamique moléculaire), menés pour la plupart entre 1970 et 1985.

Ces deux méthodes reposent sur une description des interactions intramoléculaires par une fonction d'énergie potentielle semi-empirique [1] prenant en considération les variations de longueur des liaisons covalentes, la déformation des angles de valence, les torsions autour d'angles dièdres, mais également les interactions entre atomes non liés de la molécule sous la forme d'un terme électrostatique de type Coulombien et d'un potentiel d'attraction/exclusion de type van der Waals:

$$
\begin{aligned}
V= & \sum_{\text {liaisons }} k_{b}\left(b-b_{0}\right)^{2}+\sum_{\text {angles }} k_{\theta}\left(\theta-\theta_{0}\right)^{2}+\sum_{\text {dièdres }} k_{\phi}[1+\cos (n \phi-\delta)] \\
& +\sum_{i, j}\left[4 \varepsilon_{i j}\left(\frac{\sigma_{i j}}{r_{i j}}\right)^{12}-\left(\frac{\sigma_{i j}}{r_{i j}}\right)^{6}\right]+\sum_{i, j} \frac{332 q_{i} q_{j}}{r_{i j}}
\end{aligned}
$$

Pour chaque coordonnée interne, les paramètres d'équilibre et les constantes de force du potentiel sont en général dérivées de propriétés structurales et dynamiques de petites molécules présentant des groupements chimiques analogues à ceux rencontrés dans les protéines, ou bien directement de fragments de protéines.

L'analyse en modes normaux fait l'hypothèse qu'un système moléculaire de $N$ atomes vibre de façon harmonique. Les termes d'interaction entre atomes liés sont par nature quadratiques. Par contre, dans ce type d'analyse, les interactions entre atomes non liés sont réduites à de faibles déplacements autour des positions d'équilibre. Dans le cadre de cette approximation harmonique, les trajectoires atomiques individuelles sont décrites comme la superposition des contributions des $3 N-6$ modes normaux de vibration.

Les simulations de dynamique moléculaire, à l'inverse des calculs de modes normaux, ne néglige pas les effets anharmoniques. Les équations différentielles du mouvement sont résolues numériquement par pas d'intégration de l'ordre de la $f s$, sans aucune restriction sur la fonction d'énergie potentielle. La puissance des ordinateurs permet aujourd'hui de faire des calculs de trajectoires de l'ordre de la $n s$, mais jusqu'au début des années 1990 , la limitation temporelle des mouvements échantillonnés était plutôt de l'ordre de 100ps. La dynamique moléculaire est devenue aujourd'hui un outil standard en biophysique et cette technique est utilisée pour sonder les propriétés structurales, dynamiques et thermodynamiques des protéines, en relation avec leur repliement et leur activité biologique, mais également pour réaliser des affinements de structures obtenues par diffraction de rayons-X ou par RMN [2-4].

Les premiers résultats théoriques établirent que les mouvements "basse-fréquence" dominaient les fluctuations atomiques. La caractérisation expérimentale de ces mouvements est extrêrnement difficile, en raison de leur complexité et de leur variété. La dynamique à l'échelle de la ps peut être d'origine vibrationnelle, consistant en des mouvements corrélés de grande amplitude, souvent délocalisés sur la protéine entière. Mais sur cette même échelle de temps il est également possible d'observer des transitions "anharmoniques" entre des états conformationnels correspondant à des puits de la fonction d'énergie potentielle. 
Contrastant avec les nombreuses études par simulations, très peu de travaux expérimentaux permirent de caractériser la dynamique "ps" des protéines. Jusqu'à 1985 on se limitait à démontrer expérimentalement l'existence de fluctuations dynamiques importantes sur cette échelle de temps. Le signal de fluorescence anisotrope résolue dans le temps d'un résidu aromatique (phénylalanine, tyrosine, tryptophane) présente des composantes temporelles de relaxation de l'ordre de quelques centaines de ps [5]. Des pics "basse-fréquence" ont été détectés par spectroscopie Raman et infrarouge dans de nombreuses protéines [6-9]. Par exemple, une forte absorption dans l'infrarouge à 25 et $56 \mathrm{~cm}^{-1}$ a été mesurée dans des cristaux de lysozyme [9], de toute évidence liée à des interactions entre les résidus de surface de la protéine et le solvant, puisque disparaissant en l'absence de solvant.

Une investigation beaucoup plus poussée des échelles de temps, formes et amplitudes des mouvements "basse-fréquence" a été rendue possible par l'utilisation de la diffusion inélastique de neutrons. Cette technique, communément employée dans l'étude de la dynamique de liquides ou de solides [10-11], consiste en la mesure des changements de vitesse du neutron en interaction avec les noyaux des atomes du système. Les changements d'énergie et de quantité de mouvement du neutron peuvent être reliés à des fonctions de corrélation temporelle des mouvements atomiques de l'échantillon. A partir de 1985, les premières applications de cette technique à des systèmes biologiques (principalement des protéines) ont été conduites [12-14]. Des progrès très récents, accomplis entre 1985 et 1990, ont permis une confrontation directe des spectres expérimentaux (ou quantités dérivées des spectres) avec leurs analogues simulés. L'objectif étant de comprendre quelle était la forme de l'hypersurface d'énergie potentielle échantillonnée par une protéine, sur des échelles de temps de 100ps, dans des conditions physiologiques où elle est biologiquement active ( $\mathrm{T} \sim 300 K$, hydratation suffisante, $\mathrm{pH}$ physiologique). Une revue des applications combinant neutrons et simulations est proposée par J.C Smith [15].

Ce n'est que depuis 1995 que les simulations permettent de calculer des trajectoires sur des temps plus longs approchant la $n s$, en modélisant des systèmes protéiques en interaction avec leur environnement naturel (eau + solutés pour les protéines globulaires cytosolubles, bicouche lipidique + eau pour les protéines membranaires). Les effets anharmoniques liés aux "frictions" induites par le milieu extérieur sur les mouvements internes des protéines peuvent ainsi être simulés, et leur contribution à la dynamique lente (ns) des protéines estimée.

La mesure de mouvements présentant des temps de corrélation de l'ordre de la $n s$ justifie désormais l'emploi de la diffusion quasi-élastique incohérente de neutrons, comme principale technique expérimentale pour valider les simulations sur la base d'un accord entre leurs observables communes. Etant donnée la complexité moléculaire d'une protéine, tous les protons présents dans sa structure ne sont pas équivalents dynamiquement, ce qui rend impossible l'écriture d'une fonction de diffusion théorique (comme somme des fonctions de diffusion individuelles) pour un ajustement avec les données expérimentales. L'utilisation de la diffusion quasi-élastique pour l'étude de systèmes biologiques nécessite donc de faire des approximations, en classant la population de protons en différentes "catégories dynamiques", afin de pouvoir calculer une fonction de diffusion théorique. Mais il est également possible de ne travailler que sur les spectres corrigés de diffusion en les comparant à des spectres simulés dans les conditions identiques à l'expérience: si un bon accord existe, alors les propriétés dynamiques peuvent être directement interpréter à partir des résultats produits par les simulations. Des exemples de systèmes biologiques, pour lesquels l'une ou l'autre des approches a été choisie, sont présentés dans les sections suivantes.

\subsection{La bacteriorhodopsine}

\subsubsection{Structure \& fonction}

La bacteriorhodopsine (BR) est l'unique protéine constitutive de la membrane pourpre (PM) d'Halobacterium salinarium [16], une archaebactérie appartenant au groupe des bactéries halophiles 
extrêmes, vivant dans des conditions de salinité proches de la saturation (4M NaCl - mer Morte, lacs salés, marais salants).

Henderson [17] et Blaurock [18] ont montré par diffraction de rayons-X que, dans la PM, la BR est organisée avec les lipides en réseau bidimensionnel très structuré. Le système cristallise dans le groupe d'espace $P 3$ ( $a=62 \AA, Z=3$ protéines par maille), la protéine traversant la membrane de part en part sur une épaisseur d'environ $45 \AA$. Ceci laissait penser, bien avant d'avoir une meilleure résolution structurale, que la protéine était riche en structure secondaire de type hélice- $\alpha$.

Une première structure à basse résolution $(7 \AA$ dans le plan membranaire et $14 \AA$ dans une direction transverse) a été fournie par la microscopie électronique avec reconstruction d'images et la diffraction de rayons-X [19]. Elle montrait que la BR était composée de sept hélices- $\alpha$ étroitement imbriquées entre elles, puisque séparées en moyenne de 10-12A. Henderson et al. [20] ont obtenu par cryomicroscopie électronique une structure à $3,5 \AA$ de résolution dans le plan et $7 \AA$ perpendiculairement à celui-ci, sur laquelle les résidus aromatiques (les plus volumineux par leurs chaînes latérales) étaient visibles. Ceci a permis d'interpréter la carte de densité électronique (fig. 7) en termes de séquences en acides aminés, et de pouvoir orienter en rotation chacune des hélices de façon assez précise. La meilleure structure actuelle obtenue pour des membranes naturelles est celle de Grigorieff et al. [21], mais il existe une structure de la BR à 2,5 $\AA$ de résolution obtenue par diffraction de rayons- $X$ [22] sur un cristal tridimensionnel de BR "solubilisée" dans une phase cubique lipidique. L'arrangement des 7 hélices- $\alpha$ se fait autour d'un chromophore (pigment), le rétinal (non visible sur la figure 7, mais présent dans la structure de Grigorieff). Le rétinal est lié covalemment par l'intermédiaire d'une liaison imine (ou base de Schiff, bS) au résidu Lysine_216 (figure 8), la BR comportant au total 248 acides aminés. Le rôle de ce chromophore est étroitement lié à la fonction de la BR. L'activité biologique de la BR a été élucidée en 1973 par Oesterhelt \& Stoeckenius [23]: il s'agit d'une pompe à protons activée par la lumière. Le rétinal absorbe un photon $(\lambda=568 \mathrm{~nm})$ et la protéine utilise l'énergie emmagasinée pour transporter des protons du cytoplasme vers le milieu extracellulaire, contre le potentiel de la membrane. Le gradient de concentration des charges positives ainsi généré contribue également au potentiel de la membrane et peut être utilisé comme source d'énergie pour les besoins physiologiques de la bactérie. Au cours de la phase de pompage du proton, BR et rétinal subissent des changements conformationnels. Les différents photointermédiaires, caractérisés par un pic d'absorbance et des temps de vie différents, définissent un schéma réactionnel: le photocycle.

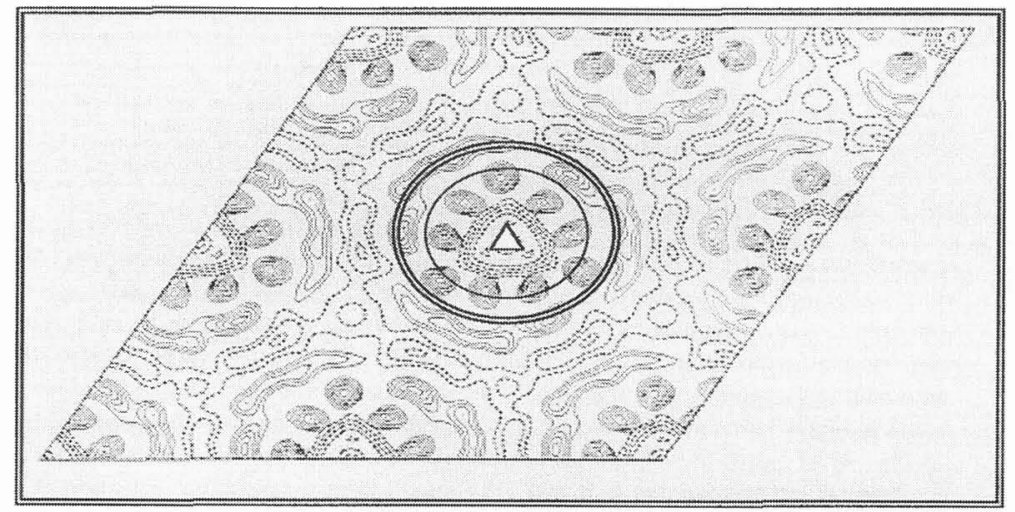

Figure 7 : Carte de densité électronique en projection sur le plan membranaire du réseau de PM. Autour de l'axe de symétrie d'ordre 3 (triangle) les hélices du trimère de BR s'organisent en deux catégories. Cercle interne: 9 hélices- $\alpha$ globalement orientées perpendiculairement à la membrane et délimitant un espace de diamètre $20 \AA$, contenant des glycolipides. Cercle externe: 12 hélices- $\alpha$ inclinées par rapport au plan membranaire. Des glycolipides et des phospholipides se trouvent dans l'espace restant. D'après référence [20]. 


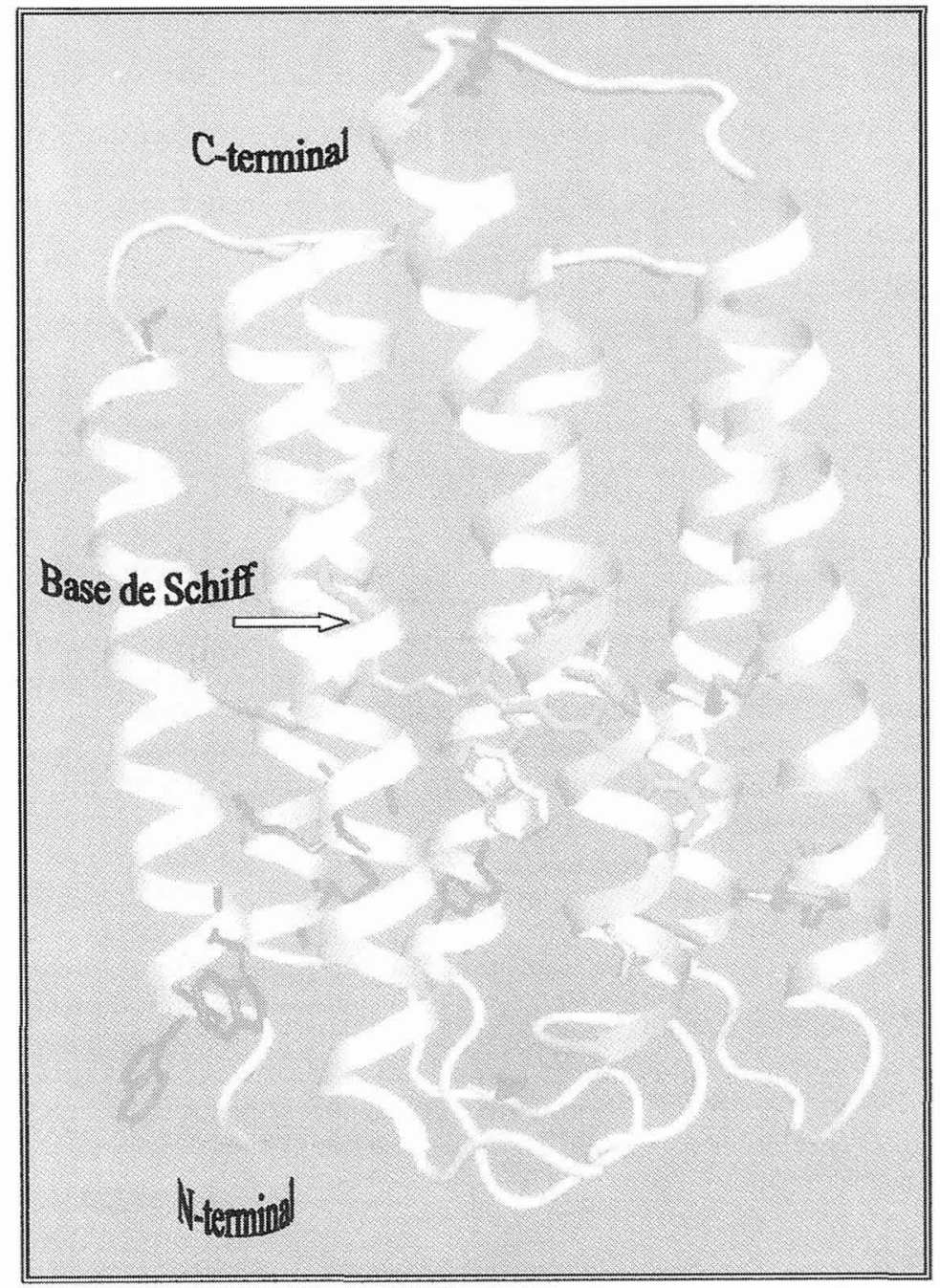

Figure 8 : La bacteriorhodopsine en vue parallèle au plan de la membrane. Les 7 hélices- $\alpha$ se propagent de part en part de la membrane depuis l'extrémité Nterminale jusqu'à l'extrémité C-terminale, connectées entre elles par des boucles extra-membranaires. La molécule de rétinal se lie à la lysine_216 par une base de Schiff dans la partie médiane de la protéine (point d'attache matérialisé par une flèche). Les chaines latérales des résidus Methionine (non aromatique) et Tryptophane (aromatique) sont indiqués : ils apparaissent majoritairement dans la poche du rétinal. Cette propriété sera utilisée pour des marquages spécifiques en vue d'expériences de diffusion neutronique (voir texte, section 3.2.5). 


\subsubsection{Fonction et photocycle}

Le photocycle est initié par l'isomérisation du rétinal qui passe d'une conformation dite all-trans à 13cis (isomérisation autour d'une double liaison carbone-carbone $\mathrm{C}_{13}-\mathrm{C}_{14}$ ). Une séquence de "réactions" donnent naissance à des photointermédiaires (BR, J,K,L,M1, M2,N,O) dont les fluctuations dynamiques sont de nature thermique. Ces changements successifs de conformation, touchant à la fois le rétinal et les parties de la protéine en contact étroit avec le chromophore, induisent le transfert de protons. La durée de ce photocycle réactionnel est d'environ 10ms. Le chemin de retour vers l'état fondamental $\left(\mathrm{BR}_{568}\right)$ est sujet à caution et plusieurs mécanismes ont été proposés: séquence linéaire de réactions unidirectionnelles, ramification en 2 branches avant l'état $L$, réversibilité de certaines réactions, etc ... Actuellement le profil de photocycle communément admis est celui de la figure 9 [24].

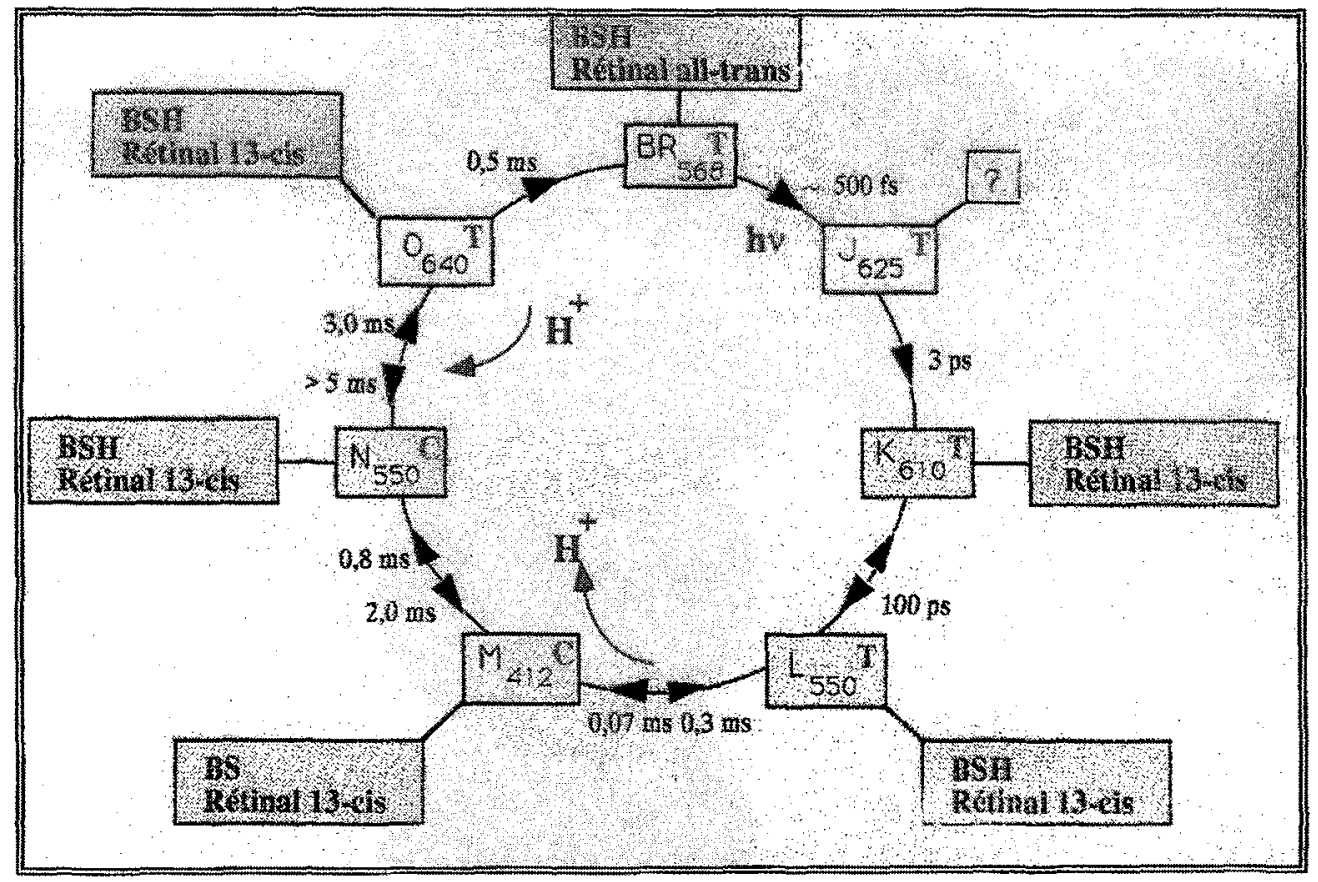

Figure 9: Photocycle de la bacteriorhodopsine. Les états d'isomérisation du rétinal ainsi que les états de protonation de la base de Schiff sont indiqués (BS, base de Schiff déprotonée, ou BSH base de Schiff protonée). Les états de la BR (fondamental, K, L, etc...) sont accompagnés de la longueur d'onde d'absorbance maximale. Le caractère réversible ou irréversible de chaque "réaction" (flèches) et les temps de vie des photointermédiaires sont indiqués. Les états conformationnels ( $\mathrm{T}$ ou $\mathrm{C}$ ) de la protéine associés à chacun des photointermédiaires correspondent à la description donnée en référence [28].

\subsubsection{Relation structure - fonction - photocycle}

Le chemin du proton à travers la membrane peut être divisé en deux parties: le demi-canal intracellulaire (IC) défini entre le milieu cytoplasmique et la bS, et le demi-canal extracellulaire (EC) défini entre la $\mathrm{bS}$ et milieu extracellulaire. La partie IC est plus large et comprend beaucoup d'acides aminés chargés alors que la partie EC est plus étroite et essentiellement hydrophobe [20]. Par mutagénèse dirigée (substitution d'un ou plusieurs acides aminés), il a été montré [25-26] que deux acides aminés sont essentiels pour le transfert du proton: l'Asp_96 situé dans le demi-canal IC fait fonction de donneur de proton vers la $\mathrm{bS}$, alors que l'Asp_85, situé du côté EC sert d'accepteur de 
proton en provenance de la bS. Dans l'état fondamental la bS est protonée, puis s'isomérise par absorption d'un photon. Ce proton est cédé à l'Asp_85 au niveau de l'état $L$, puis évacué vers le milieu extracellulaire. Il existe deux sous-états de l'état $\mathrm{M}$ : les états $\mathrm{M} 1$ et $\mathrm{M} 2$, non représentés sur la figure 9, M1 précédant M2. La réaction M1 $\rightarrow$ M2 est irréversible comme en atteste une baisse énorme de l'énergie libre [27]: elle permet le retournement de la bS. Ce retournement permet à la bS de se reprotoner à partir de l'Asp_96 au niveau de l'état M2. L'Asp_96 est chargé négativement uniquement dans l'état $\mathrm{N}$, se reprotonant immédiatement depuis le milieu intracellulaire au niveau de l'état 0 .

Pour expliquer la fonction de valve qui assure un transport vectoriel du proton, Fodor et al. [28] introduisent l'idée d'un changement conformationnel de la protéine afin de permettre le retournement de la bS et sa reprotonation. Des expériences de diffraction de neutrons ont montré des changements structuraux entre l'état fondamental $\mathrm{BR}_{568}$ et l'état $\mathrm{M} 2$ [29-30], sans perte de l'ordre cristallin, affectant principalement les hélices (G,B,E,F telles que référencées sur les cartes de densité électronique) encadrant précisément le rétinal.

\subsubsection{Influence de l'hydratation et de la température}

Zaccaï a montré [31] qu'un assèchement des membranes, à température ambiante, conduit à une diminution du paramètre de maille du réseau de la PM d'environ $2 \%$ (figure 10 ), en raison de la disparition de zones d'hydratation autour des têtes polaires lipidiques. Pour des faibles teneurs en eau des membranes $\left(<0.1 \mathrm{gD}_{2} \mathrm{O} / \mathrm{gBR}\right)$, des distorsions du photocycle apparaissent également [32]: accumulation des premiers intermédiaires en raison du caractẻre dominant des réactions "retour" $M$ $\rightarrow \mathrm{L}$ et $\mathrm{L} \rightarrow \mathrm{K}$, retour direct vers l'état initial depuis $\mathrm{M}$. La fonction de pompe à protons n'est plus assurée si l'humidité relative devient inférieure à $50 \%$ [33].

Des changements conformationnels sont nécessaires lors de l'accomplissement de la fonction. La protéine doit être capable de relaxer thermiquement d'une conformation contrainte (faisant suite à l'isomérisation du rétinal) vers une conformation d'énergie libre minimale (celle correspondant à l'état fondamental). Le système doit nécessairement franchir des barrières d'énergie, même si celles-ci sont en valeur absolue nettement plus faibles que celle franchie lors de l'absorption du photon $(\sim 50 \mathrm{kcal} / \mathrm{mol}$ soit $\sim 25000 \mathrm{~K})$. Abaisser la température peut donc permettre de piéger la BR dans une conformation contrainte. C'est exactement ce qui survient lorsqu'on abaisse la température à des valeurs inférieures à 230K: on gèle le photocycle en ralentissant la décroissance de l'état M1 [34], et la fonction est ainsi inhibée en grande partie $(-90 \%)$. L'influence d'un abaissement de la température sur la structure de la PM est comparable à un assèchement des membranes (fig. 10).

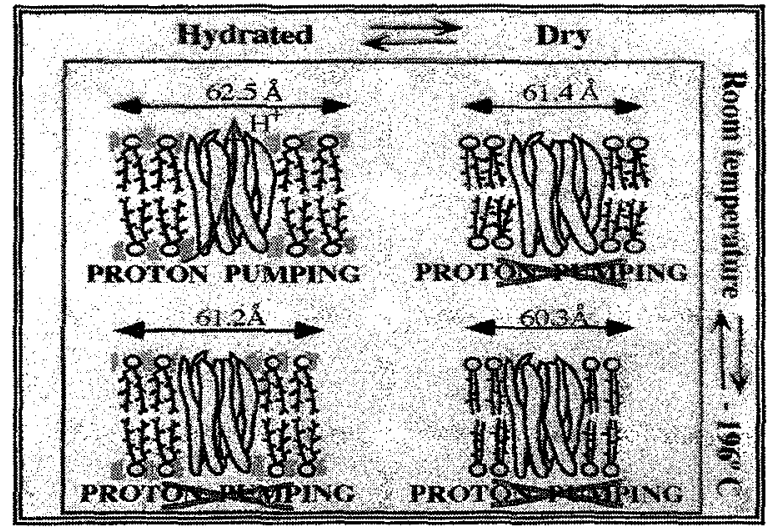

Figure 10: Variations du paramètre de la maille hexagonale de la PM en fonction de la température et de l'hydratation. L'état hydraté correspond à $93 \%$ d'humidité relative, ce qui fixe $\mathrm{h} \sim 0,31 \mathrm{gD}, \mathrm{O} / \mathrm{gBR}$. L'état sec ne contient que de l'eau résiduelle; à $\mathrm{h}-0,02 \mathrm{gD}_{2} \mathrm{O} / \mathrm{gBR}$. L'inactivation de la fonction de la $\mathrm{BR}$ est également indiquée (voir texte). D'après référence [31]. 


\subsubsection{Dynamique et activité biologique}

Diminuer l'hydratation et/ou la température affecte de la même manière la structure des membranes et l'activité biologique de la BR, en réduisant sa flexibilité et sa liberté conformationnelle. La modification de l'environnement de la BR inhibe certains mouvements internes intervenant dans la fonction. Ceci a été mis en évidence par Ferrand et al. [35] lors d'expériences de diffusion inélastique et élastique de neutrons. Ces travaux avaient pour but de détecter des changements de dynamique interne de la PM en faisant varier la température entre $10 \mathrm{~K}$ et $320 \mathrm{~K}$ pour des échantillons de $\mathbf{P M}$ sèches et hydratées, respectivement à $\mathrm{h}=0,02 \mathrm{gD}_{2} \mathrm{O} / \mathrm{gBR}$ et $\mathrm{h}=0,55 \mathrm{gD}_{2} \mathrm{O} / \mathrm{gBR}$.

Les déplacements carrés moyens $\left(<\mathrm{u}^{2}>\right)$, principalement dominés par les mouvements des atomes d'hydrogène en raison de la section de diffusion incohérente très grande de leur noyau par rapport à ceux d'autres éléments, sont représentés sur la figure 11. Le fait que les atomes d'hydrogène soient uniformément distribués sur le volume de la membrane permet la mesure de sa dynamique globale, et plus particulièrement celle de la $\mathrm{BR}$, puisque la protéine contribue pour $90 \%$ au signal incohérent total.

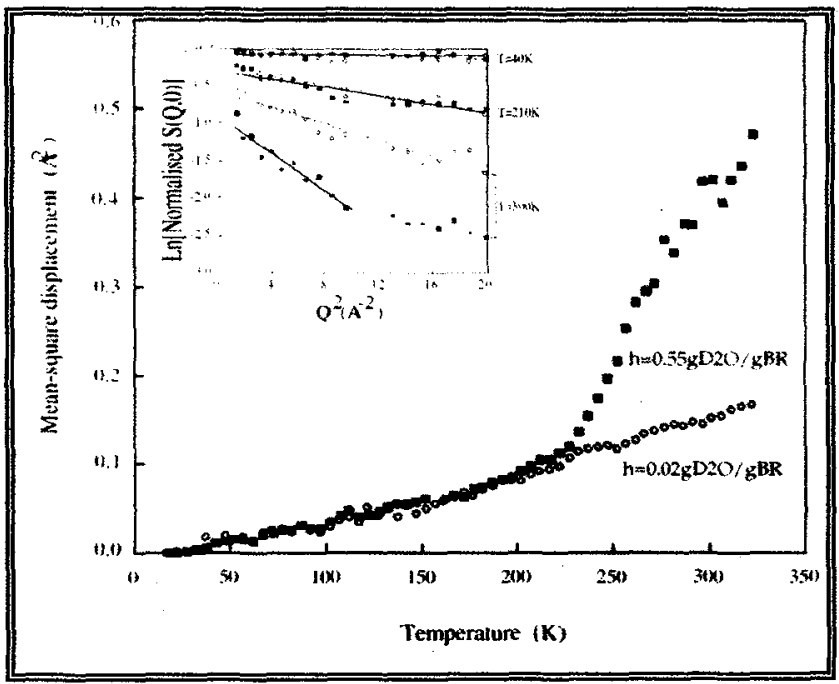

Figure 11 : Déplacements carrés moyens en fonction de la température et de l'hydratation. Les valeurs sont dérivées d'ajustements linéaires de la diffusion élastique suivant $Q^{2}$ (insert), D'après référence [35].

Pour l'échantillon de PM privé de toute hydratation, on constate que les déplacements carrés moyens évoluent linéairement sur toute la gamme en température, révélant ainsi une dynamique à caractère harmonique, sur l'échelle de temps du spectromètre utilisé (IN13, Institut Laue Langevin, largeur à mi-hauteur de la résolution instrumentale $=10 \mu \mathrm{eV}$, soit $\mathrm{t}_{\text {limite }}=400 \mathrm{ps}$ ). Par contre les membranes hydratées suivent un comportement harmonique jusqu'à une température critique de transition de l'ordre de 230-240K, où une composante anharmonique apparatt, accentuant les amplitudes des fluctuations atomiques. Le changement de régime dynamique apparaît à une température comparable à la température d'activation de la fonction biologique. Ce résultat corrélant dynamique et fonction biologique a également été renforcé par des expériences de diffusion inélastique de neutrons ( $\mathrm{N} 6, \Pi \mathrm{LL}$, résolution de $80 \mu \mathrm{V}$ ) ayant permis d'extraire les densités d'états vibrationnels (non présentées ici) pour des échantillons identiques. Les membranes sèches présentent des densités d'états vibrationnels, $\mathrm{G}(\omega)$, à $100 \mathrm{~K}, 180 \mathrm{~K}, 240 \mathrm{~K}$ et $300 \mathrm{~K}$ conformes à une loi de Debye 
$\left(\sim \omega^{2}\right)$, et donc typiques d'un système condensé vibrant harmoniquement. Les densités d'états vibrationnels dérivées des mesures sur les membranes hydratées présentent les mêmes profils jusqu'à $240 K$, mais à $300 K, G(\omega)$ s'écarte de la loi de Debye pour des fréquences $>10 \mathrm{~cm}^{-1}$, en indiquant une tendance des vibrations propres du système à être sous-amorties.

Les protons de la PM n'étant vraisemblablement pas équivalents dynamiquement, il a été suggéré, en utilisant le marquage spécifique au deutérium, de ne mesurer que la dynamique du site actif, c'est à dire la dynamique de la "poche du rétinal". Une avancée considérable dans ce domaine résulte des travaux de Réat et al. [36]. En utilisant les voies de synthèse naturelles des bactéries, des échantillons de PM entièrement deutérés ont été préparés, à l'exception d'une grande partie du site actif constituée du rétinal, des résidus Trp et Met (figure 8). La mesure des déplacements carrés moyens $\left(\mathrm{IN} 10, \mathbb{L L}\right.$, résolution $=1 \mu \mathrm{V}$, soit $\left.\mathrm{t}_{\mathrm{inite}}=4 n s\right)$ obtenus pour des membranes hydratées ont montré que le site actif était dynamiquement rigide (variation harmonique de $\left\langle\mathrm{u}^{2}\right\rangle$ en fonction de la température), semblant ainsi assurer la vectorialité du transfert de protons.

L'isomérisation "retour" du rétinal de 13-cis vers la conformation all-trans requiert des mouvements concertés avec l'environnement protéique. Les relaxations thermiques de la structure de la protéine au voisinage du site actif semblent être activées à des températures supérieures à $230 \mathrm{~K}$. L'espace conformationnel alors échantillonné par la protéine ne présente plus un caractère strictement quadratique (harmonique), mais s'étend à des régions pouvant être visitées par des mouvements à caractère diffusif (transitions dynamiques par sauts par exemple). Une tentative de caractérisation des processus diffusifs internes a été proposée par Fitter et al. [37] en utilisant la diffusion quasi-élastique de neutrons.

\subsubsection{Flexibilité de la BR induite par l'hydratation. \\ Mesures par diffusion quasi-élastique de neutrons sur des échantillons orientés de PM}

\subsubsection{Généralités}

La diffusion quasi-élastìque de neutrons (DQN) apparait, lorsque l'on augmente la température, comme composante additionnelle des contributions élastique (mouvements non résolus sur l'échelle de temps du spectromètre, diffuseurs immobiles) et inélastique (vibrations intramoléculaires, modes de réseau). Elle est la manifestation expérimentale des mouvements internes à caractère diffusif. Dans une protéine, de tels mouvements sont probablement impliqués dans les fluctuations dynamiques accompagnant les transitions entre différents sous-états conformationnels, suivant le modèle décrit par Frauenfelder et al. [38-40]. Aux basses températures, les barrières d'énergie potentielle séparant des sous-états conformationnels excèdent largement l'énergie thermique disponible, et seuls des mouvements de nature vibrationnelle extrêmement localisés se produisent. Aux conditions physiologiques de $\mathrm{pH}$, température et d'hydratation suffisante, une protéine est fonctionnelle à $100 \%$, et une fraction appréciable de ses mouvements internes ne possèdent plus de caractère harmonique mais montrent un caractère diffusif marqué.

Dans une expérience de diffusion de neutrons où la contribution incohérente des noyaux d'hydrogène est prépondérante ( $>90 \%$ du signal total pour une protéine), la double section efficace différentielle

$$
\frac{\partial^{2} \sigma}{\partial \Omega \partial \omega}=\frac{1}{4 \pi} \frac{|\vec{k}|}{|\vec{k}|} b_{i n c}^{2} \quad S_{i n c}(\vec{Q}, \omega)
$$


détermine le nombre de neutrons diffusés par l'échantillon dans l'angle solide $\delta \Omega$ et par élément de transfert d'énergie $\delta \omega . \quad b_{\text {inc }}$ est la longueur de diffusion incohérente, $\boldsymbol{k}_{0}$ et $\boldsymbol{k}$ les vecteurs d'onde incident et diffusé. L'information sur la dynamique des noyaux d'hydrogène peut être obtenue à partir de la quantité $S_{\text {inc }}(Q, \omega)$, le facteur de structure dynamique incohérent. Si on utilise le formalisme de Van Hove [41], $S_{\text {ind }}(Q, \omega)$ peut être relié à la fonction d'auto-corrélation des positions nucléaires, $G_{s}(\boldsymbol{r}, \boldsymbol{t})$, suivant

$$
S_{i n c}(\vec{Q}, \omega)=\frac{1}{2 \pi} \int_{-\infty}^{+\infty} e^{-i \omega t} \int_{-\infty}^{+\infty} e^{-i \vec{Q} \cdot \vec{r}} G_{S}(\vec{r}, t) d^{3} \vec{r} d t
$$

$G_{s}(r, t)$ décrit en fait une distribution de probabilité des positions nucléaires

$$
G_{S}(\vec{r}, t)=\frac{1}{N} \sum_{i=1}^{N}\left\langle\delta\left[\vec{r}+\vec{R}_{i}(0)-\vec{R}_{i}(t)\right]\right\rangle
$$

où $\boldsymbol{R}_{i}(0)$ et $\boldsymbol{R}_{i}(t)$ sont les positions du noyau $i$ au temps $t=0$ et pour un temps quelconque $t$. Les trajectoires $\boldsymbol{R}_{i}(t)$ ne peuvent pas être déduites des mesures de la fonction de diffusion, et l'on doit passer (en pratique) par des modèles analytiques pour décrire les mouvements individuels des noyaux. Ainsi une fonction de diffusion théorique $S_{\text {theor. }}(Q, \omega)$ est ajustée sur la fonction de diffusion expérimentale,

$$
S_{\text {inc }}^{\exp }(\bar{Q}, \omega) \propto e^{-Q^{2}\left\langle u^{2}\right\rangle}\left[S_{\text {inc }}^{\text {theor. }}(\vec{Q}, \omega) \otimes S_{\text {res }}(\vec{Q}, \omega)\right]
$$

où le facteur d'atténuation exponentiel est le facteur de Debye-Wäller, qui dépend des déplacements moyens carrés d'origine vibrationnels, et où $S_{r e s}(\boldsymbol{Q}, \omega)$ est la fonction de résolution instrumentale.

Dans le cas de macromolécules biologiques, de nombreuses sous-unités moléculaires différentes (par exemple les chaînes latérales, les éléments de structure secondaire dans leur globalité, les protons des liaisons hydrogène, etc ...) sont susceptibles d'avoir des contributions à la DQN de formes et amplitudes sensiblement différentes. Au sein d'un groupe contenant des sous-unités moléculaires identiques, des différences d'environnement induisent également des propriétés dynamiques différentes. La fonction de diffusion théorique ne peut donc se résumer à une seule composante. De la même manière, comme envisagé précédemment, elle ne peut non plus être la somme des contributions individuelles de chaque noyau d'hydrogène. Dans l'étude réalisée par Fitter et al. [35] une classification des protons de la BR est donnée: celle-ci regroupe cinq catégories présentant chacune une dynamique propre. Suivant cette approche, les paramètres qui serviront à décrire analytiquement la fonction de diffusion de chaque catégorie de protons devront être perçus comme les valeurs moyennes de distributions, et non comme des valeurs absolues reproduisant une dynamique identique pour tous les protons d'une même catégorie.

\subsubsection{Les classes dynamiques de protons}

Groupements méthyle (catégorie 1) 
De nombreuses études ont prouvé que les groupements méthyle se comportaient dynamiquement comme des "rotateurs" de symétrie axiale d'ordre 3 [42-43]. Dans le cas présent les groupements méthyle sont localisés dans les chaînes latérales de la BR, au niveau des chaînés hydrophobes des lipides [44] et en nombre réduit sur la molécule de rétinal. Tous les groupements méthyle des protéines possèdent un axe de rotation de type carbone-carbone, à l'exception des $3 \%$ contenus dans les résidus methionine, qui eux présentent un axe de rotation soufre-carbone. Volino et al. [45] ont montré que les mouvements de diffusion rotationnelle par sauts sur trois positions équivalentes présentent des temps de corrélation de l'ordre de la $p s$, ce qui se manifestera dans cette étude (voir section Résultats) par la composante quasi-élastique la plus large.

\section{Liaisons Hydrogène (catégorie 2)}

Malgré la substitution ${ }^{1} \mathrm{H}-{ }^{2} \mathrm{H}$ qui a lieu lors de la mise en suspension des membranes dans une solution d'eau lourde, ils restent des protons labiles non échangés, notamment au niveau de liaisons hydrogène. Ceux-ci appartiennent aux acides aminés les plus enfouis dans la structure de la BR. Ces protons participent à des processus diffusifs par sauts sur deux positions. Ces deux positions résultent de l'influence attractive relative entre le donneur et l'accepteur de proton au sein de la liaison hydrogène. Dans le cas de liaisons hydrogène engagées dans des éléments de structure secondaire (fig. 4), le donneur (azote $\mathrm{N}-\mathrm{H}$ ) et l'accepteur (oxygène $\mathrm{C}=\mathrm{O}$ ) présentent un caractère électronégatif comparable, et donc le proton n'a pas de position fixe intermédiaire, mais peut être considéré comme "oscillant" entre deux positions séparées par une barrière d'énergie potentielle.

\section{Molécules d'eau lourde (catégorie 3)}

En raison de la substitution des molécules de $\mathrm{H}_{2} \mathrm{O}$ par des molécules de $\mathrm{D}_{2} \mathrm{O}$, la contribution de ces dernières à la fonction de diffusion est 11 fois moins intense (section efficace de diffusion totale du proton $=81.7$ barn contre 7.64 barn pour le deutérium). Les mouvements des molécules d'eau lourde seront approximés à ceux des molécules d' $\mathrm{H}_{2} \mathrm{O}$, moyennant un facteur de pondération $(f \sim I I)$.

\section{Chaînes latérales et autres ... (catégorie 4)}

Cette classe regroupe les protons n'appartenant pas aux trois catégories précédentes et mis en jeu dans des processus de réorientations des chaînes latérales ou d'autres sous-unités moléculaires. En raison du grand nombre de protons concernés et de la variété des réorientations possibles (20 types différents de chaînes latérales, $\sim 20^{n}$ types différents d'environnement pour une chaîne latérale si $n$ est le nombre de chaînes latérales constituant l'environnement), les réorientations sont supposées s'opérer par des diffusions par sauts sur deux positions. Une distance moyenne de saut et un temps de résidence moyen résument la distribution dynamique de cette catégorie de protons.

\section{Protons fixes (catégorie 5)}

En marge des quatre catégories précédentes il existe des protons participant à des processus dynamiques très lents, qui ne sont pas détectés par le spectromètre utilisé (pour l'étude présente, MIBEMOL LLB Saclay et IRIS - Rutherford Appleton Laboratory, résolutions respectives de $50 \mu \mathrm{V}$ et $16 \mu \mathrm{eV}$ ). Ces protons sont considérés comme fixes. En raison des résolutions différentes des deux spectromètres utilisés, la catégorie 4 a été décomposée en deux parties qui présentent une dynamique rapide (résolue sur les deux instruments) et une dynamique plus lente (seulement résolue sur IRIS). En conséquence les catégories 4 et 5 ne sont pas indépendantes. 
La fonction de diffusion quasi-élastique totale est la somme des fonctions de diffusion de ces cinq catégories, pondérées par des poids statistiques $(F)$ proportionnels au nombre de protons présents dans chaque catégorie. Le dénombrement de chaque catégorie, l'expression de leur loi de diffusion quasi-élastique, ainsi que la fonction de diffusion totale, sont reportés dans la table 2

Table 2: Expression des facteurs de structure dynamique théorique associés aux différentes catégories de protons présents dans le système membranaire de la PM. Le nombre de protons concernés est indiqué en deuxième colonne. Pour plus d'informations, voir référence [37]. EISF=Elastic Incoherent Structure Factor, QISF=Quasi-Elastic Incoherent Structure Factor. Les paramètres ajustés sont soulignés (6 pour Mibemol et 9 pour Iris).

\begin{tabular}{|c|c|c|}
\hline$z$ & 180 & 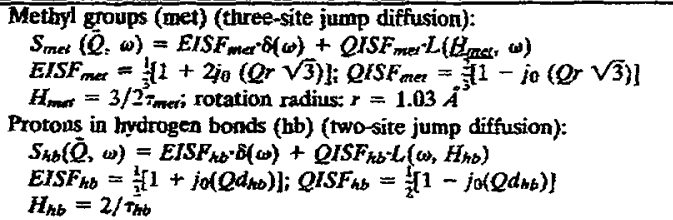 \\
\hline 3 & $60(7)^{*}$ & $\begin{array}{l}\text { Scattering from } D_{2} O \text { molecules (sol) } \\
\text { [accounted for by introducing a proton equivalent }(11 D=1 H) \text { of } \\
\text { scattering power]: } \\
\quad S_{\text {sor }}(\vec{Q}, \omega)=S_{\text {rad }}(\vec{Q}, \omega) \otimes S_{\text {trans }}(\vec{Q}, \omega)\end{array}$ \\
\hline 4 & $1431^{\dagger}$ & 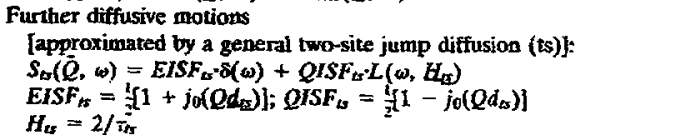 \\
\hline 5 & $1431 t$ & $\begin{array}{l}\text { Fixed protons (fix): } \\
S_{f k}(\bar{Q}, \infty)=\delta(\infty)\end{array}$ \\
\hline Sum of all $H$-stoms & $2505(2452)^{*}$ & 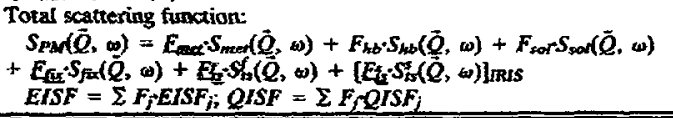 \\
\hline
\end{tabular}

\subsubsection{Résultats}

\section{Ajustements phénoménologiques}

Le but de l'étude était de déterminer à $\mathrm{T}=297 K$ des effets d'anisotropie sur le comportement dynamique des membranes lorsque l'hydratation variait. Pour cela les membranes ont été mesurées dans deux orientations de l'échantillon différentes $(\alpha)$. Les orientations de l'échantillon ont été choisies de telle manière que pour un angle de diffusion $\phi=90^{\circ}$ le transfert de moment $Q$ soit perpendiculaire $\left(\alpha=45^{\circ}\right)$ ou parallèle $\left(\alpha=135^{\circ}\right)$ au plan des membranes.

De façon uniquement qualitative, les effets de l'hydratation sur les mouvements diffusifs de la PM ont pu être évalués. Pour les membranes sèches $\left(h=0,03 g \mathrm{D}_{2} \mathrm{O} / g \mathrm{BR}\right)$, il convenait dajuster la fonction de diffusion expérimentale avec une seule fonction lorentzienne (les processus de relaxation étant exponentiels) contre deux pour les spectres de membranes hydratées $\left(h=0,28 g \mathrm{D}_{2} \mathrm{O} / g \mathrm{BR}\right)$. Dans ce dernier cas les paramètres d'une lorentzienne étaient contraints à des valeurs fixes, dérivées des ajustements réalisés pour l'échantillon de membranes sèches. Ce type d'ajustement phénoménologique est uniquement valable pour la comparaison qualitative de jeu de données mesurés avec la même résolution instrumentale. C'est une façon de prouver, si les paramètres des deux composantes diffèrent sensiblement, qu'un ajustement raisonnable et rigoureux d'un système moléculaire aussi complexe que la PM ne peut se faire qu'au moyen de plusieurs fonctions de type lorentzienne. L'analyse a démontré les caractéristiques suivantes (figure 12): 
- Forte anisotropie des mouvements diffusifs dans le cas des membranes asséchées, avec une composante plus accentuée des mouvements dans le plan de la membrane.

- En augmentant l'hydratation des membranes, la composante quasi-élastique est nettement renforcée par comparaison avec les membranes sèches. Cette évolution est davantage marquée pour des mouvements avec une directionnalité perpendiculaire au plan des membranes. Ainsi en présence d'une hydratation suffisante autour des têtes polaires lipidiques, l'anisotropie a tendance à disparaître.

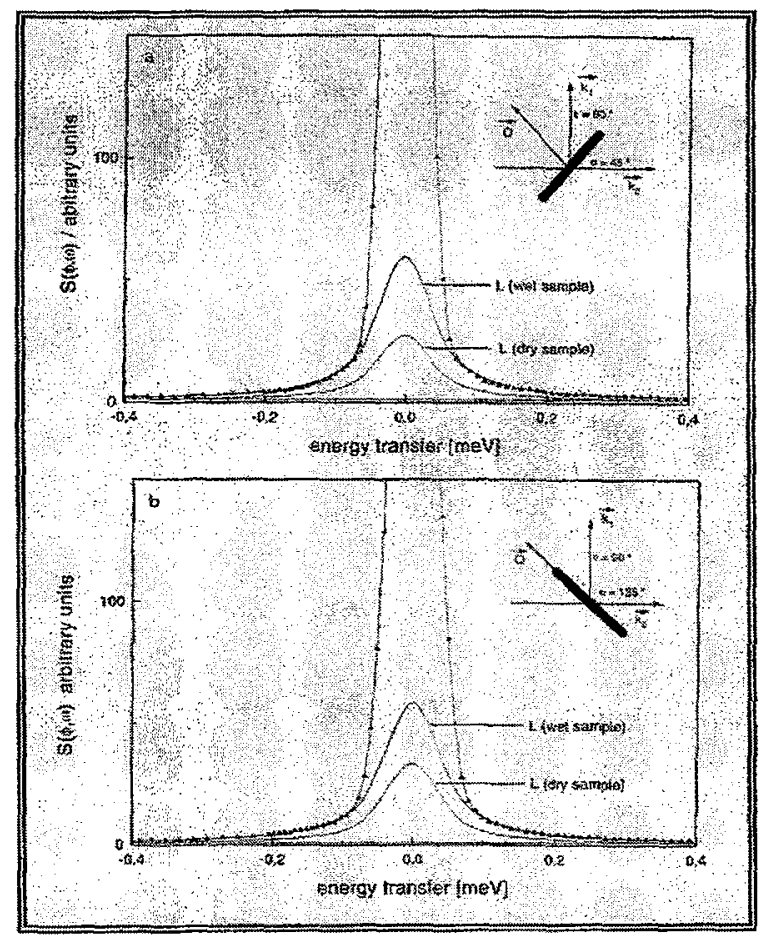

Figure 12: Résultats des ajustements phénoménologiques appliqués aux fonctions de diffusion $S(\phi, \omega)$ mesurées à angle de diffusion constant $\phi$ avec le spectromètre MIBEMOL pour l'échantillon de membranes hydratées dans deux orientations: (a) $\alpha=45^{\circ}$, (b) $\alpha=135^{\circ}$. Les composantes résultant des ajustements sont les suivantes (du haut vers le bas): diffusion totale reproduisant les valeurs expérimentales, diffusion quasi-élastique totale de l'échantillon hydraté, composante extraite des ałustements réalisés pour.l'échantillon de PM sèches et dont les paramètres ont été maintenus fixes, bruit de fond. D'après référence [37].

\section{Ajustements par la fonction de diffusion théorique à plusieurs composantes}

A priori le modèle utilisé (table 2) requiert un ajustement avec 12 paramètres. Chaque type de mouvement est caractérisé par un jeu de 3 paramètres: le poids statistique, $F$, une fréquence de saut, $1 / \tau$, et une distance de saut, $d$. La fraction de protons immobiles n'exige en fait une description de sa dynamique qu'avec un seul paramètre, $F$. En vertu de la relation $\Sigma F=1$, les poids statistiques ne sont pas indépendants et une valeur se déduit des quatre autres, ce qui réduit le nombre de paramètres indépendants à 12 . 
Comme les ajustements phénoménologiques ont pu être réalisés avec seulement deux paramètres (PM asséchées) ou quatre paramètres (PM hydratées), une réduction du nombre de paramètres du modèle semble souhaitable afin de limiter des effets de corrélation croisée. Les valeurs initiales des facteurs de pondération $F$ (table 2) montrent que les mouvements ayant la contribution majoritaire à la fonction de diffusion totale sont ceux associés aux catégories 1 et 4 . Ainsi l'analyse a plutôt été conduite de façon à contraindre les paramètres dynamiques des catégories 2 et 3 à des valeurs fixes (table 3), dérivées d'études structurales et/ou dynamiques antérieures [46-48]. Il est à noter que ces catégories représentent respectivement $7,2 \%$ et $2,4 \%$ de la diffusion totale. Ainsi le nombre de paramètres libres pour l'ajustement est réduit à 6 pour les données de Mibemol: les largeurs à mihauteur des composantes dynamiques de type lorentzienne associées aux catégories 1 et 4 , la distance

Table 3 : Valeurs des paramètres pour les catégories 1, 4 et 5 . Exceptée la distance de saut des groupements méthyle ( $d=1,78 \AA$ ), tous les paramètres résultent de l'ajustement. Les paramètres utilisés pour les catégories 2 et 3 sont: $F_{h b}=7,2 \%, d_{h b}=0,85 \AA, \tau_{h b}=6,6 p s$ et $F_{\text {sol }}=2,4 \%$. Spectromètres: I=Iris et $M=$ Mibemol. D'après référence [37].

\begin{tabular}{|c|c|c|c|c|c|c|c|}
\hline \multirow[b]{2}{*}{ Citegrory } & \multirow[b]{2}{*}{ Type of motion } & \multirow[b]{2}{*}{ Orientation } & \multirow[b]{2}{*}{ r. ps } & \multicolumn{2}{|c|}{ Wet } & \multicolumn{2}{|c|}{ Dry } \\
\hline & & & & $F, \%$ & $d_{2} \AA$ & $F, \%$ & d. $\AA$ \\
\hline$?$ & 3-site jump. $\mathrm{CH}_{3}$ & $\begin{array}{l}\alpha=45^{\circ} \\
\alpha=135^{\circ}\end{array}$ & $\begin{array}{l}4-6 \\
4-6\end{array}$ & $\begin{array}{l}25-32 \\
24-31\end{array}$ & $\begin{array}{l}1.78 \\
1.78\end{array}$ & $\begin{array}{l}11-14 \\
11-13\end{array}$ & $\begin{array}{l}1.78 \\
1.78\end{array}$ \\
\hline 4 & 2-sitc jump, "fast" & $\begin{array}{l}\alpha=45^{\circ} \\
\alpha=135^{\circ}\end{array}$ & $\begin{array}{l}13-19 \\
13-19\end{array}$ & $\begin{array}{l}13-39 \\
15-38\end{array}$ & $\begin{array}{l}3.6-4.8 \\
3.0-4.4\end{array}$ & $\begin{array}{r}7-15 \\
13-20\end{array}$ & $\begin{array}{l}2.8-3.2 \\
2.7-2.9\end{array}$ \\
\hline 4 & 2-site jump. "slow" & $\begin{array}{l}\alpha=45^{\circ} \\
\alpha=135^{\circ}\end{array}$ & $\begin{array}{l}80-110 \\
30-110\end{array}$ & $\begin{array}{l}11-26 \\
13-26\end{array}$ & $\begin{array}{l}2.4-3.2 \\
2.4-2.8\end{array}$ & - & - \\
\hline 5 & "Fixed" & $\begin{array}{l}a=45^{\circ} \\
\alpha=135^{\circ}\end{array}$ & $\begin{array}{l}\gg 100 \\
\gg 100\end{array}$ & $\begin{array}{r}17-28 \\
18-26 \\
\end{array}$ & $\begin{array}{r}0 \\
0 \\
\end{array}$ & $\begin{array}{r}64-70 \\
58-64 \\
\end{array}$ & $\begin{array}{l}0 \\
0 \\
\end{array}$ \\
\hline
\end{tabular}

de saut de la catégorie 4, les poids statistiques des catégories 1,4 et 5 . En ce qui concerne les données obtenues avec le spectromètre Iris, 9 paramètres sont nécessaires pour les ajustements: les six précédents, la largeur à mi-hauteur, la distance de saut et le poids statistique de la sous-catégorie regroupant les protons diffusant par sauts sur deux positions de façon dynamiquement lente. Malgré cette simplification certains paramètres restent corrélés et donc il n'est pas possible de donner des résultats précis pour les ajustements, mais seulement une fourchette dans laquelle ils évoluent systématiquement. Les résultats obtenus permettent néanmoins d'apprécier l'influence de l'hydratation sur les mouvements diffusifs intramoléculaires des membranes, en étant conscient qu'en raison de la complexité topologique du système étudié, nombre d'approximations ont été proposées. Des résultats, résumés dans la table 3 , se dégagent les conclusions suivantes:

- La diffusion rotationnelle des groupements méthyle (cat. 1), avec des temps de corrélation de quelques ps est d'évidence un processus dynamique beaucoup plus rapide que la diffusion locale par sauts sur deux positions (cat. 4) de sous-unités moléculaires plus grandes.

- Pour les membranes hydratées, la majorité (70 à $90 \%$ ) des protons des groupements méthyle participent à des sauts sur trois positions, avec des temps de résidence sur un site suffisamment élevés pour que ces mouvements soient détectés. En l'absence d'hydratation, ce type de dynamique ne concerne plus que $50 \%$ de cette population. Dans les deux états d'hydratation, aucune anisotropie dynamique n'est observée.

- Les valeurs obtenues pour les distances de saut $(2,4-4,8 \AA)$ des protons de la catégorie 4 sont comparables aux dimensions de l'espace conformationnel généralement échantillonné par les chaînes latérales. 
- Pour les membranes hydratées, aucune anisotropie des mouvements par sauts sur deux positions n'est observée. Pour la PM à l'état sec, l'anisotropie se manifeste pour un nombre réduit de protons participant à ces processus, essentiellement dans la direction perpendiculaire au plan membranaire.

- Le déplacement carré moyen $\left(\left\langle u^{2}\right\rangle=0,05 \AA^{2}\right)$ associé aux mouvements vibrationnels est identique pour les deux échantillons et pour les deux orientations, proche de la valeur déterminée préalablement par Ferrand et al. [35].

\subsubsection{Discussion}

L'influence des molécules d'eau sur le comportement dynamique des protéines globulaires solubles a été mis en évidence par différentes méthodes expérimentales et par des simulations de dynamique moléculaire [49-52], montrant que la mobilité intracellulaire est considérablement réduite à l'état sec. Les propriétés dynamiques des protéines sont affectées par le solvant à travers les interactions van der Waals et via l'écrantage des interactions électrostatiques [53]. A l'état hydraté, les protéines présentent des hypersurfaces d'énergie potentielle dont les barrières sont nettement moins marquées, et dont les puits sont beaucoup plus évasés. Des mouvements vibrationnels sous-amortis ont alors lieu, avec des amplitudes plus importantes, et des transitions entre sous-états conformationnels peuvent s'opérer, impliquant des mouvements à caractère diffusif.

Dans le cas de la PM, l'augmentation de la flexibilité interne des membranes en fonction du degré d'hydratation est reliée à une augmentation significative des vitesses des mouvements diffusifs, de telle sorte qu'ils deviennent observables avec la fonction de résolution instrumentale utilisée. Les distances de saut constituent également un paramètre sensible au degré d'hydratation, puisque passant de valeurs comprises dans une fourchette $2,7-3,2 \AA$ pour les membranes sèches, à $3,0-4,8 \AA$ pour les membranes hydratées. Il est possible de calculer une moyenne arithmétique des distances de sauts pour la PM hydratée, en incluant tous les processus dynamiques existant, y compris les protons immobiles $(d=0)$. La valeur moyenne trouvée est de $1,7 \AA$, corroborant les résultats issus des travaux

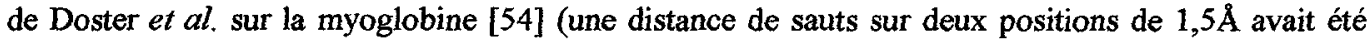
déterminée par diffusion élastique de neutrons). Malgré les nombreuses approximations, l'étude présente permet une interprétation plus détaillée de la dynamique des protéines, et de celle de la PM en particulier.

Les résultats obtenus (table 3) reflètent une bonne adéquation du modèle avec les données expérimentales. Si les protons des groupements méthyle ne montrent aucune anisotropie lorsque l'hydratation varie, il en est tout autrement pour les protons de la catégorie 4 . Pour cette classe dynamique une anisotropie des mouvements, avec une réduction notable dans la direction perpendiculaire au plan membranaire, est constatée à l'état sec: elle correspond à un empilement extrêmement compact des bicouches membranaires, séparées entre elles par une distance de $3 \AA$, contre $10 \AA$ dans l'état hydraté en raison de la présence d'une couche de solvatation, limitant ainsi les mouvements des boucles extramembranaires. Le caractère isotrope des mouvements des groupement méthyle est également justifié puisque ceux-ci sont distribués dans toute la membrane dans des orientations non spécifiques. Les temps de corrélation observés correspondent à ceux enregistrés par RMN [55], mais des expériences de diffusion inélastique de neutrons [56] sur des cristaux de dipeptide alanine (Ala-Ala) ont montré qu'il existait pour les groupements méthyle une composante dynamique beaucoup plus lente que les simulations ont attribué à l'existence de barrières torsionnelles assez importantes. Une amélioration du modèle est peut-être nécessaire, en divisant la catégorie 1 en deux parties dynamiquement lente et rapide, afin de rendre compte de cet effet. 


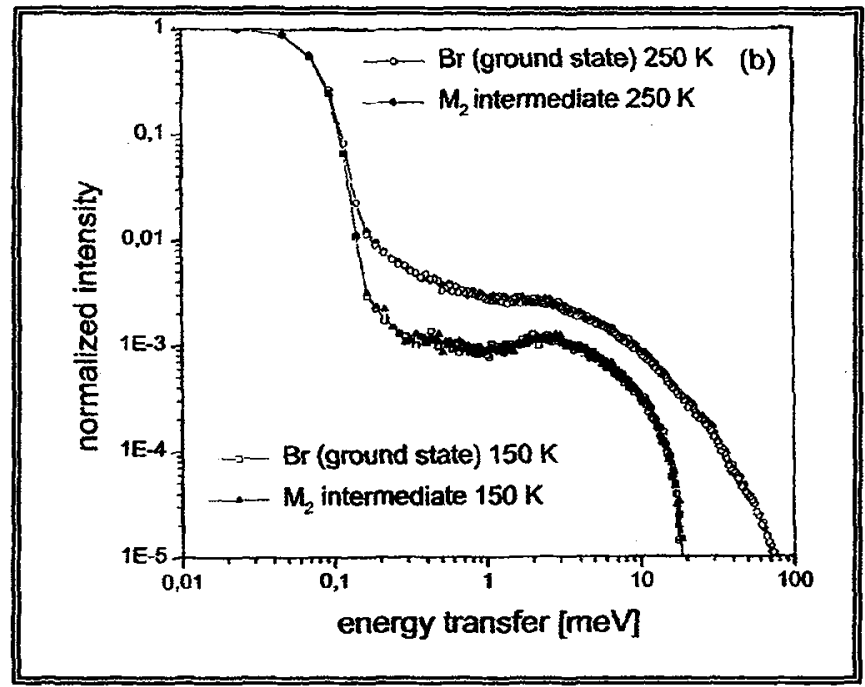

Figure 13 : Comparaison des spectres de la BR dans l'état fondamental et dans l'état M2. Angle de diffusion=94,3 $3^{\circ}$. D'après référence [57]

Relier la dynamique à caractère diffusif à la fonction biologique nécessite de caractériser, non seulement l'état fondamental $\mathbf{B R}_{568}$ comme cela a été fait par Fitter et al. [37], mais l'état $\mathrm{M} 2$ dont le rôle dans le mécanisme de pompe à protons est déterminant (voir section 3.2.3). Ces mêmes auteurs ont entrepris cette démarche [57]. L'utilisation d'un mutant Asp_96_Asn de la BR, lequel se caractérise par une forte dépendance de la décroissance de l'état $\mathrm{M}$ en fonction du $\mathrm{pH}$, a permis de piéger l'état M2 à $250 \mathrm{~K}$ pendant plusieurs jours. Des expériences de diffusion de neutrons ont alors été réalisées sur le spectromètre NEAT (Hahn-Meitner Institut, Berlin) avec une résolution de $100 \mu \mathrm{V}$, à la température de $250 \mathrm{~K}$ (à cette température une fraction considérable de diffusion quasiélastique est détectable [58]). Les échantillons utilisés étaient hydratés à $0,04 \mathrm{gD}_{2} 0 / g B R$. Aucune différence dans les spectres quasi-élastique et inélastique "basse-fréquence" ne sont visibles entre l'état fondamental et M2 (fig. 13), indiquant clairement que même si des changements structuraux ont été notifiés entre ces deux états [29-30], les propriétés dynamiques à l'échelle de la ps restent inchangées, à moins que ne soit concernée qu'une faible partie de la protéine.

\subsection{La Nucléase de Staphylocoque}

\subsubsection{Le repliement des protéines}

Une des questions majeures restant indéterminées en biologie concerne les mécanismes de repliement des protéines. La séquence primaire en acides aminés (et done le gène) définit de façon univoque la structure tridimensionnelle d'une protéine. La mise en place de la conformation native et fonctionnelle d'une protéine demeure un mystère de la biologie moderne.

En se repliant une protéine "parcourt" un profil d'énergie libre relativement complexe, explorant de nombreuses configurations. Les protéines sont des "machineries moléculaires" très sophistiquées et il est difficile d'envisager que leurs caractéristiques structurales raffinées ne jouent aucun rôle dans le repliement. Le chemin suivi par une protéine lors de son repliement n'est pas unique, sinon il pourrait être élucidé par des expériences de chimie classiques. L'idée actuelle que l'on se fait du repliement réside dans le fait que les premières étapes de ce processus (au niveau du ribosome où la synthèse polypeptidique s'opère) impliquent une variété très grande de structures de la protéine. Chercher un chemin de repliement unique n'a aucun sens, et il convient de décrire la dynamique de 
cet ensemble de structures par une description statistique de la topographie du profil (ou paysage) d'énergie libre. Si ce profil ressemble à un "entonnoir" multidimensionnel donnant lieu à une multitude de chemins de repliement différents pour finalement aboutir à la structure native, il est alors possible de caractériser statistiquement, avec un jeu minimal de paramètres, la topographie et les façons d'arriver à l'état natif. Se reposant sur des données expérimentales, Onuchic et al. [59] ont estimé la surface, la rugosité et la pente de cet "entonnoir de repliement" (fig. 14). Ces mêmes paramètres servent également comme support pour des modèles théoriques destinés à simuler de façon simplifiée la cinétique du repliement. On peut citer notamment des modèles où les protéines sont assimilées à des "chapelets de billes" (bille = acide aminé), en interaction mutuelle sur un réseau cubique tridimensionnel: les protéines simulées sont assez éloignées de la réalité, mais des informations sur la cinétique du repliement peuvent être obtenues.

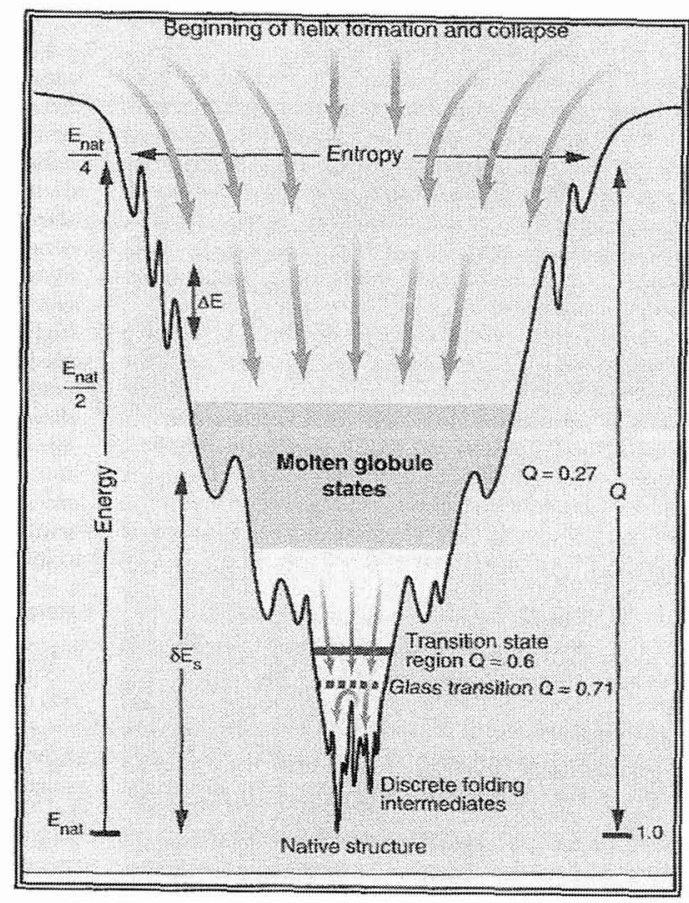

Figure 14 : Représentation schématique dun "entonnoir de repliement" pour une protéine idéale de forme hélicoïdale de 60 acides aminés [59]. La largeur de l'entonnoir représente l'entropie alors que la profondeur représente l'énergie interne. La fraction de contacts natifs formés au cours đu repliement est notée Q. Ce paramètre permet d'identifier différents états conformationnels de la protéine et des transitions entre ces états (voir texte).

Pour une protéine comportant 60 résidus, si chaque résidu peut prendre en moyenne 10 conformations distinctes, alors le nombre total de conformations pour la protéine est $10^{60}$. Ceci entraîne que l'hypersurface d'énergie libre est immense, et que le temps mis par la protéine pour l'échantilloner et trouver sa forme native est infini. Or nous savons que les cinétiques du repliement se déroulent sur des échelles de temps allant de la milliseconde à la minute. Des forces doivent donc guider cette recherche conformationnelle, la contraignant ainsi à une cinétique beaucoup plus rapide. Des études expérimentales et des modélisations [60-61] permettent d'expliquer les premières phases du repliement (fig. 15). Des résultats expérimentaux attestent que les interactions non locales sont dominantes au sein d'une protéine [62], et que l'effet hydrophobe constitue un facteur important de stabilisation des hélices dans les protéines globulaires. Ceci suppose donc que le repliement s'opère à 
l'origine par le biais d'interactions à longue distance, mais est aussi dirigé par des contraintes stériques de nature "volume exclu" entre "monomères voisins" et par la nécessité d'écranter les parties hydrophobes des protéines solubles. Le "modèle d'effondrement" (Collapse Model, voir fig. 15B) rend compte de la compétition entre interactions locales, qui conduisent à la formation d'éléments de structure secondaire, et d'interactions non locales qui contribuent à l'arrangement relatif de régions éloignées dans la séquence, sous la forme principalement d'un "effondrement hydrophobe". Ce modèle s'oppose au "Framework model" (fig. 15A), pour lequel seules les interactions locales prédominent, justifié par le fait que le repliement d'une protéine est initié au niveau du ribosome bien avant que sa synthèse ne soit achevée. Ce modèle favorise l'apparition préalable d'éléments de structure secondaire. Un modèle alternatif aux deux précédents est celui proposé par Karplus et Weaver [61].

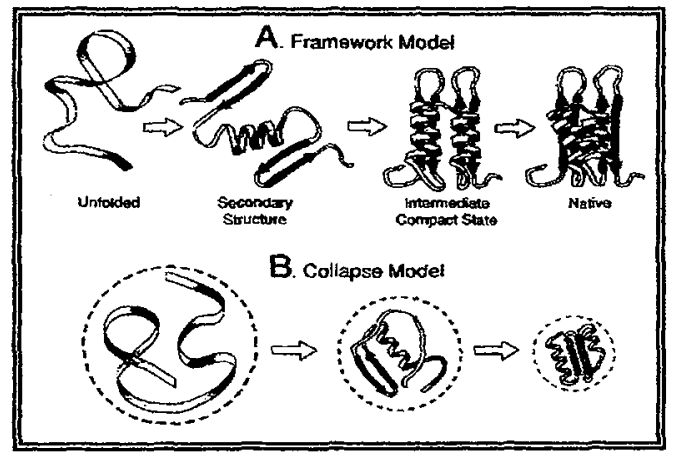

Figure 15 : Modèles pour le repliement des protéines.

Leur modèle, dit de "diffusion - collision", suppose une protéine comme constituée de plusieurs parties appelées micro-domaines, chacune d'elles de longueur assez courte de telle sorte que l'échantillonage conformationnel se fasse rapidement, en comparaison du temps caractéristique de repliement global. Les micro-domaines se structurent tout d'abord, mais leur stabilité n'est que temporaire. Ils diffusent sous l'influence de forces internes et externes à caractère stochastique et des collisions entre micro-domaines interviennent. Un repliement grossier consisterait en l'obtention, suite à diverses collisions, de la conformation quasi-finale du brin polypeptidique. Les dernières étapes consistant en la formation de la structure tertiaire exacte par la recherche d'un empilement étroit des chaînes latérales.

Tous ces modèles réduisent sensiblement l'entropie initiale du système, et donc le temps passé à explorer l'hypersurface d'énergie libre. On aboutit, plus ou moins rapidement, et avec des nuances structurales, à une protéine dans l'état de "globule fondu", état caractérisé par la présence d'éléments de structure secondaire (éventuellement non définitifs) et par une fraction de contacts natifs de l'ordre de $30 \%$ (fig. 14). La réduction d'entropie qui se produit ne correspond pas à une évolution thermodynamique spontanée du système. La direction du repliement est commandée par une baisse notoire de l'enthalpie, à travers les nombreuses liaisons (hydrogène, ponts disulfures, ioniques, etc) qui s'établissent. Il se peut que le système soit alors piégé dans un minimum local de la surface d'énergie libre, de façon comparable à un liquide brusquement refroidi dans un état amorphe ou vitreux. A des températures bien au dessus de la température de transition vitreuse (fig. 14), un profil de la surface d'énergie libre même rugueux peut être aisément traversé. Par contre à des températures inférieures à cette transition vitreuse, le temps mis pour atteindre la conformation native peut être considérable. Si le profil d'énergie libre présente une "pente moyenne" importante, alors les minima locaux se concentrent au fond de l'entonnoir, près de la structure native.

La diffusion quasi-élastique de neutrons ne se propose pas de "mesurer" la cinétique du repliement des protéines, celui-ci s'effectuant sur des échelles de temps beaucoup trop longues. Par 
contre la diffusion quasi-élastique de neutrons se propose d'étudier les propriétés dynamiques d'intermédiaires stables du repliement, et de les comparer aux propriétés dynamiques de l'état natif. Généralement un intermédiaire (stable) du repliement est entrevu comme une "relique" ayant éventuellement "fossilisée les forces qui ont dirigé ce repliement. Son étude en tant que mémoire du repliement peut apporter des informations sur les mécanismes qui le gouvernent. Les différences de structure (facteur $Q$, fig. 14) entre l'état natif et les intermédiaires du repliement peuvent engendrer des différences significatives de leurs propriétés dynamiques. Ainsi la diffusion quasi-élastique de neutrons peut nous renseigner sur l'éloignement entre un intermédiaire et l'état natif au niveau du profil d'énergie libre. L'enzyme Nucléase de Staphylocoque servira d'illustration pour une telle étude.

\subsubsection{Présentation de la Nucléase de Staphylocoque (SNase)}

\subsubsection{SNase, un modèle d'étude pour le repliement}

La nucléase de Staphylocoque est un système protéique pour l'étude et la compréhension du processus de repliement. La protéine native, SNase, présente lintérêt d'être relativement petite (149 résidus) et de se dénaturer réversiblement in vitro. Lorsqu'on tronque les 13 derniers résidus, du côté C-terminus, la forme native est déstabilisée, et le fragment ainsi constitué, SNase $\Delta$, forme une structure compacte et partiellement dénaturée à l'équilibre [63]. Cette protéine tronquée pourrait servir de modèle pour un polypeptide n'ayant pas fini de se replier. En effet, comme le temps de synthèse au sein du ribosome est beaucoup plus lent que les processus mis en jeu dans les mécanismes du repliement, $S N a s e \Delta$ pourrait ressembler à une protéine émergeant du ribosome.

\subsubsection{SNase, fonction et structure}

La SNase est une protéine extracellulaire responsable de la dégradation de l'ADN et de l'ARN en petits oligonucléotides en présence de calcium; elle clive spécifiquement les liaisons phosphodiester. Cette protéine a été isolée pour la première fois en 1956 [64] à partir de cultures de Staphylocoque doré, et en 1963 Anfinsen démontrait que SNase était constituée d'une seule chaîne polypeptidique de 149 résidus. C'est donc une protéine de petite taille, qui peut être dénaturée réversiblement par la température, la pression, des dénaturants chimiques ou encore des conditions extrêmes de pH. Les premières études sur la SNase ont fait l'objet d'une revue par Tucker en 1979 [65]: études des propriétés cinétiques suivant qu'il s'agisse de substrats naturels ou synthétiques [66], rôle de l'ion métallique [67], inhibition par des substrats analogues [68] et analyse du site de liaison [69-70]. Anfinsen a démontré la capacité qu'avaient les fragments de la SNase (résidus 1-126, 49-149,6-48) à s'auto-associer et à former une structure native [71], prouvant ainsi toute l'importance de la coopérativité dans le processus du repliement.

La structure de la SNase en présence de l'ion métallique $\left(\mathrm{Ca}^{2+}\right)$ et de l'inhibiteur thymidine-3',5'biphosphate (pdTp, un analogue des nucléotides "naturels" des acides nucléiques) a été résolue pour la première fois en 1979 (déposée à la Protein Data Bank, PDB, sous le nom 2SNS) [72]. Depuis de nombreuses études structurales ont été entreprises, pour aboutir à la structure déterminée par Loll et

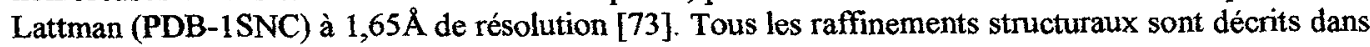
la thèse de doctorat de Goupil-Lamy [74], pour ne retenir que l'essentiel: la SNase est du type $(\alpha+\beta)$, comportant 3 hélices- $\alpha$ reposant sur un "tonneau"- $\beta$ formé par cinq brins- $\beta$ (fig. 16). La densité électronique est très incertaine pour trois parties de la séquence très "dynamiques": les résidus $N$ terminaux (1-6), les résidus C-terminaux (142-149) et la boucle constituée des résidus 44-50. L'inhibiteur se fixe dans une "crevasse", son cycle en regard de résidus hydrophobes et sa partie phosphate établissant de nombreuses liaisons hydrogène avec des résidus polaires. La structure en solution a également été abordée par de nombreuses études RMN [75-78], présentant très peu de différences entre elles, ce qui confirme leur validité. Elles attestent de la présence des éléments de 
structure secondaire déterminée par diffraction de rayons-X, mais n'apportent aucune information structurale détaillée.

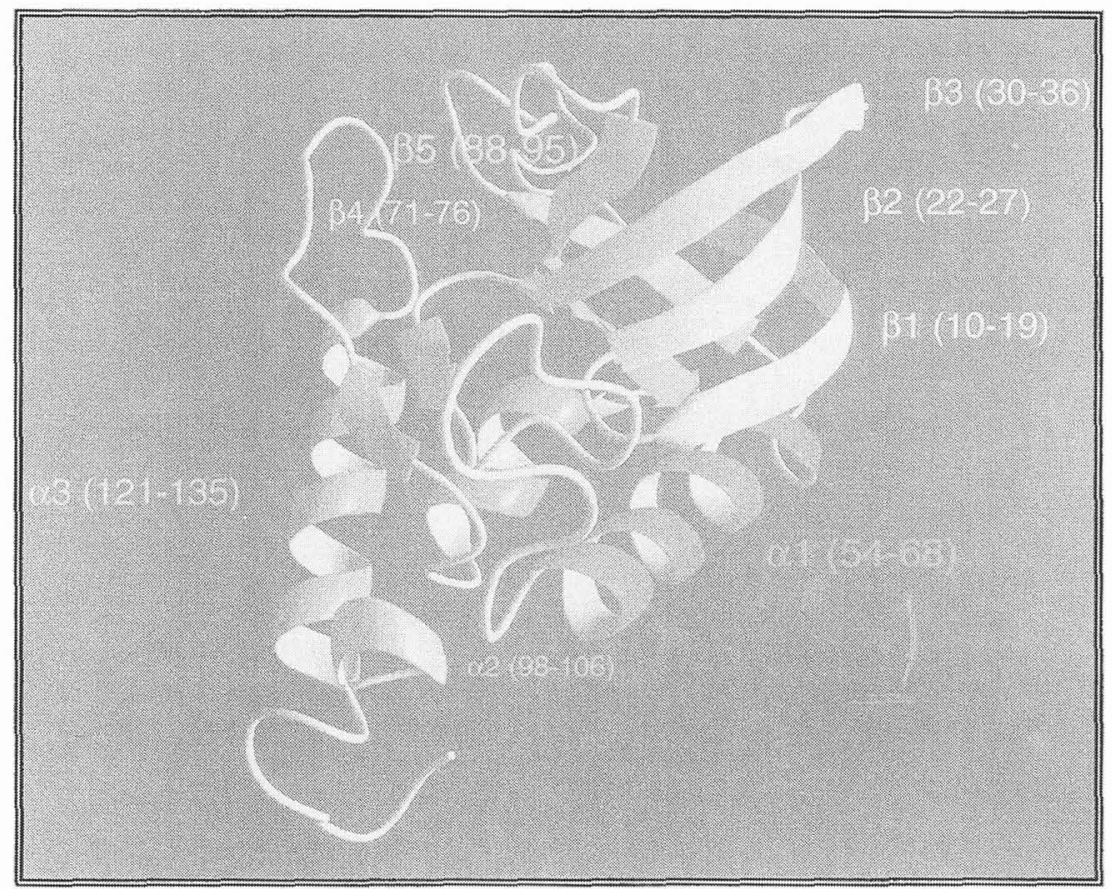

Figure 16: Structure de la SNase construite à partir de la structure cristallographique $1 \mathrm{STN}$. 1STN $=1 \mathrm{SCN}$ sans l'inhibiteur. D'après référence [74].

\subsubsection{Hétérogénéité conformationnelle}

Il a été montré que l'isomérisation de type cis-trans d'une liaison peptidique $X-P r o l i n e ~(X:$ tout résidu) donne lieu à une phase lente dans le processus de repliement des protéines [79]. L'enthalpie d'activation pour l'isomérisation étant assez élevée $(18-25 \mathrm{kcal} / \mathrm{mol})$, les taux d'isomérisation sont très lents $\left(0,02\right.$ à $0,05 s^{1}$ à $\left.25^{\circ} \mathrm{C}\right)$ et sont fortement dépendants de la température [80]. Des travaux plus récents ont montré qu'au sein des protéines (natives ou dénaturées) les liaisons pouvaient exister dans les deux formes cis ou trans [81-82]. Pour la SNase, la RMN a montré que la liaison Lys 116Pro 117 était la cause d'une hétérogénéité conformationnelle [83-86]. En présence de l'inhibiteur pdTp, cette hétérogénéité conformationnelle disparaît [72-73], alors que pour la SNase non complexée la forme cis prédomine à $90 \%$ à temperature ambiante et que cette tendance s'inverse en élevant la température. Dans le cristal, avec ou sans inhibiteur, la forme cis est la seule existante. De plus une étude du peptide de synthèse constitué par les résidus 113 à 122 indique que la liaison Lys_116-Pro_117 est majoritairement dans la forme trans $(96 \%)$. Des mutants où la PRO_117 a été remplacée par un résidu Gly ne présentent aucune hétérogénéité conformationnelle [83]. Tous ces résultats tendent à prouver que cette liaison pourrait se stabiliser tardivement lors du repliement de la protéine.

\subsubsection{Propriétés du fragment SNased(137-149)}

Shortle et Meeker [63] ont montré que l'élimination des 13 derniers résidus du côté C-terminus déstabilise la SNase. Néanmoins le fragment conserve son activité enzymatique en présence de sel et 
d'ADN ce qui laisse croire que l'intégrité du site actif n'est pas affectée. La caractérisation de ce fragment a été réalisée par dichroïsme circulaire et diffusion aux petits angles de rayons- $X$ [87-88].

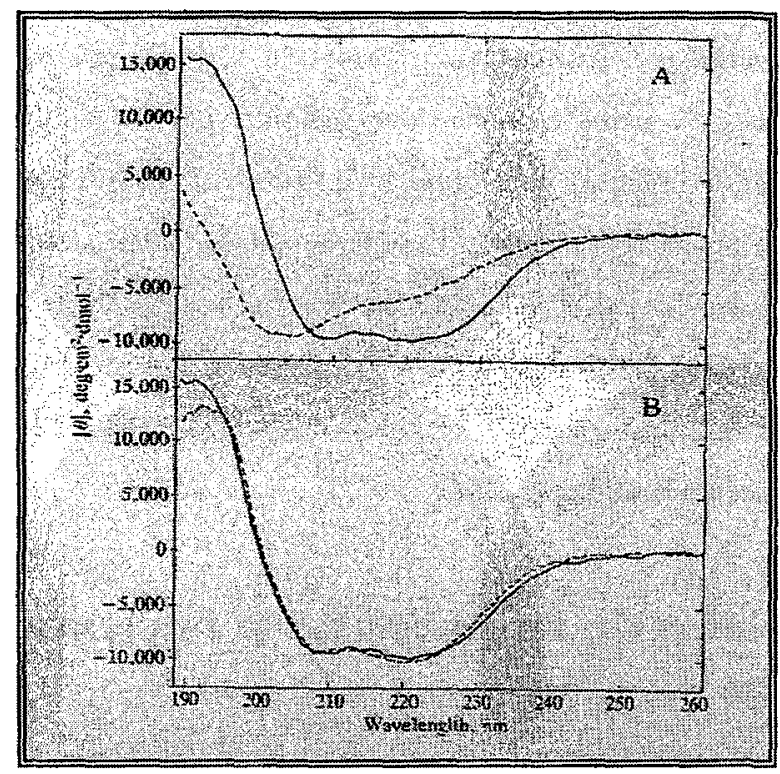

Figure 17 : Spectres de dichroisme circulaire. A. SNase (continu) et SNased (pointillé). B. Idem A, mais avec pdTP et calcium. D'après référence [87].

Sur la figure 17 sont présentés les spectres de dichroisme circulaire de SNase et SNase $\Delta$ [87]. Sur la partie $A$ de la figure le spectre nous indique qu'il s'agit bien d'une protéine $(\alpha+\beta)$, avec en particulier une absorption caractéristique à $222 \mathrm{~nm}$ des hélices- $\alpha$. Pour le fragment on voit très nettement que le nombre de résidus impliqués dans la formation des hélices a diminué d'environ $50 \%$. En présence de l'inhibiteur pdTp et d'ions $\mathrm{Ca}^{2+}$, le spectre du fragment se confond de nouveau avec celui de la forme native.

Des expériences de diffusion de rayons- $X$ aux petits angles ont permis de mesurer la structure globale de la protéine en déterminant la valeur de son rayon de giration $R_{g}$, suivant l'approximation de Guinier couramment faite en tel cas. Le rayon de giration de SNase a été trouvé égal à $15,9 \AA$ contre $20,2 \AA$ pour le fragment. La fixation à l'inhibiteur permet de retrouver une valeur proche de celle mesurée dans l'état natif, $15,6 \AA$ précisément. A titre indicatif, ces valeurs doivent être comparées au rayon de giration de la SNase complètement dénaturée dans $5 M$ d'urée: $35 \AA$.

La transformation de Fourier de la caractéristique $I(Q)$ mesurée par diffusion aux petits angles permet d'obtenir la fonction radiale de Patterson $P(r)$, représentant la distribution des vecteurs interatomiques. Cette "distribution de paires" a été dérivée pour SNase et pour le fragment (fig. 18). Pour la protéine native cette distribution est symétrique, caractéristique d'une protéine de forme sphérique (plus grande dimension $=47 \AA$ ). La courbe correspondante pour la protéine tronquée en présence de pdTp se confond rigoureusement avec celle de la forme native, alors qu'en l'absence de pdTp elle présente un caractère bi-modal (plus grande dimension $=63 \AA$ ). Ceci suggère que la troncature entraine des modifications structurales sous la forme d'un allongement global de la molécule. 


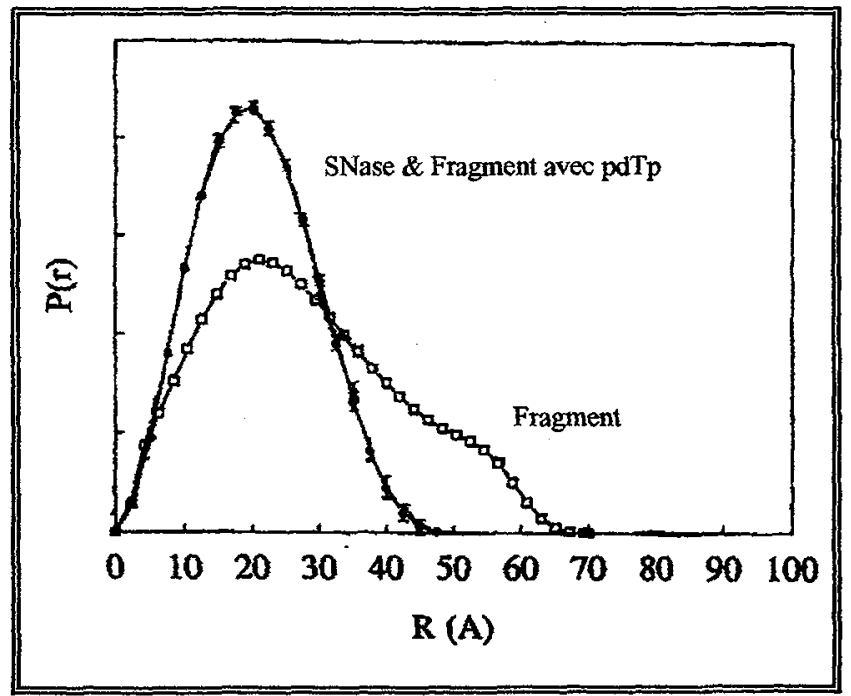

Figure 18 : Distribution radiale de Patterson, $P(r)$. D'après référence [88].

La persistance d'éléments de structure secondaire dans la forme tronquée SNase $\Delta$ laisse néanmoins penser que si dénaturation il y a, celle-ci est partielle, et que la protéine conserve une certaine compacité. De plus l'intermédiaire formé est stable, et présente une réversibilité vis à vis des processus de dénaturation et de renaturation. Ainsi SNase $\Delta$ représente un objet de choix comme modèle d'étude du repliement. La caractérisation dynamique, à température ambiante $(300 \mathrm{~K})$, de la forme sauvage (native) et de la forme tronquée, restait à réaliser. Ce fut l'objet d'une étude comparative par diffusion quasi-élastique de neutrons et simulations de dynamique moléculaire.

\subsubsection{Dynamique moléculaire comparée de SNase et SNased}

\subsubsection{Neutrons}

Les expériences de diffusion quasi-élastique de neutrons ont été réalisées sur le spectromètre temps de vol IN5 de 1'Institut Laue Langevin (Grenoble). La protéine native et son fragment ont été exprimés dans Escherichia Coli, et purifiées par chromatographie sur colonne échangeuse d'ions [8990]. Afin d'optimiser le signal incohérent de la protéine, les expériences ont été réalisées en solution d'eau lourde, à des concentrations d'environ $80 \mathrm{mg} / \mathrm{ml}$. Les transmissions des échantillons étaient respectivement de $91 \%$ (SNase) et $92 \%$ (SNase $\Delta$ ), invariables dans le temps tout comme l'intensité diffusée dans l'angle solide constitué de la banque des détecteurs d'N5, attestant ainsi qu'aucune agrégation ou précipitation n'est survenue durant le temps d'exposition des échantillons ( $-40 \mathrm{~h})$. La longueur d'onde incidente utilisée était de $5 \AA$, ce qui correspond à une résolution en énergie de l'ordre de $80 \mu \mathrm{eV}$ (FWHM = Full Width at Half Maximum). Des processus dynamiques se déroulant sur des échelles de temps plus rapides que $\sim 100$ ps peuvent être ainsi détectés. Les spectres de diffusion ont été mesurés à $300 \mathrm{~K}$ pour les deux solutions de protéine et pour l'eau lourde pure. La soustraction du signal de l'eau lourde a été faite en tenant compte du volume spécifique "moyen" des protéines, mesuré par diffusion de neutrons aux petits angles, de l'ordre de $0,74 \mathrm{~cm}^{3} / \mathrm{g}$, et de la densité de $\mathrm{D}_{2} \mathrm{O}$ à $300 \mathrm{~K}\left(\mathrm{~d}=1,10567 \mathrm{~g} / \mathrm{cm}^{3}\right)$. Le signal de la cellule vide a été soustrait en tenant compte des facteurs de correction géométriques (porte-échantillon "plan", d'épaisseur 1,5mm) rendant compte de l'atténuation par auto-absorption de l'intensité diffusée. Le facteur de structure dynamique incohérent 
a été dérivé pour 13 angles "moyens" de diffusion, correspondant à une résolution en transfert de moment de l'ordre de $0.2 \AA^{-1}$ dans une gamme allant de 0.3 à $2.1 \AA^{-1}$.

Comme SNase est une protéine globulaire de petite taille, très peu de résidus constituent le cour hydrophobe et la majorité des liaisons hydrogène s'établissant au niveau du brin polypeptidique doivent être exposées au solvant. Ceci est à plus forte raison valable pour SNase $\Delta$, partiellement dépliée. En conséquence, la mise en suspension dans l'eau lourde permet d'échanger une grande majorité des protons labiles engagés dans la formation de ces liaisons hydrogène. A l'inverse de ce qui a été décrit pour la bacteriorhodopsine (voir section 3.2.6.2) nous ne décrirons donc aucune classe dynamique de protons associée aux liaisons hydrogène. L'analyse des mouvements diffusifs sera restreinte à seulement deux catégories de protons:

- les protons liés de façon covalente aux carbones- $\alpha$ du brin polypeptidique, et donc assujettis à suivre la dynamique diffusive du carbone (12 fois plus lourd). Des simulations de dynamique moléculaire [91-92] ont montré que les fluctuations atomiques des carbones- $\alpha$ de la chaîne polypeptidique sont généralement de l'ordre de $1 \AA$, confirmées par les valeurs des facteurs de température dérivées des expériences de diffraction de rayons- $X$ sur de très nombreuses protéines. Cette catégorie de protons sera dynamiquement caractérisée par des mouvements de diffusion à l'intérieur d'une sphère de rayon $R$.

- les protons appartenant aux chaînes latérales qui sont l'objet de mouvements de réorientations globales, modélisés par une diffusion par sauts sur deux positions séparées d'une distance $d$. Ces mouvements de réorientation sont fortement corrélés aux déplacements du brin

Les spectres de diffusion quasi-élastique ont donc été ajustés par une fonction de diffusion théorique (cf. équation 6) ne comportant qu'une composante lorentzienne, $L(Q, \omega)$. Un facteur de structure expérimental, $A_{0}(Q)$ se déduit donc du rapport de l'amplitude du signal élastique sur le signal total:

$$
S_{\text {inc }}(Q, \omega)=A_{0}(Q) \delta(\omega) R(\omega)+\left[1-A_{0}(Q)\right] L(Q, \omega) \otimes R(\omega)
$$

où $R(\omega)$ est la fonction de résolution instrumentale dont la mesure a été réalisée avec un échantillon standard de vanadium. Les spectres ajustés sont représentés sur la figure 19. Les différences observées expérimentalement entre les formes native et tronquée sont mineures. Aux grands angles de diffusion une réduction d'environ $10 \%$ de la composante élastique a été détecté pour la SNase $\Delta$ (normalisée à la valeur trouvée à faible $Q$ ). Sur une échelle absolue, on dénote également une diminution de l'ordre de $10 \%$ de la diffusion totale entre les deux formes de la SNase: cela correspond à la différence de matière entre les deux échantillons, suite à la troncature des 13 derniers résidus C-terminus. La contribution quasi-élastique est sensiblement comparable pour les deux échantillons, tant en amplitude qu'en largeur ( $\sim 40 \mathrm{ps}$ ). A priori les différences de comportement dynamique entre la structure native et la structure partiellement dépliée, mais compacte de SNase, ne concernent pas la partie diffusive des mouvements, mais la composante statique (fraction immobile de protons) et/ou la composante vibrationnelle (facteur de Debye-Wäller).

Les valeurs "expérimentales" des EISF (facteur de structure élastique, $\mathrm{A}_{0}(\mathrm{Q})$ ), dérivées des ajustements suivant le modèle donné par l'équation 7 , ont été ajustées en tenant compte de l'expression du facteur de structure élastique théorique associé à chacune des classes de protons préalablement mentionnées:

$$
A_{0}(Q)=\left[p+\frac{1}{2}(1-p)\left\{1+j_{0}(Q d)\right\}\left\{\frac{3 j_{1}(Q R)}{Q R}\right\}^{2}\right] \exp \left\{-\frac{1}{6}\left\langle u^{2}\right\rangle Q^{2}\right\}
$$




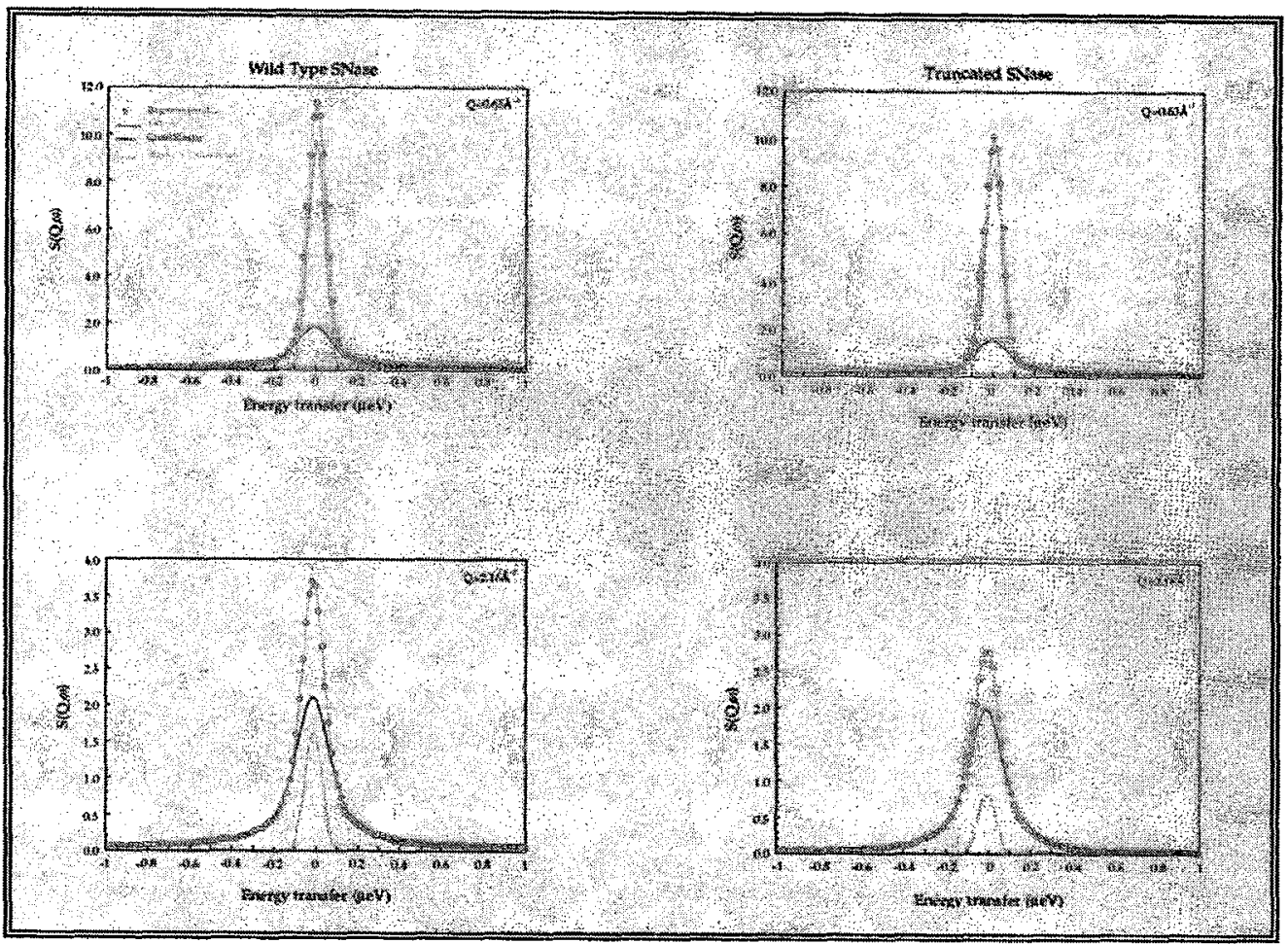

Figure 19 : Facteurs de structure dynamique incohérent de SNase (partie gauche) et de SNase $\Delta$ (partie droite), pour deux valeurs différentes du transfert de moment $Q=0.63 \AA^{-1}$ (haut) et $Q=2.16 \AA^{-1}$ (bas). Les points expérimentaux, après soustraction du signal de l'eau lourde, sont représentés par des cercles. Les composantes élastique (trait clair) et quasi-élastique (trait foncé) donnent par addition le signal total qui se superpose parfaitement à l'expérience. D'après référence [93].

où $d$ et $R$ sont les paramètres "distance de saut" et "rayon de la sphère", auxquels viennent s'ajouter une fraction de protons fixes $(p)$ et un déplacement carré moyen d'origine strictement vibrationnel $\left.\left(<u^{2}\right\rangle\right)$. Les ajustements donnent lieu aux résultats présentés sur la figure 20 . Les différences au niveau des EISF sont reportés dans la table 4.

Table 4 : Paramètres dérivés des ajustements des EISF.

\begin{tabular}{|ll|}
\hline SNase native & SNase $\Delta$ tronquée \\
\hline $\mathrm{p}=0,52$ & $\mathrm{p}=0,50$ \\
$\mathrm{R}=1,1 A$ & $\mathrm{R}=1,2 A$ \\
$\mathrm{~d}=5,5 A$ & $\mathrm{~d}=5,3 A$ \\
$\mathrm{SQRT}(<\mathrm{u} 2>)=0,49 A$ & $\mathrm{SQRT}(<\mathrm{u} 2>)=0,61 A$ \\
\hline
\end{tabular}

Les facteurs de structure élastique sont équivalents pour les deux formes de SNase dans une région $0.3 \AA^{-1}<\mathrm{Q}<1.3 \AA^{-1}$, les différences "notoires" apparaissant au delà de $1.3 \AA^{-1}$. Cette différence ne trouve son explication que dans les variations observées pour le facteur de Debye-Wäller, et non dans une fraction de protons immobiles qui serait plus importante dans la forme native. Du point de vue expérimental, la dynamique diffusive de SNase et SNase $\Delta$ à l'échelle de $100 \mathrm{ps}$ présente un 
comportement identique, indépendant des effets de troncature de séquence d'acides aminés. Seule la composante vibrationnelle est différente, avec des amplitudes de vibration en augmentation de $20 \%$ dans la forme partiellement dépliée. Ceci tendrait à prouver que l'intermédiaire stable du repliement que représente SNase $\Delta$, qui pourrait servir à modéliser un polypeptide émergeant du ribosome, n'est pas très éloigné d'un point de vue structural et dynamique de la forme native. Dans le paysage énergétique schématisé sur la figure 14 , il se situerait au niveau de la zone "des intermédiaires discrets du repliement", avec une compacité (ou un nombre de contacts natifs, Q) proche de la structure native. Cette étude expérimentale va également dans le sens d'une synthèse peptidique beaucoup plus longue temporellement que le processus de repliement.

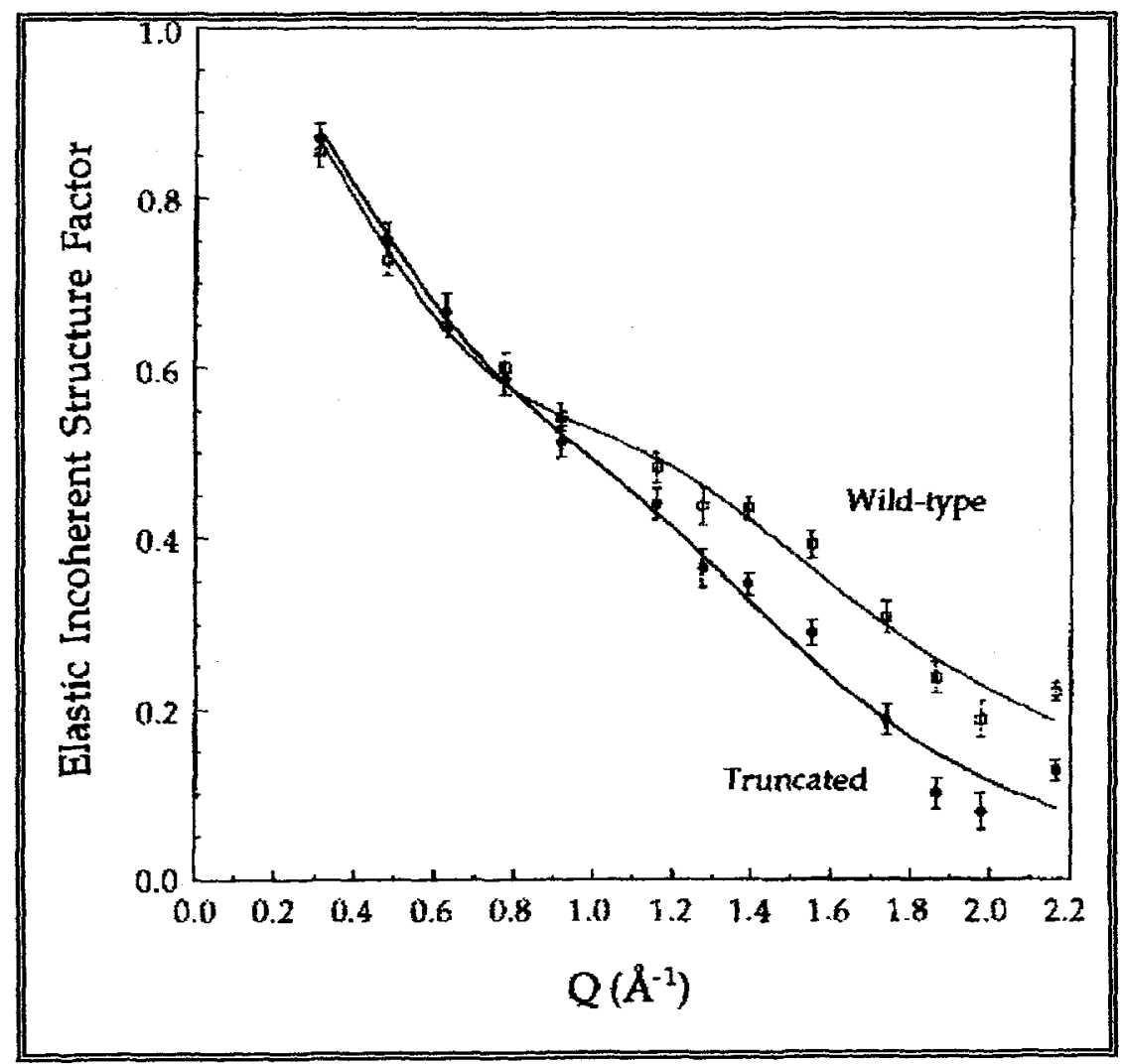

Figure 20 : Facteurs de struchure élastique de la forme native (ou sauvage) et de la forme tronquée de la nucléase de Staphylocoque. Les lignes continues résultent des ajustements en accord avec l'équation 7. D'après référence [93].

\subsubsection{Simulations de dynamique moléculaire}

Dans le but d'avoir une information au niveau atomique beaucoup plus détaillée, tant du point de vue structural que dynamique, des simulations de dynamique moléculaire ont été entreprises sur la nucléase de Staphylocoque. Le programme utilisé pour les simulations est $C H A R M M$ version $24 b 1$ (Chemistry at HARvard Molecular Mechanics) [94], utilisant une fonction d'énergie potentielle semiempirique telle que décrite par l'équation 1. 


\subsection{Caractérisation structurale de SNase et SNaseA}

Pour les simulations de la SNase native, les coordonnées initiales proviennent de la structure cristallographique 1STN-PDB [95] à $1,7 \AA$ de résolution. Cette structure ne contient pas les coordonnées des résidus 1-5 et 142-149, désordonnés dans le cristal. Les atomes d'hydrogène ont été construits par la méthode $H B U I L D$ de $C H A R M M$. Les 83 molécules d'eau présentes dans la structure ISTN ont été incluses dans les simulations. Les résidus manquants ont été topologiquement construits grâce aux valeurs des coordonnées internes à l'équilibre des acides aminés isolés, puis une minimisation d'énergie a été réalisée en fin de construction en maintenant fixe le reste de la protéine. Pour la protéine tronquée, il a suffi d'enlever les cinq derniers résidus de 1STN.

Afin de simuler la nucléase de Staphylocoque dans des conditions de solvatation rigoureusement identiques aux conditions expérimentales $(80 \mathrm{mg} / \mathrm{ml})$, nous avons placé le système moléculaire protéique dans une boîte de $56 \times 56 \times 75 A^{3}$ contenant des molécules d'eau à une densité de $1 \mathrm{~g} / \mathrm{cm}^{3}$, et dont la structure a été au préalable énergétiquement équilibrée. Les molécules d'eau situées à une distance inférieure à $2,6 \AA$ de la protéine ont été retirées. Le système simulé "SNase native" comportait 6787 molécules d'eau contre 6869 pour le système simulé "SNase tronquée". Les détails de calcul sont fournis en référence [74]. La température des simulations était de 300K. Des simulations de 460ps et 1050ps ont été respectivement réalisées pour les formes native et tronquée. L'écart quadratique moyen entre la structure moyenne pour les 100 dernières $p s$ de la simulation et la structure cristallographique 1 STN, est de $1,9 \AA$ et $3,4 \AA$ pour les formes native et tronquée. L'écart quadratique moyen entre la protéine tronquée et la structure moyenne simulée de la protéine native a été calculé à chaque instant de la trajectoire (fig. 21).

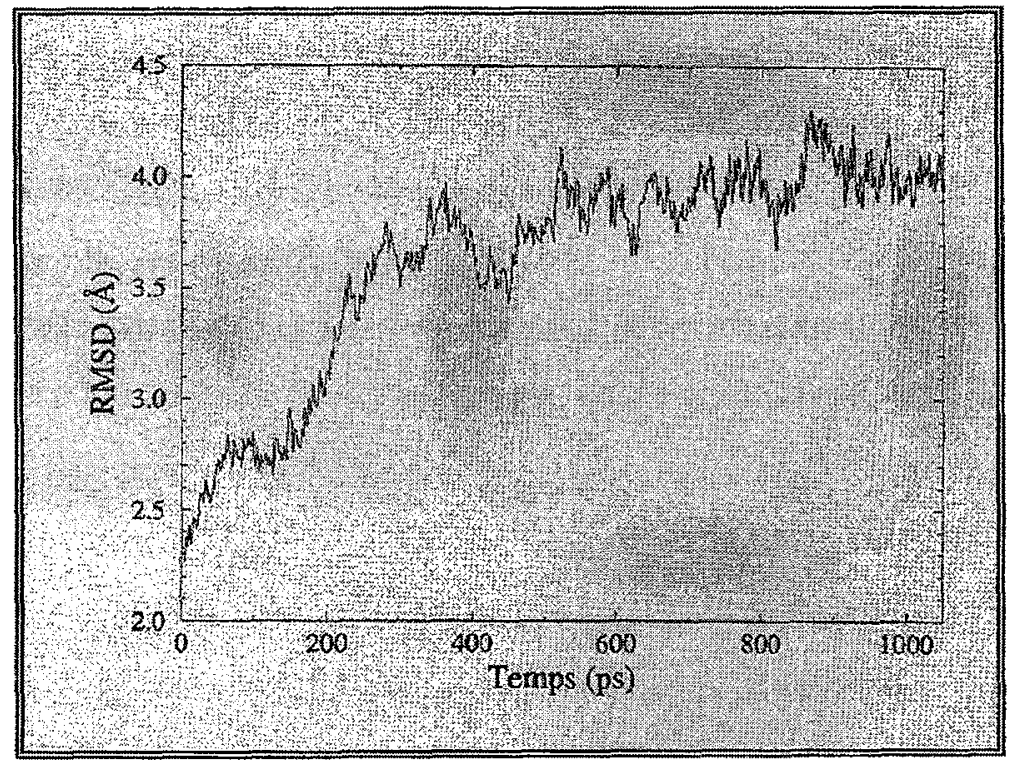

Figure 21 : Ecart quadratique moyen entre $S N a s e \Delta(t)$ et la structure moyenne de SNase. D'après référence [74].

On constate que la structure de SNase $\Delta$ s'écarte rapidement de celle de SNase entre 0 et 400ps pour ensuite se stabiliser. Sur les figures 22 A\&B sont représentées les structures fínales de la protéine native et de la protéine tronquée. Alors que les structures secondaires sont relativement bien conservées pour la protéine native, on constate que le fragment a perdu une partie des structures 
secondaires et quelques interactions tertiaires. L'hélice $\alpha 3$ s'est écartée sensiblement de la protéine. Le tonneau $\beta$ est toujours compact mais le brin $\beta 1$ s'est éloigné du brin $\beta 4$, en raison de la perte d'une liaison hydrogène entre les résidus 10 et 74 . Les fiuctuations atomiques du brin polypeptidique ont également été détaillées, de telle façon à déterminer la distribution de mobilité le long de la séquence primaire. Les molécules ayant eu des mouvements de rotation et de translation dans la boîte d'eau, il faut réorienter chaque conformation "instantanée" du brin polypeptidique sur la structure moyenne de ce brin calculée sur toute la trajectoire. Ceci étant réalisé, il est alors possible de calculer les fluctuations des carbone- $\alpha$ (fig. 23), qui ont été comparées aux valeurs trouvées à partir des facteurs de température cristallographiques, $B$. Les fluctuations de la protéine native $(0,96 \AA)$ sont généralement en accord avec les fluctuations expérimentales sauf pour la région contenant l'hélice $\alpha 1$ et la partie C-terminale de l'hélice $\alpha 2$. Pour la protéine tronquée, les fluctuations sont en général plus importantes $(1,24 \AA)$ concernant principalement les boucles reliant $\alpha$ let $\beta 4, \beta 4$ et $\beta 5, \beta 5$ et $\alpha 2$, et la partie C-terminale de $\alpha 3$.
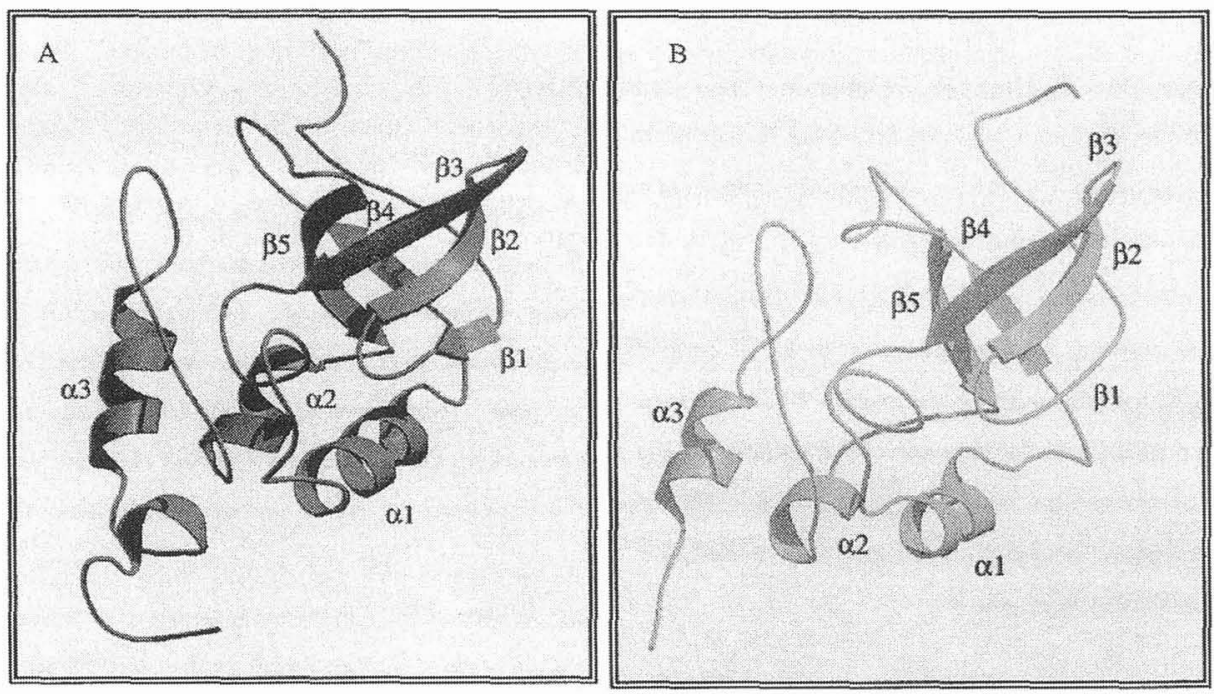

Figure 22: Conformations tridimensionnelles de la protéine native (A) et tronquée (B) en fin de simulations. Représentation de type "ruban". D'après référence [74].

Si on superpose la structure initiale et les structures moyennées sur les 100 dernières ps de la dynamique pour la protéine native et la protéine tronquée, en prenant soin de dissocier les résidus comportant des protons amides s'échangeant lentement et rapidement lors d'expériences de RMN [75], on peut dériver des écarts quadratiques moyens (EQM) pour la protéine native se distribuant comme suit: $\mathrm{EQM}_{\text {lent }}=1,19 \AA$ et $\mathrm{EQM}_{\text {rapide }}=2,40 \AA$. Pour la protéine native, on met ainsi nettement en évidence une structure stable pour le cœur, essentiellement constituée du tonneau $\beta$, comparativement aux hélices et aux boucles très fluctuantes. Il est utile de noter que la structure en solution (RMN) pourrait être relativement différente de celle du cristal (rayons- $\mathrm{X}$ ) et ainsi les résidus dont les protons amides s'échangeraient dans la structure RMN très lentement, attestant d'une grande stabilité, ne correspondraient pas du tout aux parties stables observées en comparant les simulations à la structure obtenue par rayons-X. Ce n'est pas du tout le cas, ce qui indique que la structure en solution doit être voisine de la structure cristalline. Pour la protéine tronquée: les brins $\beta 4$ et $\beta 5$ ne sont plus superposables, la boucle les reliant s'étant abaissée vers la cavité du site actif. Les orientations des hélices ont également changé [74]. 


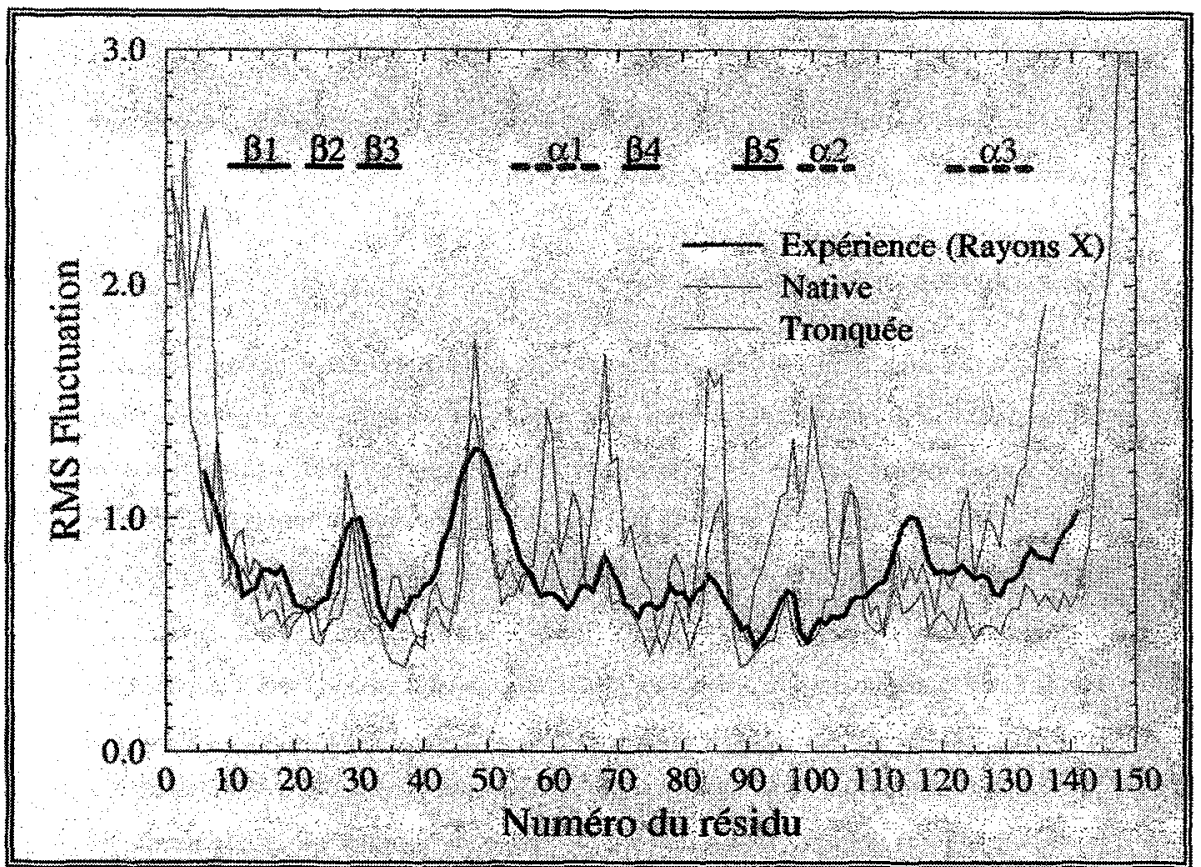

Figure 23 : Fluctuations des carbone- $\alpha$ calculées pour $410 p s$ de dynamique $[50-460 p s]$ en fonction du numéro de résidu. Les structures secondaires de la structure cristallographique sont indiquées. $D^{\prime}$ après référence [74].
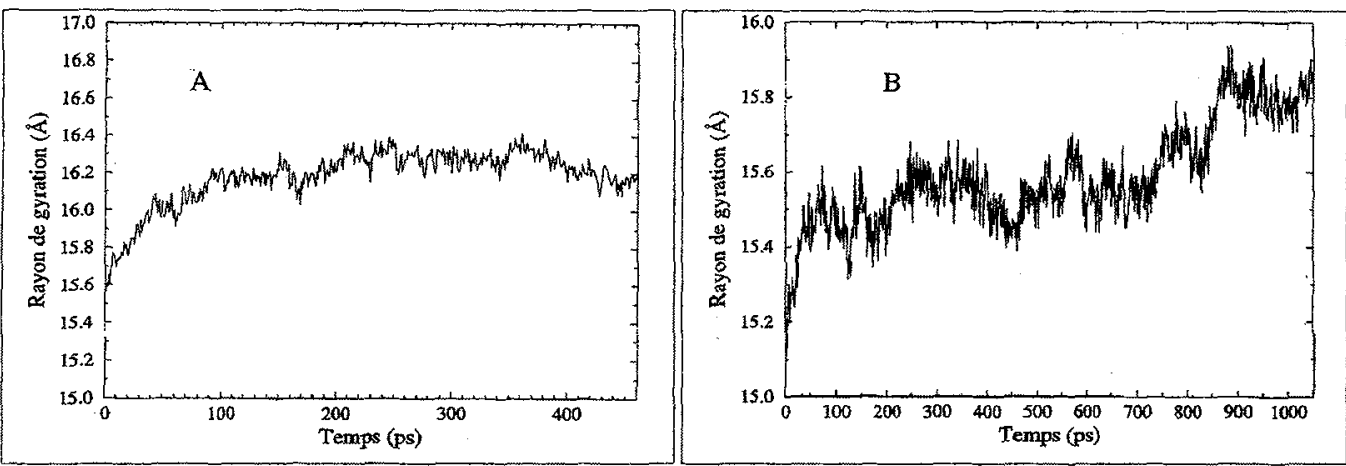

Figure 24 : Evolution fonction du temps des rayons de giration pour SNase (A) et SNase $\Delta$ (B). D'après référence [74].

Une dernière caractérisation structurale des simulations réside dans la détermination du rayon de giration "instantané", par référence au centre de masse "instantané" de la protéine. Pour la protéine native (fig. 24A) le rayon de giration augmente progressivement pour se stabiliser rapidement à la valeur de $16,2 \AA$. Cette valeur correspond à la valeur expérimentale obtenue par rayons-X [87]. Le rayon de giration de la protéine tronquée (fig. 24B) ne se stabilise pas, même après 1 ns de dynamique. Il marque une stabilité durant $400 \mathrm{ps}$ (entre 100 et $500 \mathrm{ps}$ ). Le rayon de giration de la protéine tronquée est initialement plus petit que celui de la protéine native en raison de la troncature. Il ne converge pas durant la simulation vers sa valeur expérimentale de $21,2 \AA$ [87], indiquant que la SNase $\Delta$ n'a pas atteint son état dénaturé. Prenant en considération l'hétérogénéité conformationnelle de la SNase causée par l'isomérisation cis-trans de la liaison Lys116_Prol17 (voir section 3.3.2.3), un modèle moléculaire a été construit où cette liaison a été artificiellement assignée en conformation 
trans. La structure secondaire en hélices- $\alpha$ est faiblement représentée mais le tonneau- $\beta$ est toujou présent (fig 25). Il a été possible de calculer la fonction de Patterson $P(r)$ pour la forme native et forme tronquée trans (fig. 26). Dans les deux cas les caractéristiques expérimentales sont largeme1 reproduites, avec notamment pour la protéine tronquée, une distribution bi-modale et une dimensio maximale à $65 \AA ̊$. Des expériences de RMN [84] ont identifié un intermédiaire du repliement e conformation trans mais avec une structure proche de la forme native, ce qui tendrait à démontr que lors du repliement lisomérisation vers la forme cis s'opère tardivement, et donc qu'en phas terminale de synthèse au niveau du ribosome le polypeptide est toujours en conformation trans.

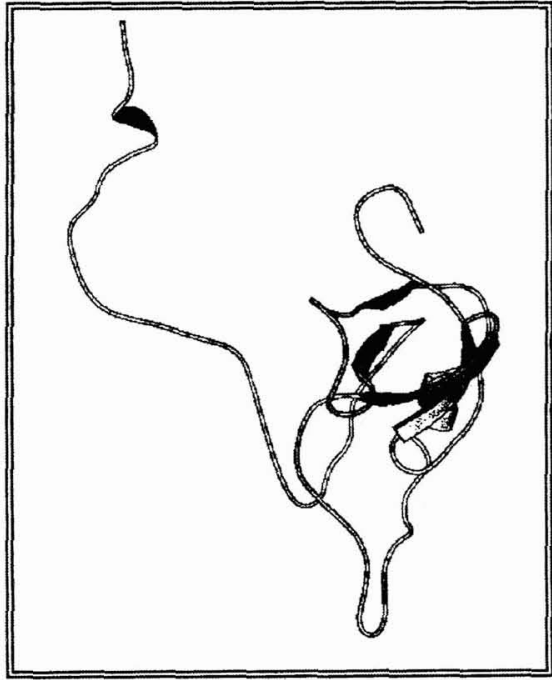

Figure 25 : Structure du modèle tronqué avec avec la liaison Lys1 16_Prol 17 en conformation trans. D'après référence $[74]$.

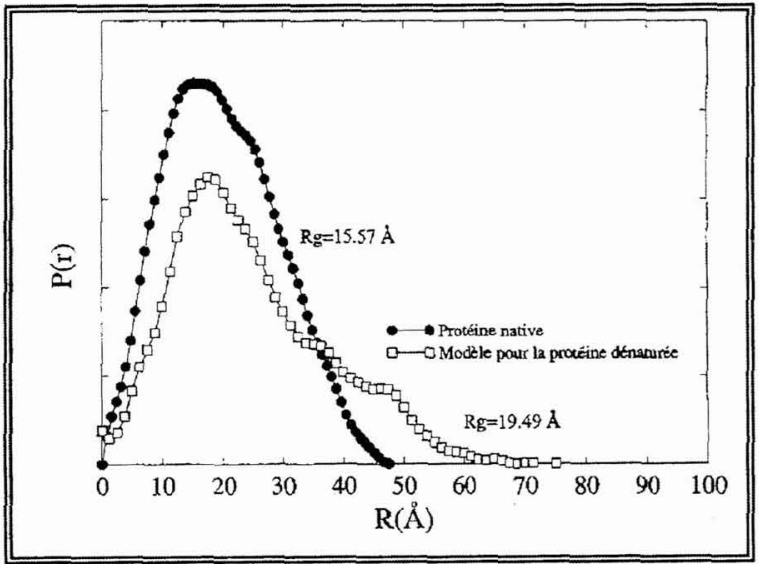

Figure 26 : Fonction de distribution de paires pour la protéine native (cercles noirs) et pour la protéine tronquée avec la liaisor Lys116_Prol 17 en conformation trans (cercles blancs).
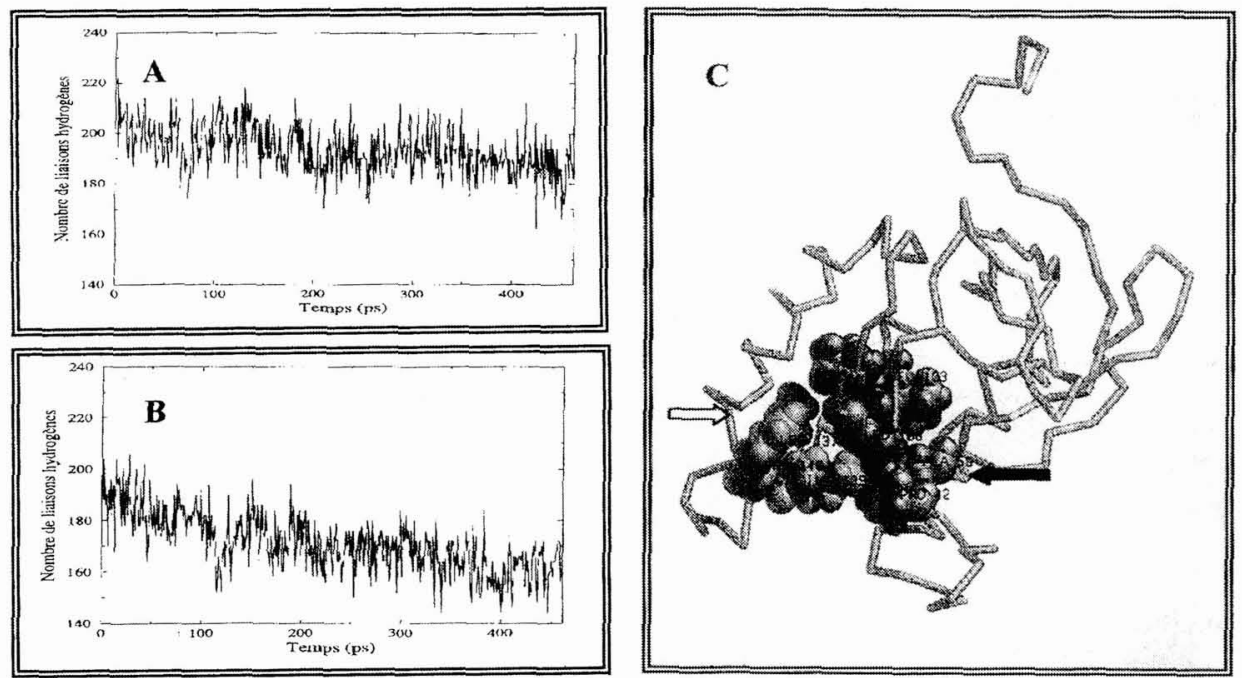

Figure 27 : Nombre de liaisons hydrogène protéine-protéine en fonction du temps pour la protéine native (A) et la protéine tronquée (B). Dans le fragment une liaison hydrogène capitale entre les résidus Gly_107 et Ile_139 n'existe plus en raison de la troncature (C). Cette liaison stabilise les interactions entre une région hydrophobe (flèche blanche) et une région hydrophile (flèche noire). La troncature aboutit de fait à l'éloignement de l'hélice $\alpha 3$. D'après référence [74]. 
La simulation d'une protéine tronquée en forme trans pourrait être alors justifiée, bien qu'il soit raisonnable de penser que le processus de dénaturation prenne plus de 1050ps. Néanmoins le fragment, tel que simulé, semble évoluer vers une structure se rapprochant de la structure expérimentale, avec perte de la structure des hélices, des brins $\beta$ moins compacts, des mouvements de translation et de réorientation des hélices causés par la perte de liaisons tertiaires importantes, notamment des liaisons hydrogène (fig. 27).

\subsection{Caractérisation dynamique de SNase et SNaseA}

Des expériences de RMN [96] ont montré que sur l'échelle de temps considérée ( $\mu s-m s)$ le fragment de SNase est beaucoup plus dynamique que la protéine native. Sur l'échelle de temps des simulations, à savoir $\sim 400 \mathrm{ps}$, l'estimation des différences de comportement dynamique entre les formes native et tronquée de la protéine peut être réalisée en calculant les fluctuations atomiques des carbone- $\alpha$. Chaque élément de la matrice des fluctuations s'écrit:

$$
\begin{aligned}
& \Delta C_{\alpha}[i, j]=\sqrt{\left\langle d_{i j}^{2}(k)-\left\langle d_{i j}(k)\right\rangle^{2}\right\rangle} \\
& d_{i j}(k)=\sqrt{\left(x_{j}(k)-x_{i}(k)\right)^{2}+\left(y_{j}(k)-y_{i}(k)\right)^{2}+\left(z_{j}(k)-z_{i}(k)\right)^{2}}
\end{aligned}
$$

où les moyennes sont calculées sur toutes les conformations $k$ accessibles pendant la simulation, $d_{\text {ij }}$ représentant la distance entre deux carbones- $\alpha i$ et $j$. La figure 28 permet de comparer les mobilités relatives des formes native et tronquée, mais également les mobilités relatives d'éléments de structure secondaire pour une forme donnée. En effet de faibles variations $\Delta \mathrm{C}_{\alpha}[i, j]$ indiquent que les deux atomes $i$ et $j$ se comportent dynamiquement comme une "structure rigide" et présentent une dynamique moyenne concertée. Sur la figure 28 , il apparaît nettement que la protéine tronquée est beaucoup plus dynamique que la protéine native, cette dernière présentant notamment des brins $\beta$ très compacts. Pour le fragment seule une partie du brin $\beta 5$ présente une dynamique commune avec les brins $\beta 1, \beta 2$ et $\beta 3$. De plus les brins $\beta 4$ et $\beta 5$ ne constituent plus une structure rigide avec les résidus suivants (96-136), alors que les brins $\beta 1, \beta 2$ et $\beta 3$ semblent conserver une "rigidité dynamique" avec ces résidus. Le tonneau $\beta$ se décompose donc dans le fragment en deux groupes dynamiques bien distincts. Les hélices présentent des fluctuations plus marquées que les brins. L'hélice $\alpha 3$ relativement rigide dans SNase l'est beaucoup moins dans SNase $\Delta$. Les régions de forte mobilité apparaissent en jaune ou en rouge sur la carte de la figure 28 . Généralement ces régions correspondent aux boucles, notamment celle centrée autour du résidu 48, mais également le centre de l'hélice $\alpha 1$. Des commentaires détaillés sont donnés par ailleurs [74], globalement en accord avec des expériences de RMN à deux dimensions effectuées par Ramakrisnha \& Sasidhar [97].

Les différences de comportement dynamique observées directement à partir des simulations ontelles un sens physique? Pour répondre à cette question, il nous faut rattacher les simulations à l'expérience. En l'occurrence les seules données expérimentales dont nous disposons sur l'échelle de temps des simulations sont précisément les spectres de diffusion quasi-élastique mesurés sur IN5 (voir section 3.3.4.1). Le calcul des spectres de diffusion quasi-élastique à partir des trajectoires atomiques simulées est possible puisqu'on peut calculer les fonctions de corrélation de paires et d'auto-corrélation des positions atomiques, reliées d'une part à la diffusion cohérente des neutrons, et d'autre part à la diffusion incohérente. Un programme tel que nMoldyn [98] réalise ce genre d'opérations à partir des coordonnées et des vitesses obtenues lors des simulations: calcul de la 
fonction intermédiaire de diffusion $F_{i n c}(Q, t)$, du facteur de structure dynamique $S_{i n c}(Q, \omega)$, de la densité d'états vibrationnels $G(\omega)$, etc ...

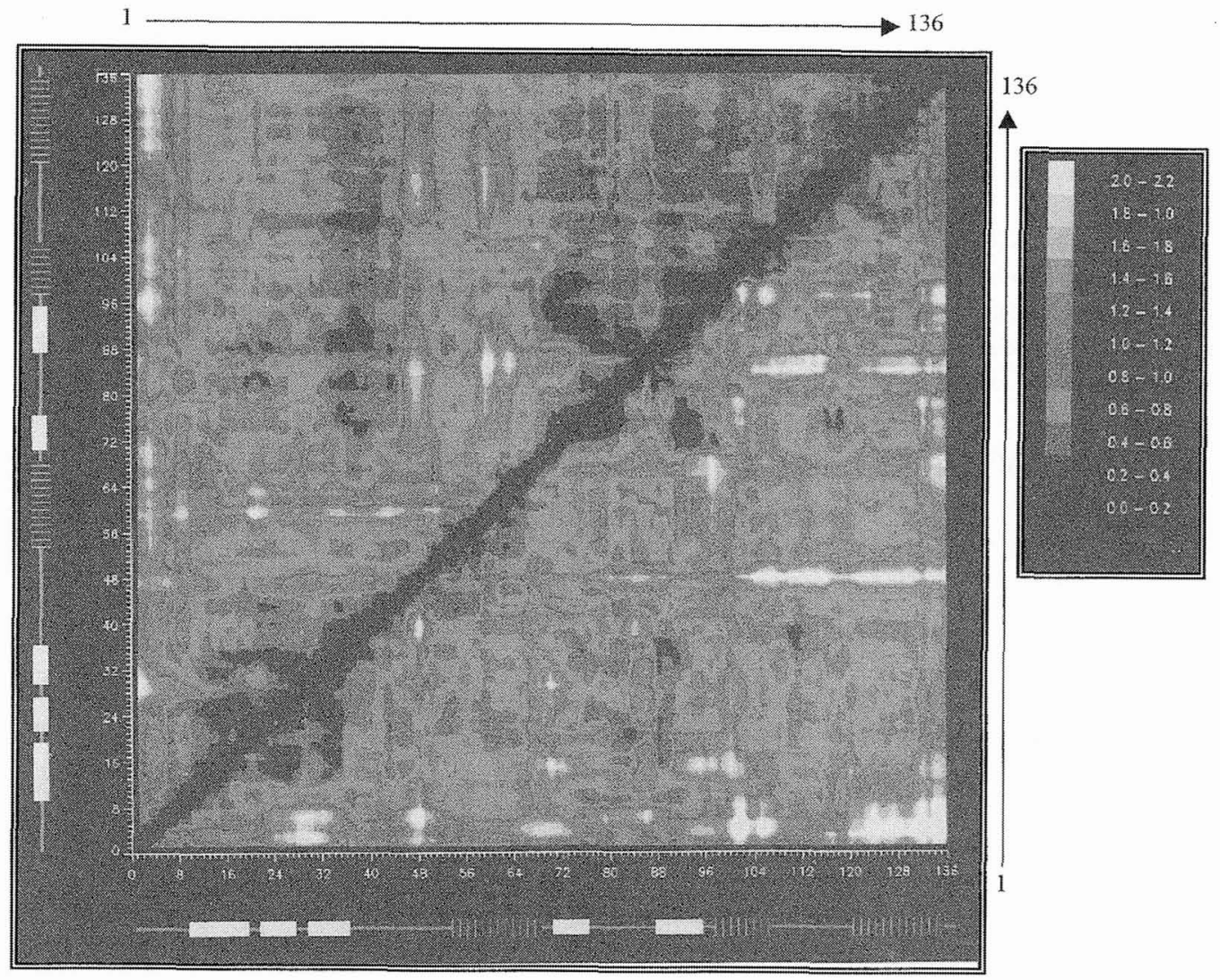

Figure 28 : Carte des fluctuations des distances inter-atomiques $\mathrm{C}_{\alpha}-\mathrm{C}_{\alpha}$ pour une dynamique de $400 \mathrm{ps}$ pour la protéine native (triangle en haut à gauche) et pour la protéine tronquée (triangle en bas à droite). Les valeurs des fluctuations sont données en $\AA$ par le code de niveaux de gris à droite. Les structures secondaires sont indiquées en regard du numéro de résidu (rectangle $=$ brin $\beta$, hachures $=$ hélice $\alpha$ ). D'après référence (74].

Une caractéristique importante pour ce calcul, est de définir numériquement une fonction de résolution instrumentale afin de convoluer nos données simulées. La fonction expérimentale d'IN5, à la longueur d'onde utilisée, a été ajustée par une fonction gaussienne (c'est actuellement la seule fonctionnalité analytique permise par nMoldyn). Le résultat est reporté sur la figure 29. La largeur à mi-hauteur a été trouvée égale à $0,09 \mathrm{meV}$, soit encore $2,010^{-2} \mathrm{THz}$. Dans l'espace des temps cette gaussienne est donc une gaussienne de largeur à mi-hauteur $\sigma_{\mathrm{t}}=37 p s$, et d'expression :

$$
R(t)=e^{-4 \ln 2\left(\frac{t}{\sigma_{t}}\right)^{2}}
$$


fonction intermédiaire de diffusion $F_{\text {inc }}(Q, t)$, du facteur de structure dynamique $S_{i n c}(Q, \omega)$, de la densité d'états vibrationnels $G(\omega)$, etc ...

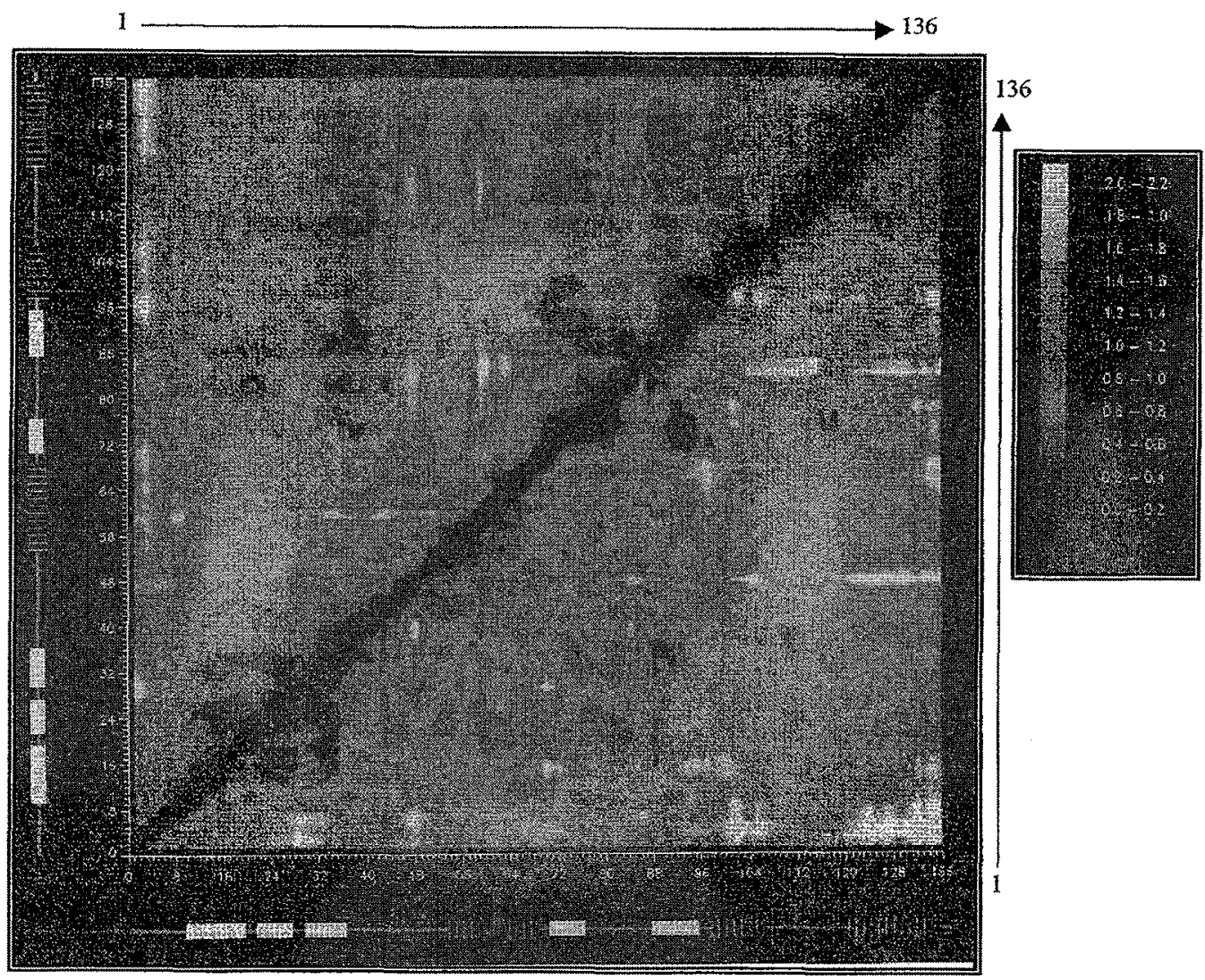

Figure 28 : Carte des fluctuations des distances inter-atomiques $\mathrm{C}_{\alpha}-\mathrm{C}_{\alpha}$ pour une dynamique de $400 \mathrm{ps}$ pour la protéine native (triangle en haut à gauche) et pour la protéine tronquée (triangle en bas à droite). Les valeurs des fluctuations sont données en $\AA$ par le code de niveaux de gris à droite. Les structures secondaires sont indiquées en regard du numéro de résidu (rectangle $=$ brin $\beta$, hachures $=$ hélice $\alpha$ ). D'après référence (74].

Une caractéristique importante pour ce calcul, est de définir numériquement une fonction de résolution instrumentale afin de convoluer nos données simulées. La fonction expérimentale d'IN5, à la longueur d'onde utilisée, a été ajustée par une fonction gaussienne (c'est actuellement la seule fonctionnalité analytique permise par nMoldyn). Le résultat est reporté sur la figure 29. La largeur à mi-hauteur a été trouvée égale à $0,09 \mathrm{meV}$, soit encore $2,010^{-2} \mathrm{THz}$. Dans l'espace des temps cette gaussienne est donc une gaussienne de largeur à mi-hauteur $\sigma_{\mathrm{t}}=37 p s$, et d'expression :

$$
R(t)=e^{-4 \ln 2\left(\frac{t}{\sigma_{t}}\right)^{2}}
$$




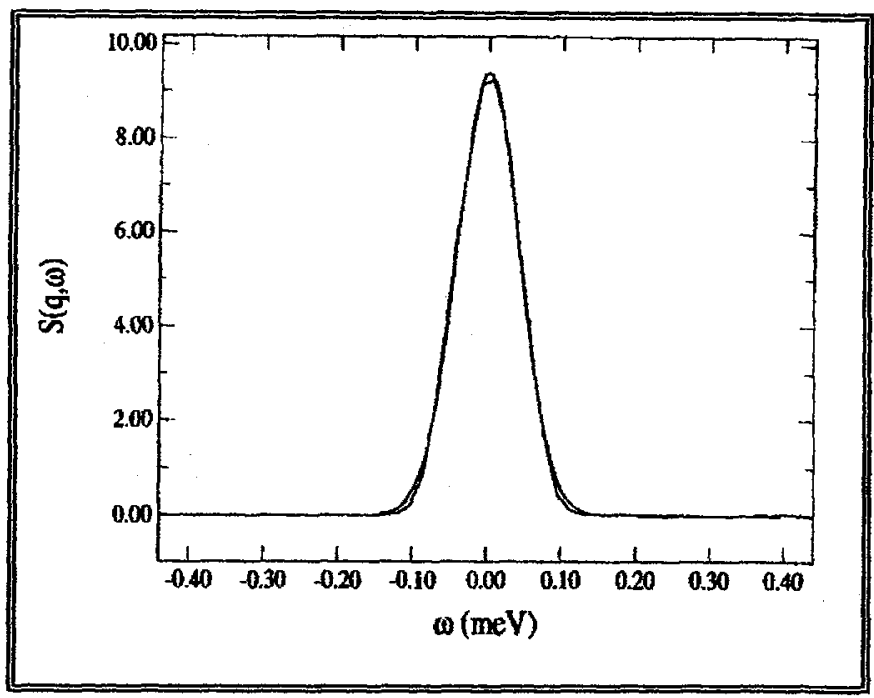

Figure 29: Spectre expérimental du Vanadium à l'angle de diffusion $2 \theta=118,8^{\circ}$ et la gaussienne ajustée. D'après référence [74].

Le calcul des facteurs de structure dynamique passe tout d'abord par l'évaluation de la fonction de diffusion intermédiaire:

$$
F_{i n c}(\vec{Q}, t)=\frac{1}{N} \sum_{\alpha} b_{\alpha}^{2}\left\langle e^{-i \vec{Q} \cdot R_{\alpha}(0)} e^{-i \vec{Q} \cdot R_{\alpha}(t)}\right)
$$

La somme porte sur les $N$ atomes $\alpha$ de l'échantillon, principalement les hydrogènes dont la longueur de diffusion incohérente $b$ est la plus importante. L'opérateur quantique $R(t)$ associé à la position atomique est ici remplacé par le vecteur de position classique. En conséquence l'expression de l'équation 10 peut être calculée à partir des trajectoires générées par la simulation, puisque $F(Q, t)$ devient une fonction de corrélation temporelle classique. Puisque les échantillons sont isotropes, les grandeurs calculées sur plusieurs orientations $Q$ (à norme constante) ont été moyennées. La fonction de diffusion intermédiaire a ensuite été multipliée par la "gaussienne temporelle" (équation 9), puis par transformée de Fourier temporelle on dérive le facteur de structure dynamique:

$$
S_{\text {inc }}(Q, \omega)=\frac{1}{2 \pi} \int_{-\infty}^{+\infty} e^{-i \omega t} F_{i n c}(Q, t) d t
$$

La comparaison des spectres expérimentaux de la protéine native (aux 13 angles de mesure) avec les spectres simulés est donnée sur la figure 30 . L'évolution globale du facteur de structure dynamique en fonction de $Q$ est bien reproduite par le calcul. L'intensité diminue bien en fonction de $Q$, mais reste trop importante aux grands angles de diffusion pour la partie calculée. Les spectres calculés présentent également une distribution plus régulière. Au cours des simulations, la protéine a subi des mouvements de rotation et de translation globale dans la boîte d'eau. Afin d'étudier l'influence des mouvements globaux et des mouvements internes sur le facteur de structure 
dynamique, deux cas ont été considérés: une simulation non orientée où le mouvement total de la protéine est pris en considération, et une simulation orientée pour laquelle translation et rotation sont éliminées en ajustant (a posteriori) chaque conformation instantanée sur la conformation moyenne. Une comparaison de ces deux méthodes est donnée sur la figure 31 pour la protéine native et sur la figure 32 pour le fragment.
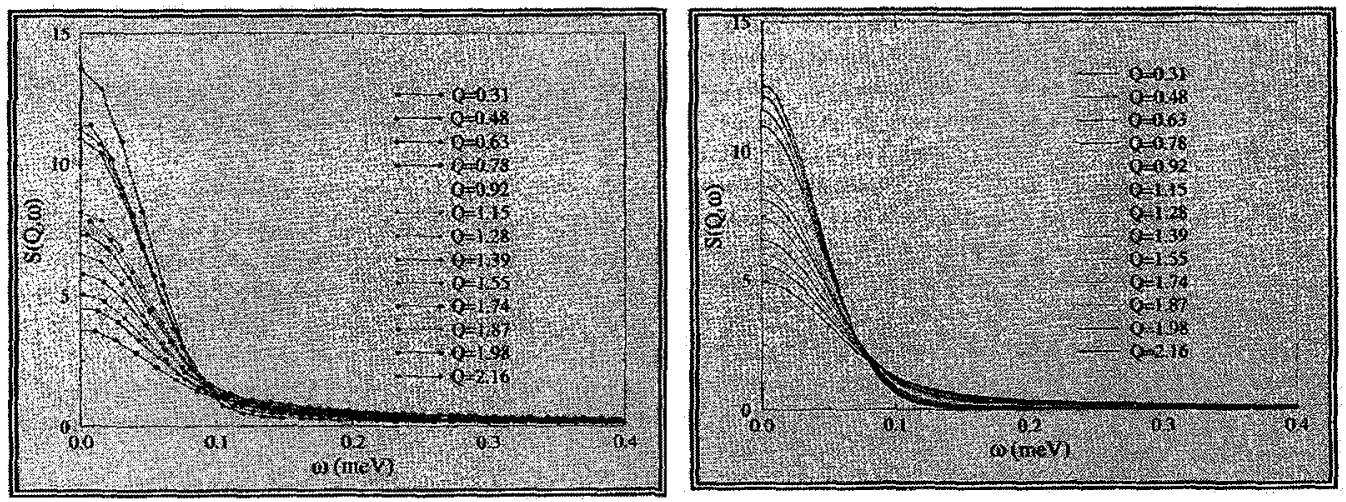

Figure 30 : Facteurs de structure dynamique $S(Q, O)$ de la protéine native. Expérimental (A). Simulé (B). Les transferts de moment, $Q$, s'échelonnent de 0.31 à $2.16 \AA^{-1}$ depuis le bas vers le haut (à $\left.\omega=0\right)$ ). D'après référence [74].
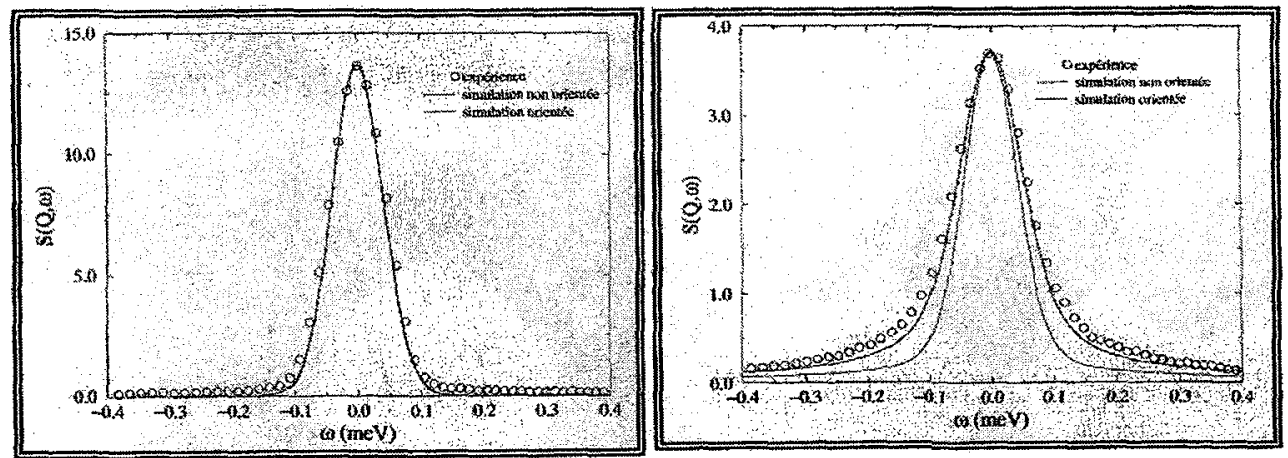

Figure 31: Facteurs de structure dynamique pour la protéine native à $Q=0,31 \AA^{-1}$ (gauche) et $Q=2,16 \AA^{1}$ (droite). Points expérimentaux (cercles); Simulation non orientée et orientée se confondent pour $Q=0,31 \AA^{-1}$. La simulation non-orientée est plus proche de l'expérience pour $Q=2,16 \AA^{1}$. D'après référence [74].
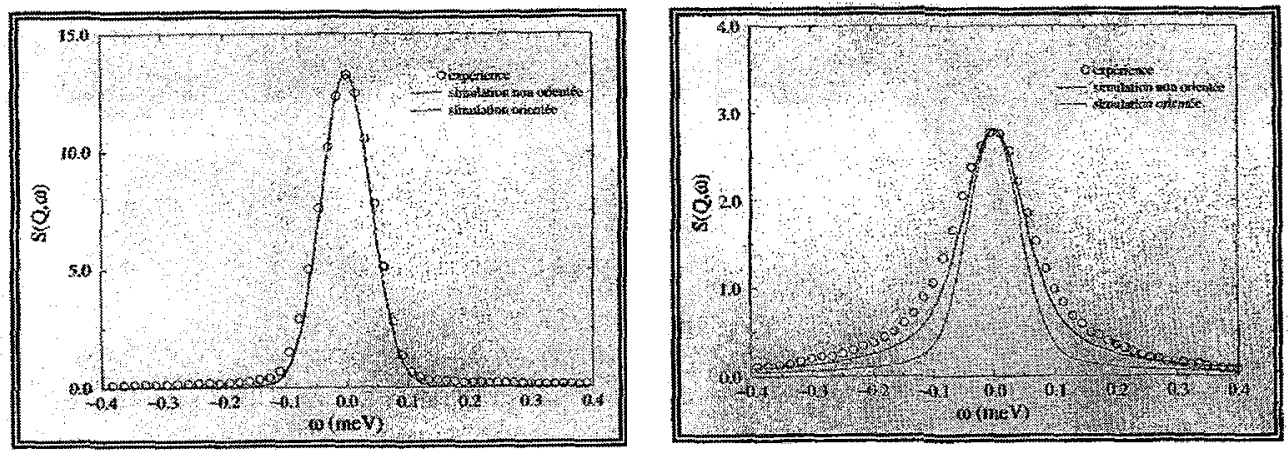

Figure 32: Facteurs de structure dynamique pour la protéine tronquée à $Q=0,31 \AA^{-1}$ (gauche) et $Q=2,16 \AA^{1}$ (droite). Points expérimentaux (cercles); Simulation non orientée et orientée se confondent pour $Q=0,31 \AA^{-1}$. La simulation non-orientée est plus proche de l'expérience pour $Q=2,16 \AA^{1}$. D'après référence [74]. 
Deux angles de mesures extrêmes ont été choisis: $\mathrm{Q}=0,31 A^{-1}$ et $\mathrm{Q}=2,16 A^{-1}$. Aux petits angles rien ne permet de différencier la simulation orientée et la simulation non-orientée, qui se superposent presque intégralement avec le spectre expérimental, à l'exception d'une très légère contribution quasiélastique. $\mathrm{A} \mathrm{Q}=2,16 A^{-1}$, on observe des résultats différents pour les deux simulations. la simulation non-orientée est en meilleure accord avec l'expérience, avec une composante quasi-élastique nettement plus marquée que la simulation orientée, et donc se rapprochant de l'expérience, en la sousestimant toutefois. Le même type de comportement caractérise la protéine tronquée, la différence à $\mathrm{Q}=2,16 \AA^{t}$ entre expérience et simulation non-orientée étant encore plus grande. Une comparaison directe entre les formes native et tronquée est proposée sur les figures $33 \mathrm{~A}$ (spectres expérimentaux) et $33 \mathrm{~B}$ (spectres calculés). Aucune différence manifeste n'apparaît à $\mathrm{Q}=0,31 \dot{A}^{-1}$ entre SNase et SNase $\Delta$, tant sur le plan expérimental (voir fig. 19 et 20 également) que sur le plan des simulations. Par contre à grand transfert de moment, les simulations non-orientée de la protéine native et du fragment sont quasi-identiques, alors que l'expérience atteste d'une différence significative.

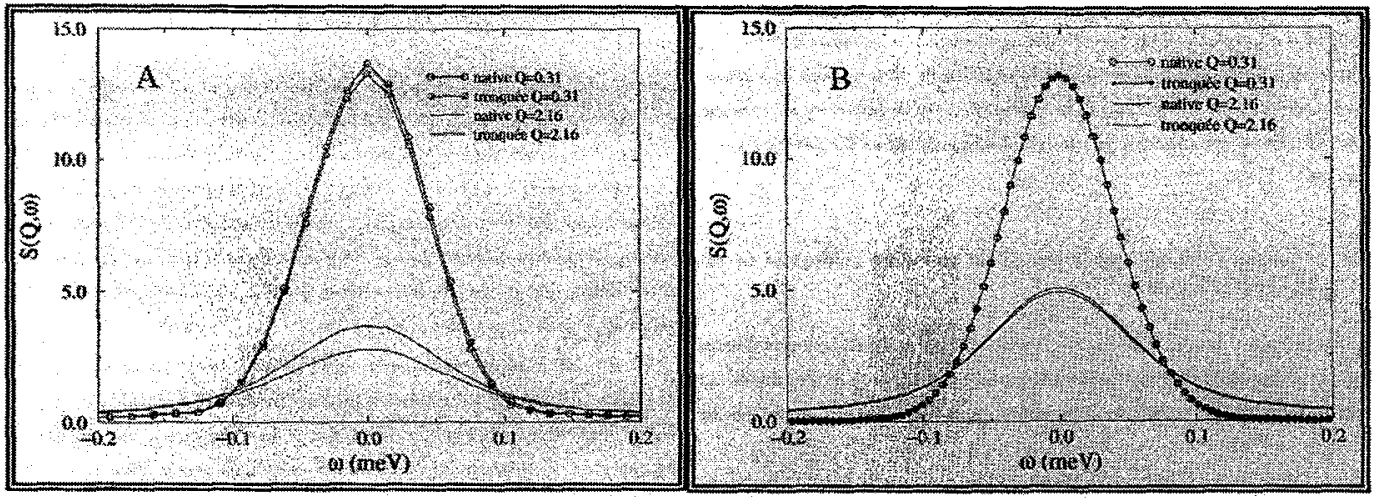

Figure 33 : Facteurs de structure dynamique expérimentaux (A) et calculés (B) pour la protéine native et la protéine tronquée aux valeurs de $Q=0,31 \AA^{-1}$ (courbes du haut) et $Q=2,16 \AA^{-1}$ (courbes du bas). $D^{\prime}$ après référence [74].

Ce type de comportement est inquiétant puisque nous avons montré que SNase et $\mathrm{SNase} \Delta$ constituaient des protéines dynamiquement différentes, notamment lorsqu'on considérait les fluctuations internes relatives des éléments de structure secondaire (fig. 28). Cette différence devrait être visible sur les spectres. Un problème lié à la méthode en est peut être la cause. Sans remettre en cause le champ de forces semi-empirique de CHARMM, qui a somme toute permis de produire des trajectoires différentes de SNase et $\mathrm{SNase} \Delta$, il nous faut considérer l'influence de la résolution instrumentale dans les méthodes de calcul des facteurs de structure dynamique.

Nous avons travaillé dans l'espace " $F(Q, t)$ " pour tenter d'analyser ce problème. Sur la figure 34 est représentée la fonction de diffusion intermédiaire de la protéine native et du fragment. Contrairement à ce qui est observé pour le facteur de structure dynamique $S(Q, \omega)$, des différences existent au niveau de la fonction de diffusion intermédiaire. Aux petites valeurs de $Q$, une très légère différence apparaît entre SNase et SNased, que ce soit pour la simulation orientée ou non-orientée. Aux grandes valeurs de $Q$, cette différence s'accentue: la décroissance temporelle de la fonction de diffusion intermédiaire "orientée" étant plus rapide pour le fragment que pour la protéine native, traduisant une perte de corrélation des positions atomiques individuelles plus rapide dans le fragment. Ceci met en valeur la part des mouvements internes à caractère diffusif, plus importante pour le fragment. Les fonctions de diffusion intermédiaires "non-orientées" sont plus difficiles à interpréter: elles se chevauchent plusieurs fois et la différence est nettement moins marquée, les effets de diffusion globale compensant vraisemblablement la diffusion interne de domaines de la protéine. Lorsqu'on multiplie 
par la fonction de résolution instrumentale, ces différences s'estompent, justifiant ainsi le peu de différences observées pour les facteurs de structure dynamique $S(Q, \omega)$, et prouvant que la raison en est analytique.
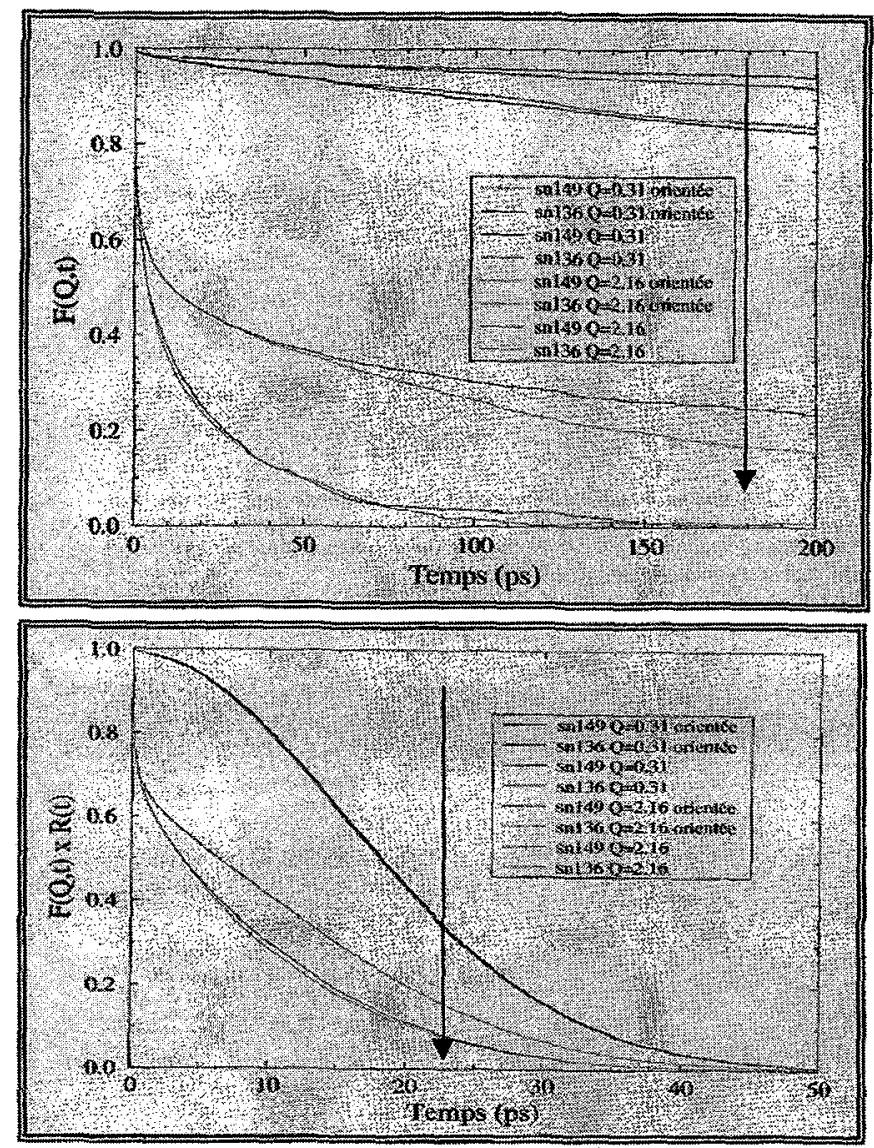

Figure 34 : Fonction de diffusion intermédiaire seule (haut) et multipliée (bas) par la fonction de résolution $R(t)$ pour la protéine native (sn149) et la protéine tronquée (sn136) aux deux valeurs de Q extrêmes choisies. La liste correspond aux courbes parcourues dans le sens des flèches. Référence [74].

Ce travail constitue la première tentative de comparaison de spectres expérimentaux de diffusion quasi-élastique de neutrons avec des spectres calculés à partir de simulations de dynamique moléculaire sur une protéine globulaire en solution. L'étude comparative entre simulations et expérience méritent une compréhension plus poussée des déviations observées. Néanmoins d'après les simulations, il semblerait que la prise en considération des mouvements globaux de la protéine soit nécessaire pour "approcher" l'expérience. La dynamique de la protéine tronquée qui a été calculée n'est peut-être pas celle de l'état expérimental partiellement déplié comme la caractérisation structurale le suggère. Tous ces éléments méritent d'être approfondis, et à ce jour dans le cas bien précis de la nucléase de Staphylocoque, seuls les résultats expérimentaux peuvent être considérés comme fiables et prévalent de facto. 


\section{REFERENCES}

[1] Burkert U. \& Allinger N. (1982) Molecular Mechanics. ACS Monograph. American Chemical Society.

[2] Mc Cammon J.A. \& Harvey S.C. (1987) Dynamics of Proteins and Nucleic Acids. Cambridge University Press.

[3] Brooks C.L., Karplus M. \& Petitt B.M. (1988) Proteins:a theoretical perspective of dynamics, structure and thermodynamics. Adv. chem. Physics, 71, (Eds I. Prigogine \& S. Price) Wiley.

[4] Karplus M. \& Petsko G. (1990) Molecular Dynamics Simulations in Biology. Nature, Lond., 347, 631-639.

[5] Munro I., Pecht I. \& Stryer L. (1979), Proc. Natl. Acad. Sci. USA, 76, 56-60.

[6] Petitcolas W.L. (1979) Methods in Enzymology, 61, 425-458.

[7] Brown R.G., Erfirth S.C., Small E.W. \& Petitcolas W.L. (1972) Proc. Natl. Acad. Sci. USA, 69(6), 1467-1469.

[8] Genzel L., Keilmann F., Martin T.P., Winterling G., Yacobi Y., Frohlich H. \& Makinen M. (1976) Biopolymers, 15, 219-225.

[9] Ataka M. \& Tanaka S. (1979), Biopolymers, 18, 507-516.

[10] Lovesey S. (1984) Theory of Neutron Scattering from Condensed Matter, International Series of Monographs on Physics, no. 72. Oxford Science Publications. Oxford: Clarendon.

[11] Bée M. (1988) Quasielastic Neutron Scattering: Principles and Applications in Solid State Chemistry, Biology and Materials Science. Bristol and Philadelphia: Adam Hilger.

[12] Middendorf H.D. (1984) Rev. Biophys. Bioengng, 13, 425-451.

[13] Middendorf H.D. \& Randall J.T. (1985) Structure and Motion; Membranes, Nucleic Acids and Proteins (Eds. E. Clementi \& R.H. Sarna) Adenine Press.

[14] Cusack S. (1986) Comm. molec. cell. Biophys., 3(4), 243-271.

[15] Smith J.C. (1991) Quaterly Reviews of Biophysics, 24(3), 227-291.

[16] Oesterhelt D. \& Stoeckenius W. (1971), Nature New Biol., 233, 149-152.

[17] Henderson R. (1975) J. Mol. Biol., 93, 123-138.

[18] Blaurock A.E. (1975) J. Mol. Biol., 93, 139-158.

[19] Henderson R. \& Unwin P.N.T. (1975) Nature (London), 257, 28-32.

[20] Henderson R., Baldwin J.M., Ceska T.A., Zemlin F., Beckmann E. \& Downing K.H. (1990) J. Mol. Biol., 213, 899-929.

[21] Grigorieff N., Beckmann E. \& Zemlin F. (1995), J. Mol. Biol., 254, 404-415.

[22] Pebay-Peroula E., Rummel G., Rosenbusch J.P., Landau E.M. (1997) Science, 277, 1676-1691.

[23] Oesterhelt D. \& Stoeckenius W. (1973), Proc. Natl. Acad. Sci. USA, 70(10), 2853-2857.

[24] Lanyi J.K. \& Varo G. (1995), Israel J. Chem., 35, 365-385.

[25] Butt H.J., Fendler K., Bamberg E., Tittor J. \& Oesterhelt D. (1989), EMBO J., 8, 1657-1663.

[26] Holz M., Drachev L.A., Mogi T., Otto H., Kaulen A.D., Heyn M.P., Skulachev V.P. \& Khorana H.G. (1989), Proc. Natl. Acad. Sci. USA, 86, 2167-2171.

[27] Varo G. \& Lanyi J.K. (1991), Biochemistry, 30, 5016-5022.

[28] Fodor S.P., Ames J.B., Gebbard R., von der Berg E.M., Stoeckenius W., Lugtenburg J. \& Mathies R.A. (1988), Biochemistry, 27, 7097-7101.

[29] Dencher N.A., Dresselhaus D., Zaccaï G. \& Büldt G. (1989), Proc. Natl. Acad. Sci. USA, 86, 7876-7879.

[30] Koch M.H.J., Dencher N.A., Oesterhelt D., Plöhn H.J., Rapp G. \& Büldt G. (1991), EMBO J., $10(3), 521-526$.

[31] Zaccaï G. (1987), J. Mol. Biol., 194, 569-572.

[32] Varo G. \& Lanyi J.K. (1991), Biophys. J., 59, 313-322.

[33] Weik M. (1995), Diplomarbeit: "Structure, hydratation et cristallinité de la bacteriorhodopsine de Halobacterium salinarium; Etude par diffraction de neutrons", Université J. Fourier-Grenoble 1 $\&$

Fridericiana-karslruhe.

[34] Tokunaga F. \& Iwasa T. (1982), Methods in Enzymology, 88, 163-167. 
[35] Ferrand M., Dianoux A.J., Petry W. \& Zaccaï G. (1993), Proc. Natl. Acad. Sci. USA, 90, 96689672.

[36] Réat V., Patzelt H., Ferrand M., Pfister C., Oesterhelt D. \& Zaccaï G. (1998), Proc. Natl. Acad. Sci. USA, 95, 4970-4975.

[37] Fitter J., Lechner R.E., Büldt G. \& Dencher N.A. (1996), Proc. Natl. Acad. Sci. USA, 93, 76007605.

[38] Frauenfelder H., Petsko G.A. \& Tsernoglou D. (1979), Nature (London), 280, 558-563.

[39] Ansari A., Berendzen J., Bowne S.F., Frauenfelder H., Iben I.E.T., Sanke T.B., Shyamsunder E. \& Young R.D. (1985), Proc. Natl. Acad. Sci. USA, 82, 5000-5004.

[40] Knapp E.W., Fischer S.F. \& Parak F. (1982), J. Phys. Chem., 86, 5042-5047.

[41] Van Hove L. (1954), Phys. Rev., 95, 249-262.

[42] Hervet H., Dianoux A.J., Lechner R.E. \& Volino F. (1976), Physique, 37, 587-594.

[43] Bée M., Jobic H. \& Sourisseau C. (1985), J. Phys. C., 18, 5771-5781.

[44] Kates M., Kushwaha S.C. \& Sprott G.D. (1982), Methods in Enzymology, 88, 98-111.

[45] Volino F. , Dianoux A.J., Lechner R.E. \& Hervet H. (1975), Phys. Colloq., 36, (C1)83-(C1)88.

[46] Lechner R.E., Dencher N.A., Fitter J., Büldt G. \& Belashkin A.V. (1994), Biophys. Chem., 49, 91-99.

[47] Stahn M., Lechner R.E., Dachs H. \& Jacobs H.E. (1983), J. Phys. Chem., 16, 5073-5082.

[48] Lechner R.E., Dencher N.A., Fitter J \& Dippel T. (1994), Solid State Ionics, 70/71, 296-304.

[49] Bone S. \& Pethig R. (1985), J. Mol. Biol., 181, 323-326.

[50] Cusack S. (1988), in The Enzyme Catalysis Process, Rds. Cooper A., Houben J.L. \& Chien L.C. (Plenum, New York), 16, 103-122.

[51] Goldanskii V.I. \& Krupyanskii Y.F. (1989) Quaterly Reviews of Biophysics, 22, 39-92.

[52] Steinbach P.J. \& Brooks B.R. (1993), Proc. Natl. Acad. Sci. USA, 90, 9135-9139.

[53] Norin M., Haeffner F., Hult K. \& Edholm O. (1994), Biophys. J., 67, 548-559.

[54] Doster W., Cusack S. \& Petry W. (1989), Nature (London), 337, 754-756.

[55] Shirley W.M. \& Bryant R.G. (1982), J. Am. Chem. Soc., 104, 2910-2918.

[56] Kneller G.R., Doster W., Settles M., Cusack S. \& Smith J.C. (1992), J. Chem. Phys, 97, 88648879 .

[57] Fitter J., Verclas S.A.W., Lechner R.E., Büldt G., Ernst O.P., Hofmann K.P. \& Dencher N.A. (1999), Physica B, 266, 35-40.

[58] Fitter J., Lechner R.E. \& Dencher N.A. (1997), Biophys. J., 73, 2126-2137.

[59] Onuchic J. N., Wolynes P. G., Luthey-Schulten Z. \& Socci N. D. (1995), Proc. Natl. Acad. Sci. $U S A, 92,3626-3630$.

[60] Dill K.A., Bromberg S., Yue K., Fiebig K.M., Yee D.P., Thomas P.D. \& Chan H.S. (1995), Protein Science, 4, 561-602.

[61] Karplus M. \& Weaver D.L. (1994), Protein Science, 3, 650-668.

[62] Nozaki Y. \& Tanford C. (1971), J. Biol. Chem., 246, $2211-2217$.

[63] Shortle D. \& Meeker A.K. (1989), Biochemistry, 28, 936-944.

[64] Cunningham L., Catlin B.W. \& Privat deGarithe (1956), J. Am. Chem. Soc., 78, 4642-4645.

[65] Tucker P.W., Hazen E.E. \& Cotton F. (1979), Mol. Cell. Biochem., 23, 131-139.

[66] Cuatrecasas P., Wilchek M. \& Anfinsen C.B. (1969), Biochemistry, 8, 2277-2284.

[67] Sulkowsky E. \& Laskowsky M. (1970), Biochim. Biophys. Acta, 217, 538-540.

[68] Cuatrecasas P., Fuchs S. \& Anfinsen C.B. (1967), J. Biol. Chem., 242, 1541-1547.

[69] Cuatrecasas P., Wilchek M. \& Anfinsen C.B. (1968), Science, 162, 1491-1493.

[70] Markley J.L. \& Jardetzky O. (1970), J. Mol. Biol., 50, 223-233.

[71] Tanuichi H. \& Anfinsen C.B. (1971), J. Biol. Chem., 246, 2291-2301.

[72] Cotton F.A.; Hazen E.E. \& Legg M.J. (1979), Proc. Natl. Acad Sci. USA, 76, 2551-2555.

[73] Loll P.J. \& Lattman E.E. (1989), Proteins, struct. funct. gen., 4, 183-201.

[74] Goupil-Lamy A. (1997), Thèse de Doctorat Université Paris VI.

[75] Torchia D.A., Sparks S.K. \& Bax A. (1989), Biochemistry, 28, 5509-5524.

[76] Wang J.F., LeMaster D.M. \& Markley J.L. (1990), Biochemistry, 29, 88-101.

[77] Wang J.F., Hinck A.P., Loh S.N. \& Markley J.L. (1990), Biochemistry, 29, 102-113. 
[78] Wang J.F., Hinck A.P., Loh S.N. \& Markley J.L. (1990), Biochemistry, 29, 4242-4253.

[79] Kim P.S. \& Baldwin R.L. (1982), Ann. Rev. Biochem., 51, 459-489.

[80] Gratwohl C. \& Wuthrich K. (1981), Biopolymers, 20, 2623-2633.

[81] Fox R.O., Evans P.A. \& Dobson C.M. (1986), Nature, 320, 192-194.

[82] Chazin W.J., Kordel J., Drakenberg T., Thulin T., Brodin P., Grunstrom T. \& Forsen S. (1989), Proc. Natl. Acad. Sci. USA, 86, 2195-2198.

[83] Evans P.A., Dobson C.M., Krautz R.A., Hatfull G. \& Fox R.O. (1989), Nature, 329, 266-268.

[84] Evans P.A., Krautz R.A., Fox R.O. \& Dobson C.M. (1989), Biochemistry, 28, 362-370.

[85] Alexandescu A.T., Ulrich E.L. \& Markley J.L. (1989), Biochemistry, 28, 204-211.

[86] Stancyk S.M., Bolton P.H., Dell'Acqua M. \& Gerlt J.A. (1989), J. Am. Chem. Soc., 111, 83178318.

[87] Flanagan J.M., Kataoka M., Shortle D. \& Engelman M. (1992), Proc. Natl. Acad. Sci. USA, 89, 748-752.

[88] Flanagan J.M., Kataoka M., Fujisawa T. \& Engelman M. (1993), Biochemistry, 32, 1035910370 .

[89] Shortle D. (1986), J. Cell. Biochem., 30, 281-286.

[90] Alexandescu A.T., Abeygunawardana C. \& Shortle D. (1994), Biochemistry, 33, 1063-1072.

[91] Ferrand M., Zaccaï G., Nina M., Smith J.C., Etchebest C. \& Roux B. (1993), FEBS Letters, 327, 256-260.

[92] Furois-Corbin S., Smith J.C.? Kneller G. (1993), Proteins, struct. funct. gen, 16, 141-154.

[93] Kataoka M., Ferrand M., Goupil-Lamy A., Kamikubo H., Yunoki O., Smith J.C (1999), Physica $B, 266,20-26$.

[94] Brooks B.R., Bruccoleri R.E., Olafson B.D., Swaminathan S. \& Karplus M. (1983), J. Comp. Chem. , 4, 187-217.

[95] Hynes T.R. \& Fox R.O. (1991), Proteins, struct. funct. gen., 10, 92-105.

[96] Shortle D. \& Abeygunawardana C. (1993), Structure, 1, 121-134.

[97] Ramakrisnha V. \& Sasidhar Y.U. (1997), Biopolymers, 41, 181-191.

[98] Kneller G., Keiner V., Kneller M. \& Schiller M. (1995), Comp. Phys. Comm., 91, 191-214. 